Illinois State University

ISU ReD: Research and eData

Theses and Dissertations

2-1-2017

\title{
Mediating the Relation of Socioeconomic Risk and Kindergarten Readiness with Self-Regulation: Investigating the Moderating Role of Teacher-Child Relationships
}

Leah Cohen Marks

Illinois State University, leahcmarks@gmail.com

Follow this and additional works at: https://ir.library.illinoisstate.edu/etd

Part of the Psychology Commons

\section{Recommended Citation}

Marks, Leah Cohen, "Mediating the Relation of Socioeconomic Risk and Kindergarten Readiness with SelfRegulation: Investigating the Moderating Role of Teacher-Child Relationships" (2017). Theses and Dissertations. 735.

https://ir.library.illinoisstate.edu/etd/735

This Dissertation is brought to you for free and open access by ISU ReD: Research and eData. It has been accepted for inclusion in Theses and Dissertations by an authorized administrator of ISU ReD: Research and eData. For more information, please contact ISUReD@ilstu.edu. 


\title{
MEDIATING THE RELATION OF SOCIOECONOMIC RISK AND KINDERGARTEN READINESS WITH SELF-REGULATION: INVESTIGATING THE MODERATING ROLE OF TEACHER-CHILD RELATIONSHIPS
}

\author{
Leah Cohen Marks
}

\section{Pages}

School readiness is important for children, families, teachers, and schools. School readiness is defined as children's preparedness to be successful in the kindergarten setting. It can encompass academic, social-emotional, and behavioral skills, all of which predict future outcomes (Duncan et al., 2007). School readiness can be particularly important for children at risk for school failure due to poverty (Ryan, Fauth, \& Brooks-Gunn, 2013). Considering which risk and resilience factors may be present for these children is important. Another important variable is self-regulation, which includes voluntary control approach and withdrawal behavior tendencies including the ability to inhibit a dominant response and resist interference or distractions (Liew, 2012; Rothbart \& Bates, 2006; Ursache, 2012). An additional variable relevant to school readiness is the teacher-child relationship, which is far less studied than the parent-child relationship, but can have important implications for children's school functioning. The teacher-child relationship is linked to both academic and social-emotional components of school readiness (Peisner-Feinberg et al., 2001; Pianta \& Stuhlman, 1994). The goal of this study was to test the moderating role of teacher-child relationship qualities on the mediating role of self-regulation on the relation of socioeconomic risk and school readiness. As such, this study was the first to examine school readiness in light of socioeconomic risk, self-regulation, and 
teacher-child relationships. Three mediated moderator models were tested. These examined the moderating relation of the teacher-child relationship at various points in the mediated relations of self-regulation on socioeconomic risk on school readiness. Results indicated that self-regulation mediated the relation between socioeconomic risk and school readiness. Additionally, the teacher-child relationship moderated self-regulation within this mediated model. These findings suggest that the teacher-child relationship can affect the relation between self-regulation and school readiness and that the teacher-child relationship has the potential to change the level of self-regulation's direct impact on school readiness. These findings contribute to the literature on the factors that predict school readiness and have important implications for schools, children, and families.

KEYWORDS: School Readiness, Teacher-Child Relationships, Self-Regulation, Socioeconomic Risk, Early Childhood Education 
MEDIATING THE RELATION OF SOCIOECONOMIC RISK AND KINDERGARTEN

READINESS WITH SELF-REGULATION: INVESTIGATING THE MODERATING

ROLE OF TEACHER-CHILD RELATIONSHIPS

LEAH COHEN MARKS

A Dissertation Submitted in Partial

Fulfillment of the Requirements

for the Degree of

DOCTOR OF PHILOSOPHY

Department of Psychology

ILLINOIS STATE UNIVERSITY 
Copyright 2017 Leah Cohen Marks 
MEDIATING THE RELATION OF SOCIOECONOMIC RISK AND KINDERGARTEN READINESS WITH SELF-REGULATION: INVESTIGATING THE MODERATING ROLE OF TEACHER-CHILD RELATIONSHIPS

\section{LEAH COHEN MARKS}

COMMITTEE MEMBERS:

Alycia M. Hund, Chair

Renée M. Tobin

Matthew Hesson-McInnis

Amanda Quesenberry 


\section{ACKNOWLEDGMENTS}

I would like to thank my dissertation committee members: Dr. Alycia Hund, Dr. Matthew Hesson-McInnis, Dr. Renée Tobin, and Dr. Amanda Quesenberry. Their feedback and involvement has been greatly appreciated. I would like to especially thank Dr. Alycia Hund for her extensive support throughout this project, from early conception to final editing. She has provided amazing guidance and mentoring, which has included writing, developing hypotheses, and executing the project. She is a true role model for an amazing researcher, teacher and mentor. Also, thank you to Matthew Hesson-McInnis for his expertise in creating the models and conducting the statistics. I am also greatly appreciative for the grant funding that supported this project and my ability to present the results at conferences, which was supported by the National Association of School Psychology Student Research Grant, the Illinois School Psychology Association Research Grant, and the Ora Bretall Graduate Fellowship. I would like to thank my research team of undergraduate and graduate students who assisted with data collection, coding, and data entry. I would also like to thank the children, families, and early childcare centers and preschools who agreed to participate and make this project possible. Finally, I would like to thank my family and friends for their unending support, especially my husband Sammy. I cannot think of anyone else who has been more encouraging and supportive so that I can become "Dr. Leah." 


\section{CONTENTS}

\section{Page}

ACKNOWLEDGMENTS

CONTENTS

ii

TABLES

vi

FIGURES

vii

CHAPTER I: INTRODUCTION 1

CHAPTER II: REVIEW OF RELEVANT LITERATURE 4

$\begin{array}{ll}\text { School Readiness } & 4\end{array}$

Four Theoretical Perspectives on Readiness 4

Measuring School Readiness 5

Academic/Cognitive Readiness 5

$\begin{array}{ll}\text { Social-Emotional Readiness } & 8\end{array}$

Children At-Risk $\quad 10$

Self-Regulation $\quad 12$

Personality and Temperament Perspective: Effortful Control 13

The Development of Effortful Control $\quad 14$

Measuring Effortful Control 14

Direct Measures $\quad 14$

Indirect Measures 16

Cognitive, Executive Functioning Perspective: Inhibition 17

$\begin{array}{ll}\text { The Development of Inhibition } & 18\end{array}$

Hot and Cool Self-Regulation Systems $\quad 19$

Measuring Inhibition $\quad 20$

$\begin{array}{ll}\text { Direct Measures } & 20\end{array}$

Integrating Personality and Cognitive Perspectives 22

Self-Regulation and Children-At-Risk $\quad 24$

Linking Self-Regulation and School Readiness 24 
$\begin{array}{ll}\text { Teacher-Child Relationships } & 26\end{array}$

Teacher-Child Relationships and the Bio-ecological Model 27

The Link Between Attachment Theory and Teacher-Child Relationships 28

Internal Working Models 29

Multiple Attachments and Attachment Hierarchies 30

Measuring Teacher-Child Relationship Qualities $\quad 32$

Linking Teacher-Child Relationships and School Readiness 34

Linking Teacher-Child Relationships and Self-Regulation 35

Integrating School Readiness, Self-Regulation and

Teacher-Child Relationships 36

$\begin{array}{ll}\text { The Present Study } & 37\end{array}$

$\begin{array}{ll}\text { CHAPTER III: METHOD } & 41\end{array}$

$\begin{array}{ll}\text { Participants } & 41\end{array}$

$\begin{array}{ll}\text { Materials } & 46\end{array}$

$\begin{array}{ll}\text { Child Measures } & 46\end{array}$

$\begin{array}{ll}\text { Self-Regulation } & 46\end{array}$

Dinky Toys 46

Head Toes Knees Shoulders (HTKS) $\quad 47$

Bear Dragon $\quad 47$

Day Night Stroop $\quad 47$

$\begin{array}{ll}\text { School Readiness } & 47\end{array}$

Academic Readiness 47

Social-Emotional Readiness $\quad 48$

$\begin{array}{ll}\text { Nonverbal Reasoning } & 48\end{array}$

$\begin{array}{ll}\text { Teacher Questionnaires } & 49\end{array}$

Self-Regulation Questionnaire $\quad 49$

Teacher-Child Relationship Questionnaire $\quad 49$

$\begin{array}{ll}\text { Procedure } & 50\end{array}$ 
$\begin{array}{ll}\text { Child Tasks } & 54\end{array}$

Self-Regulation Tasks $\quad 54$

Head Toes Knees Shoulders Task $\quad 54$

Dinky Toys Task $\quad 54$

Bear Dragon Task $\quad 55$

Day Night Stroop Task $\quad 56$

$\begin{array}{ll}\text { School Readiness Tasks } & 56\end{array}$

Academic Readiness 56

Social-Emotional Readiness $\quad 57$

$\begin{array}{ll}\text { Nonverbal Reasoning } & 58\end{array}$

$\begin{array}{ll}\text { Teacher Questionnaires } & 58\end{array}$

Parent/Guardian Questionnaires $\quad 58$

CHAPTER IV: RESULTS

Data Reduction $\quad 59$

Excluded Data $\quad 61$

$\begin{array}{ll}\text { Preliminary Analyses } & 62\end{array}$

Test of Order Effects $\quad 62$

Nesting Screening $\quad 62$

Hypothesis Testing $\quad 64$

Model 1A Teacher-Child Relationship and the Interaction Between the Teacher-Child Relationship Moderating Risk to Regulation Pathway 67

Model 1B Teacher-Child Relationship and the Interaction Between the Teacher-Child Relationship Moderating Risk to Regulation Pathway With Direct Risk to Readiness Pathway 69

Model 2 Teacher-Child Relationship Moderating Self-Regulation 70

Model 3A Teacher-Child Relationship and Teacher-Child Relationship Self-Regulation Interactions Moderating Path From Self-Regulation to School Readiness

Model 3B Teacher-Child Relationship and the Interaction Between SelfRegulation and Teacher-Child Relation Moderating Path From SelfRegulation to School Readiness with Direct Path From Socioeconomic Risk to School Readiness

$\begin{array}{ll}\text { Synthesis of Results } & 75\end{array}$

CHAPTER V: DISCUSSION 76 
$\begin{array}{ll}\text { Summary of Results } & 76\end{array}$

School Readiness $\quad 77$

$\begin{array}{ll}\text { Socioeconomic Risk } & 79\end{array}$

Direct and Indirect Links Between Socioeconomic Risk and School Readiness

Self-Regulation

The Teacher-Child Relationship $\quad 84$

The Teacher-Child Relationship and Resilience $\quad 85$

The Teacher-Child Relationship as a Moderator $\quad 88$

$\begin{array}{lr}\text { Implications for Schools } & 89\end{array}$

Supporting Self-Regulation $\quad 92$

The Roles of Administrators and School Psychologists 93

One Possible Structure: Response to Intervention 95

Other Strategies for Supporting Teachers $\quad 97$

Policy Implications $\quad 98$

Specific Strategies for Promoting the Teacher-Child Relationship 99

$\begin{array}{ll}\text { Limitations and Future Directions } & 101\end{array}$

$\begin{array}{ll}\text { Conclusions } & 108\end{array}$

$\begin{array}{ll}\text { REFERENCES } & 110\end{array}$ 


\section{TABLES}

Table

Page

1. Parent Education Level 42

2. Reported Gross Annual Income for Families 43

3. Income Per Person Living in the Home 44

4. Teacher Race/Ethnicity Information 45

5. Teacher Education 46

6. Number of Participants Per Order 53

7. Number of Participants Completing the Self-Regulation Tasks 61

8. Intra-Class Correlations (ICC) With No Covariate 63

9. Intra Class Correlations (ICC) with Socioeconomic Risk as a Covariate 63

10. Correlation Matrix and Descriptive Statistics for Composite Variables 64

11. Fit Statistics for All Models $\quad 67$ 


\section{FIGURES}

Figure

Page

1. Overview of Hypothesized Models

2. Model 1A

3. Model 1B

70

4. Model 2

71

5. Model 3A

73

6. Model 3B

74 


\section{CHAPTER I: INTRODUCTION}

School readiness is important for children, families, teachers, and schools. It is essential that children come to school ready to learn and that schools support children as they make the transition into formal schooling. School readiness is children's preparedness to be successful in the kindergarten setting (Bovin \& Bierman, 2014). Specifically, readiness encompasses children's academic skills in areas such as mathematics and literacy but also social-emotional and behavioral skills that are necessary to learn in a school environment (Denham, 2006). School readiness has been a priority in both state and federal policies. Specifically, The School Readiness Act (2005) was passed to mandate federal programs to facilitate children's gains in skills relevant to their readiness for kindergarten (Liew, 2012). An emphasis on school readiness stems from its ability to predict future schooling outcomes for children. Both early academic skills and early social-emotional/behavioral skills predict future outcomes (Duncan et al., 2007; Hair, Halle, Terry-Humen, Lavelle, \& Calkins, 2006).

School readiness is particularly important for children who are at risk for school failure. For these children, unless particular attention is provided and interventions are implemented, it is less likely that they will be successful in school both academically and in the development of a wide range of skills (Campbell \& Ramey, 1994; Conger, Conger, \& Martin, 2010; Ramey \& Ramey, 1999). Although risk for school failure can include many components, one variable that has been linked to school readiness deficits is poverty (Ryan, Fauth \& Brooks-Gunn, 2013), which is sometimes conceptualized as socioeconomic risk. Poverty is often associated with inadequate food, clothing, housing, and healthcare, which all have consequences for children's overall development. It is important to consider these factors so that children who are at-risk can be targeted to improve skills associated with school readiness. These improvements can be 
accomplished by capitalizing on children's resilience and strengths to build the skills that will be helpful in their future schooling.

One possible source of resilience, and another important variable when considering school readiness, is self-regulation. Self-regulation is an important skill necessary for success in the school environment, including children's academic, behavioral, and social-emotional success within this setting. Self-regulation includes voluntary control over approach or withdrawal behavior tendencies, the ability to inhibit a dominant response, and the ability to resist interference or distraction (Liew, 2012; Rothbart \& Bates, 2006; Ursache, 2012). Self-regulation encompasses cognitive and personality/temperament perspectives. Additionally, self-regulation is conceptualized as including both hot (emotional) and cool (cognitive) components (Metcalfe \& Mischel, 1999). From a personality and temperament perspective, self-regulation sometimes is conceptualized as effortful control (e.g., Rothbart \& Bates, 2006). Effortful control often is studied in the context of social-emotional abilities (Zhou, Chen, \& Main, 2012). From a cognitive perspective, self-regulation is conceptualized as one of several executive functions and often is identified as inhibition. Other executive functions include shifting/flexibility and working memory. Both of these perspectives provide important details about the implications of self-regulation for school readiness. When children enter school, they face more demands on their self-regulation skills, and therefore self-regulation provides a powerful predictor for positive classroom behavior, pre-academic skills, and later academic achievement (Allan \& Longian, 2011; Blair \& Razza, 2007; McClelland \& Cameron, 2012). There is also documented research that self-regulation can be predicted by children's background of poverty. Specifically, children who come from a background of poverty are at-risk for poor development of selfregulation (Blair, 2010; Blair \& Raver, 2012, Ursache et al., 2012). Linking this research 
together, therefore, is the idea that poverty can lead to poor self-regulation, which can in turn lead to poor school readiness. Considering self-reguation as a mediator between socioeconomic risk and overall development is validated in the literature, and it has particular relevance to the school environment and school readiness (Raver, 2012). This idea is strengthened because of the the connection between self-regulation and success in the school environment (Brock, RimmKaufman, Nathanson, \& Grimm, 2009). Thus, a mediated model was hypothesized.

A final piece that is important to consider with regard to school readiness is the teacherchild relationship. Although far less studied than the parent-child relationship, the teacher-child relationship can have important implications for the child's learning, school behaviors and interactions, and future school relationships. The teacher-child relationship can be conceptualized as similar to an attachment relationship and therefore can predict a child's future behaviors and outlook on teachers and how to interact with them (Howes \& Spieker, 2008). Teacher-child relationship qualities are linked to both the academic and social-emotional components of school readiness and school success (Peisner-Feinberg et al., 2001; Pianta \& Stuhlman, 2004).

Socioeconomic risk, self-regulation, and teacher-child relationships all have important connections to school readiness. What is unclear is how these variables combine to contribute to school readiness. The goal of this study was to test the moderating role of teacher-child relationship qualities on the mediating role of self-regulation on the relation of socioeconomic risk and school readiness. As such, this study was the first to examine school readiness in light of socioeconomic risk, self-regulation, and teacher-child relationships. 


\section{CHAPTER II: REVIEW OF RELEVANT LITERATURE}

\section{School Readiness}

School readiness is children's preparedness to be successful in the academic setting once entering kindergarten (Boivin \& Bierman, 2014). Promoting readiness is a top priority for researchers, clinicians, teachers, and parents, and also in federal and state policies (Liew, 2012). The School Readiness Act (2005) was passed to mandate federal programs that facilitate children's gains in language and comprehension skills, literacy and mathematics, as well as cognitive abilities and social-emotional development (Liew, 2012). Additionally, goals for the year 2000 were set by the National Education Goals Panel. The goal was that by the year 2000 all children would enter school "ready to learn" ("Promising practices: Progress toward the goals," 2000). This emphasis indicates the importance of school readiness (Rimm-Kauffman, 2004). The concept of school readiness is broad and often difficult to define. Examining multiple theories and dichotomies that are present within the area of school readiness can shed light on its conceptualization in the context of research and practice.

\section{Four Theoretical Perspectives on Readiness}

According to Miesels (1999), there are four theoretical perspectives on readiness, (a) the idealist/nativity perspective, (b) the empiricist environmental perspective, (c), the social constructivist perspective, and (d) the interactionist perspective. These perspectives offer unique views on when a child is ready for kindergarten. The idealist/nativist perspective asserts that children are ready to start school when they reach a level of maturity that enables them to perform socially acceptable behaviors in school (Miesels, 1999). According to this perspective, the environment has little influence on a child's development. A contrasting view is the empiricist or environmental perspective. Readiness is defined entirely by practical characteristics 
of the child's behavior. Specifically, the focus is on external evidence of learning, and the environment is viewed as dictating the child's development and readiness. A third view, the social constructivist perspective, views the child's readiness as determined in social and cultural terms. Specifically, school readiness is neither dictated fully internally or externally. Therefore, readiness is defined by community and contextual demands (Miesels, 1999). A final view that is especially relevant to current conceptualizations of school readiness is the interactionist perspective. In this perspective, readiness is bidirectional. It focuses on the child's skills, knowledge, and abilities within the context of the environment in which the child is taught. Specifically, it is the interaction of the child's genetics, experience, maturation, and cultural context that determine the child's readiness. Central to this view is the idea that a child's educational success results from the reciprocal relationships between the child and the school.

\section{Measuring School Readiness}

Despite divergence in theoretical conceptualizations of school readiness, it is possible to indicate specific behaviors and skills that help educators and parents to know whether children are ready for school. Clarity can be drawn through an examination of skills that make up school readiness not only from an academic and cognitive perspective but also from a social-emotional and behavioral perspective. These definitions contribute to the establishment of specific measurement strategies to quantify school readiness. Specifically, readiness can be examined in the context of social-emotional, behavioral, cognitive, and academic indicators (Bierman, Torres, Domitrovich, Welsh, \& Gest, 2008).

Academic/cognitive readiness. One area of school readiness is academic skills and cognitive abilities. Early signs of cognitive ability and maturity have been linked to performance in school and therefore can be valuable measures (Miesels, 1999). It is important to consider the 
intended purpose of different school readiness assessments. Specifically, some readiness assessments are intended to provide recommendations for further assessment (screeners), whereas others measure specific levels of readiness in various areas. These considerations are important when using school readiness assessments to make decisions regarding special education placement and referrals.

Many measurements of school readiness involve direct assessment of children's skills and abilities. Some tests are designed specifically for the purpose of examining school readiness and provide information about a broad range of competencies and skills. They may include developmental skill components in addition to pure academics. Sometimes these assessments are used to screen for possible developmental delays or need for further assessments in addition to overall school readiness. Some examples of readiness assessments include the Developmental Indicators for Success of Learning-Fourth Edition (DIAL-IV, Mardell \& Goldenberg, 2011), the Brigance Early Childhood Developmental Inventory-Third Edition (Brigance-III, Brigance \& French, 2013), and the Bracken School Readiness Assessment-Third Edition (BSRA-3, Panter, \& Bracken, 2009). This last measure includes subtests that measure letter and number knowledge, shape knowledge, and other early skills to create a composite readiness score and an age equivalent that can be compared with the child's chronological age. The BSRA-3 was selected for use in the this study to measure academic readiness. Other measures such as the Mullen Scale of Early Learning (Mullen, 1995) combine cognitive and motor aspects of development. Achievement tests also are administered to measure a child's academic readiness, often examining a child's skills in literacy and numeracy, such as the Woodcock Johnson $4^{\text {th }}$ EditionTests of Achievement (WJ IV-Tests of Achievement, Woodcock, Schrank, McGrew, \& Mather, 2014) or the Peabody Individual Achievement Test (PIAT-R/NU, Markwardt, 1997). 
Achievement tests may be easily linked to testing for the child later in life, but may not target as many readiness skills as tests designed to assess school readiness.

Another manner of assessment used is intelligence tests such as the Wechsler Preschool and Primary Scale of Intelligence-Fourth Edition (WPPSI-IV, Wechsler, 2012). The Woodcock Johnson $4^{\text {th }}$ Edition: Tests of Cognitive Abilities can also be used with preschoolers, although the test age range goes through adulthood (WJ-IV-Tests of Cognitive Abilities, Woodcock, Schrank, McGrew, \& Mather, 2014). The Stanford-Binet Intelligence Scale- Fifth Edition can also serve this function. (SB5, Roid, 2003). Whereas these intelligence tests provide some information about a child's overall functioning, they may not have direct ecological relevance to the child's ability to be successful in kindergarten.

Another method of assessment within the cognitive and academic realm includes the examination of specific skills that are believed to predict readiness, such as pre-literacy measures. One example is the Peabody Picture Vocabulary Test-Fourth Edition (PPVT-4, Dunn, \& Dunn, 2007), which examines the receptive vocabulary level of students. It is important to test oral language abilities such as vocabulary and phonological awareness because they have been linked to future literacy skills, so they are often considered essential for measurement of readiness in regards to literacy (Dionne, Mimeau, \& Mathieu, 2014).

Many school districts develop their own screening instruments for children who are enrolling in their kindergarten classrooms. Although this may allow the districts to gain specific information relevant to their curriculum, these measures often lack the validity and reliability of standardized measures. Additionally, these measures often are not normed beyond the immediate school population. It may be advantageous for districts to select standardized measures to gain a normative perspective on incoming students. 
Social-emotional readiness. The relation between readiness and achievement is far more complex than academic and cognitive skills alone (Bierman et al., 2008; Duncan et al., 2007; Hair et al., 2006). Readiness has come to include a broad definition that integrates academic skills with social, emotional and behavioral abilities and skills. Social-emotional readiness can be defined and measured in many ways that integrate these emotional, social, and behavioral components.

Social-emotional readiness can be difficult to assess and is often defined in measurement through parent or teacher report. One popular adult-report measure of social-emotional readiness is the Ages and Stages Social-Emotional Questionnaire (ASQ-SE, Squires \& Bricker, 2009). This questionnaire can be used for children aged 3-66 months and has both teacher- and parent-report forms. It includes items related to the child's behaviors and relationships that are relevant to developmental expectations for that age.

Another popular questionnaire that can be completed by teachers and parents is the Devereux Early Childhood Assessment for Preschoolers-Second Edition (DECA-2, Center for Resilient Children, 2013). This questionnaire examines the social-emotional strengths of each child, including initiative, self-regulation, attachment/relationships, and behavioral concerns. The $D E C A-2$ can be used for children age 3 years until their $6^{\text {th }}$ birthday. Additionally, the Devereux Student Strengths Assessment (DESSA, Nickerson, \& Fishman, 2009) can be used to assess children beginning in kindergarten through $8^{\text {th }}$ grade. This assessment provides a socialemotional composite that includes measures of self-awareness, social awareness, selfmanagement, goal-directed behavior, relationships skills, personal responsibility, decisionmaking, and optimistic thinking. 
Another manner of measuring social-emotional readiness is by capturing this variable through an examination of adjustment difficulties in the transition to kindergarten. This overall view of adjustment can include teachers' perspectives on academic functioning but also has important components relevant to social-emotional functioning. Specifically, kindergarten teachers can be surveyed on children's abilities to perform specific behaviors within the classroom that are relevant to their social-emotional functioning, such as following directions, working independently, problems with social skills, and communication difficulties (RimmKaufman, Pianta, \& Cox, 2000). This measure is useful because of its ecological validity. That is, it targets the specific behaviors that are necessary for functioning in a kindergarten classroom. In an attempt to integrate various components of social-emotional readiness, Denham (2006) proposed that a battery of measures targeting five different areas of social-emotional competence would be helpful in fully capturing a preschooler's social-emotional functioning level: (1) emotional expressiveness, (2) understanding of emotion, (3) regulation of emotion and behavior, (4) social problem solving, and (5) social and relationship skills. Her proposed battery uniquely includes both adult-report and direct child measures. Denham applied her recommendations through the use of a similar battery by examining emotion knowledge, emotional and social behaviors, social problem-solving, and self-regulation through various tests (Denham et al., 2012).

Another measure of social-emotional readiness that captures some of these components is a subtest drawn from the Bracken Basic Concepts Scale (BBCS-3: R, Bracken, 2006). The social and self-awareness subtest asks children a series of questions about emotions and inferences about others' emotions and behaviors based on pictures and scenarios. Pictures are presented accompanied by questions in which the child must select one of several options by pointing to 
the picture (Bracken, 2006), thereby providing a direct measure of social-emotional readiness that is untapped at the questionnaire level. A combination of the Bracken School Readiness Assessment-Third Edition (BSRA-3)and the Social/Self-Awareness Subtest was selected to capture a direct measure of academic and social-emotional readiness for this study (Bracken, 2006; Panter, \& Bracken, 2009).

\section{Children At-Risk}

One group for whom school readiness is particularly important is children who are at-risk for school failure (Ramey \& Ramey, 1999). There are many reasons why children may be at-risk for school failure. These reasons include past difficulties in school, health issues, and other environmental factors (Pianta \& Walsh, 1996). One major risk factor for school failure is children who come from backgrounds of persistent poverty (Bierman et al., 2008; Pianta, \& Walsh, 1996). Poverty is often associated with inadequate food, clothing, housing, and healthcare, all of which have consequences for children's overall health and development (Ryan et al., 2013). Without intervention, these students are less likely to achieve success in academic achievement and overall development (Campbell, \& Ramey, 1994; Conger, Conger \& Martin 2010). For the purpose of this study, the term socioeconomic risk was used to describe the sample and to predict readiness outcomes.

It is important to consider how socioeconomic risk can impact overall cognitive, physical, and social-emotional development. Children can become at-risk neonatally because of healthrelated impacts (i.e., low birth weight). Additionally, poverty may be related to food insecurity in the first years of life, which can be linked to poorer developmental outcomes. When comparing children living in poverty to children not living in poverty, cognitive differences emerge within the first two years of life. By the time children are 5 years old, these differences become even 
more pronounced (Ryan et al., 2013). The result of these risks and their cascading effects over development is differences in cognitive, academic, and social functioning that are present for children at the time of kindergarten entry (Ryan, Fauth, \& Brooks-Gunn, 2006). In addition to difficulties at school entry, at-risk children score lower on standardized tests, repeat grades more often, and drop out of school at higher rates than other children (Bowman, 1999). Additionally, they are overrepresented in special education programs (Bowman, 1999).

One way to understand the influence of socioeconomic risk on children is to view risk through a developmental, bioecological model. Specifically, it is important to consider what factors related to poverty put children-at risk for school failure and other difficulties. For example, children from a background of poverty can be exposed to family turmoil and violence, experience family stress, receive less social support, and have parents who are less responsive and less able to invest money in education (Evans, 2004; Ryan, et al., 2013). Additionally, these children may be read to less often, watch more television, have less access to computers, and be exposed to air and water of poor quality, which is linked to physical deterioration (Evans, 2004). It is also important to consider the persistence of poverty as well as its severity and timing, which can have major implications for its influence on children and their readiness for school (VernonFeagans \& Cox, 2013). All of these factors could be linked directly or indirectly to developmental success and failure.

Nonetheless, it is important to capitalize on resiliency in supporting children throughout development, especially during the transition to kindergarten. Just as risk can be viewed through an ecological lens and therefore exists at multiple levels of a child's environment and relationships, so can resiliency (Masten, 2007). Specifically, resilience is something that can 
commonly occur with the proper environmental factors in place. Resilience emerges when specific adaptive systems are in place, despite the presence of other risk factors. (Masten, 2014).

It may also be helpful to consider how different models of risk and resilience lead to specific outcomes. Both mediated and moderated models of resilience are possible when resiliency factors have an indirect effect on outcomes based on particular risk factors. These resiliency factors and the associated outcomes may be important when considering the relation between variables such as socioeconomic risk and school readiness, which are both complex in nature. A final notion to consider is that there are established factors that have been validated in a wide range of studies as important resiliency factors. Some of these factors describe adaptive environments such as effective schools and supportive communities, whereas others are personal factors such as self-regulation, close relationships, and problem solving skills (Masten, 2014).

Specific strategies for building resiliency in school involve in building supports within that setting itself. Comprehensive support for children and families in the transition to elementary school and early elementary years; good preparation of children, families, and schools for adjustment; and positive expectations by children, family, and schools can contribute to a successful school transition. This successful transition, in turn, can lead to overall positive school adjustment and successful transition to adolescence and adulthood later (Ramey \& Ramey, 1999). Understanding how schools, families, and children interface is important in conceptualizing children's experience before, during, and after the transition to formal schooling.

\section{Self-regulation}

Self-regulation is an essential skill for children to be successful in the school environment academically, behaviorally, and social-emotionally. Although the importance of self-regulation is clear, there is little agreement on its definition because self-regulation is multidimensional and 
complex (McClelland \& Cameron, 2012). Debates that complicate the definition of selfregulation include whether it is internal or transactional (Karoly, 1993), whether it is extrinsic or intrinsic, and whether it is conscious or automatic (Gullone \& Taffe, 2012). In an attempt to understand these debates, it is helpful to integrate two major theoretical perspectives that explain the processes of self-regulation: (1) the personality or temperament perspective and (2) the cognitive or executive functioning perspective.

\section{Personality and Temperament Perspective: Effortful Control}

One overarching perspective in which self-regulation is studied stems from personality and temperament research. Intrinsic to the temperament perspective of self-regulation is the understanding of an inherent personality influence on a child's behavior. From this perspective, self-regulation is defined often as effortful control, which involves voluntary control over approach or withdrawal behavioral tendencies (Liew, 2012). Specifically, effortful control includes the activation and inhibition of behavioral tendencies via the shifting and focusing of inhibitory control mechanisms (Liew, 2012). Self-regulation contributes to the organization of temperament by modulating reactivity (Rothbart, Ellis, \& Posner, 2011). Effortful control can be described as the efficiency of executive attention, which includes the ability to inhibit a dominant response and to activate a subdominant response that helps to plan and detect errors (Rothbart \& Bates, 2006). Effortful control involves children's reactivity, which includes positive emotionality and angry emotionality. There is a documented gene by environment interaction that can influence attention and in turn self-regulation (Rueda, Posner, \& Rothbart, 2011). It is important to think about the inclusion of motivation, which may impact regulatory processes (Aksan \& Kochanska, 2004). Effortful control often is studied in the context of social-emotional abilities (Zhou et al., 2012). 
The development of effortful control. The development of effortful control can be understood by examining the development of temperament overall. Individual differences in motor and emotional activity set the stage for other aspects of temperament, including regulatory behaviors via effortful control. Early self-regulation stems from early attentional systems in infancy that involve infants' orientating, and attentional persistence. However, systems that involve specific self-regulatory mechanisms develop later in life (Eisenberg, Smith, \& Spinrad, 2011). Effortful control emerges around the age of two years and rapidly increases during the preschool years until stabilizing between 33 and 45 months (Kim, Nordling, Yoon, Boldt, \& Kochanska, 2013; Rothbart \& Bates, 2006). There is evidence for stability within the early years of life (i.e., attention-related tasks in toddlers) and also stability in early childhood and adolescence (Eisenberg et al., 2011).

Measuring effortful control. Measuring effortful control often includes a multidimensional approach. One approach is to include direct measures of children's behavior in various situations. Another method involves indirect measures in which teachers, parents, or children respond to questionnaires about children's functioning.

Direct measures. Direct measures of effortful control come in a variety of forms. One option is to create a situation that elicits specific emotions, reactions, or urges to measure how a child responds. Other measures are motor tests that target children's ability to inhibit specific behavioral responses. Finally, there are measures that examine children's physiological responses. All three of these methods can be considered to target the "hot" system, given emotion is involved in these tasks.

One measure in which specific emotions are elicited is the mistaken gift paradigm or the disappointing gift paradigm (Cole, 1986; Saarni, 1984). In this procedure, typically conducted 
with children ages 3 to 5 years old, children are asked to rank a set of possible gifts. The children are then given a wrapped box which contains one of their lowest-ranked choices. The children's behavioral response to this situation is measured, indicating a specific level of effortful control. The researcher waits about 20 seconds and then exchanges the undesirable toy for the children's second-favorite toy. The 20 second segments when the children receive each toy are coded based on the children's display of a general positive affect, general negative affect, smiling, surprise, disappointment, disgust, and anger (Cole, 1986; Kieras, Tobin, Graziano, \& Rothbart, 2005; Saarni, 1984). Another procedure used to elicit positive emotions requires children to keep a secret from the clinician. The children's ability to keep the secret and behavioral response to keeping the secret is measured (Carlson \& Wang, 2007).

The second set of measures includes tests of children's ability to inhibit specific behavioral responses, including motor and verbal responses. Motor responses can be divided into two categories: slow-down motor activities and suppress or initiate motor response activities. Slow-down motor activities include asking children to walk on a line as slowly as possible (Walk a Line Slowly, or Balance Beam), or asking children to draw a circle or line as slowly as they can after trials in which they were asked to draw fast (Turtle's house, Telephone poles, Circle \& Star). One example of a task in which children are required to suppress or initiate a motor response is a pinball game in which children are instructed to pull a lever on a pinball machine but not release it until the clinician says go (Kochanska, Murray, \& Coy 1997; Kochanska, Murray, Jacques, Koenig, \& Gadegeest, 1996; Reed, 1984; Smith-Donald, Raver, Hayes, \& Richardson, 2007). Another example is Head Toes Knees and Shoulders (HTKS) in which body parts spoken are associated with touching a different part of the body when a researcher says a name (Ponitz, McClelland, Matthews, \& Morrison, 2009). HTKS was one of the direct measures 
of self-regulation utilized in this study. Yet another example is Simon Says where children must inhibit touching different parts of their body in the absence of the instruction "Simon says" (Kieras et al., 2005; Strommen, 1973). Another task called the Puzzle Box task requires a child to assemble a puzzle in a wooden box without looking. Children have the option of peeking with a cloth. The child's persistence in the task without peeking measures their effortful control (Eisenberg et al., 2001). Similarly, the Dinky Toys Task is one in which children are instructed to keep their hands on their knees while verbally indicating to the researcher which toy they would like to select (Kochanska et al., 1996; Kochanska, Murray, \& Harlan, 2000). Dinky Toys was another measure used in this study.

Indirect measures. Effortful control also can be measured indirectly, via questionnaires administered to parents, teachers, and/or children themselves. The Effortful Control Scale (Lonigan \& Phillips, 2001) is one questionnaire that targets effortful control specifically rather than as an aspect of the broader context of temperament. An additional series of questionnaires is the Infant Behavior Questionnaire (IBQ, ages 3-12 months, Rothbart, 1981, Gartstein \& Rothbart 2003), the Child Behavior Questionnaire (CBQ, ages 3-7 years, Putnam \& Rothbart, 2006; Rothbart, Ahadi, Hershey \& Fisher, 2001), and the Temperament in Middle Childhood Questionnaire (TMCQ, ages 7-10 years, Simonds, Kieras, Rueda, \& Rothbart, 2007). There are also short and very short form versions of the $C B Q$ (Putnam \& Rothbart, 2006). The original $C B Q, I B Q$, and $T C M Q$ are parent-report measures, however, the $C B Q$ also has been modified to be used with teachers. There are short and very short forms of the $C B Q$ teacher report. The three dimensions of temperament represented in the $C B Q$ include extraversion/surgency, negative affectivity, and effortful control. The effortful control scale encompasses subscales such as inhibitory control, attentional focusing, low intensity pleasure, and perceptual sensitivity 
(Rothbart et al., 2001). A teacher report of the Effortful Control subscale of the Child Behavior Questionnaire Very Short Form was used in this study.

A final way that effortful control is measured indirectly is via physiological responses. For example, researchers introduce behavioral and emotional situations in which regulation is necessary for preschool participants then measure participants' heart rate. The inhibitory activity of the vagal nerve, an important component of the parasympathetic nervous system, is inferred (Calkins \& Keane, 2004).

Because there are many possible measurements to use when examining effortful control, researchers must select measures that are suitable for the purposes of the study. Variables to consider include the age of the children and access to multiple sources of information (i.e., parent report, teacher report, direct observation). For the purpose of this study, Head Toes Knees Shoulders and Dinky Toys Task were selected to serve as direct measures of effortful control. Additionally, a teacher-report of effortful control, (Child Behavior Questionnaire effortful control subscale) was used as an indirect measure of effortful control.

\section{Cognitive, Executive Functioning Perspective: Inhibition}

From a cognitive perspective, self-regulation is defined as part of a large set of processes called executive functions. Executive functions encompass the ability to engage in deliberate, goal-directed thought and action (Liew, 2012). These functions are accomplished through three main processes: the ability to hold information in working memory (information updating and monitoring), the ability to shift the focus of attention (mental set shifting), and the ability to resist interference or distraction (inhibition of prepotent responses, Liew, 2012; Ursache, 2012). The inhibition of prepotent responses can be broken down into inhibiting a dominant response, interrupting an ongoing response, and protecting the self-directed responses that occur within the 
delays (Barkley, 2011). The three aspects of executive functioning have been found to be moderately correlated in adults but also clearly distinct in that they contribute uniquely to the performance of complex executive tasks (Miyake et al., 2000). There is considerable debate about whether these components are separable in early childhood, with recent findings indicating that the three distinct, yet overlapping components emerge by adolescence (Miyaki et al., 2000). As mentioned earlier, executive functions are often studied using cool tasks; meaning that the tasks involve cognitive effort but are not necessarily emotion-driven. Moreover, the tasks involve abstract, decontextualized problems (Metcalfe \& Mischel, 1999; Zelazo \& Carlson, 2012; Zelazo, \& Muller, 2011). Cool executive functioning tasks engage the dorso-lateral prefrontal cortex. These tasks are contrasted with hot tasks that engage the orbital prefrontal cortex (Willoughby, Kupersmidt, Voegler-Lee, \& Bryant, 2011). It has been proposed that selfregulation and executive functions may have a bi-directional relationship. Specifically, selfregulation can play both a bottom up and top down role, and can possibly be interrelated with other executive functions (Blair \& Ursache, 2011). This project focuses on the executive function of inhibition.

The development of inhibition. To understand the development of inhibition, it is important to look at the overall development of executive functioning in children. Aspects of executive functioning emerge around the end of the first year of life and continue to develop across a wide range of ages, with particularly rapid development during the preschool years. On some tests of executive functioning, children 12 years of age perform at adult levels, whereas on other tests, there are continued improvements into adulthood. The development of executive functioning is associated with the development of the prefrontal cortex (Zelazo \& Muller, 2010). 
One important distinction involves simple and complex response inhibition. This distinction is important to understand in the context of the development of executive functioning as a whole but also in the development of inhibition more specifically. The difference is the inclusion of working memory and other executive functioning skills in the measurement of complex response inhibition, whereas simple response inhibition involves a purer measure of inhibition. Simple response inhibition begins in toddlers when they stop an enjoyable activity at a caregiver's request. Specifically, researchers have found that 8-month-olds are able to inhibit behavior $40 \%$ of the time (Kochanska, Tjebkes, \& Forman, 1998). Complex response inhibition tasks, however, are difficult for children who are under three years. For example, children completing a Stroop-like task must remember a rule and inhibit a prepotent response. Responses improve dramatically between three and four years (Carlson, 2005). An important consideration regarding complex response inhibition tasks is that they may involve both hot and cool executive functioning. Understanding developmental issues is critical for selecting meaningful measures of inhibition.

Hot and cool self-regulation systems. An additional important consideration of both the effortful control and inhibition perspectives on self-regulation is the idea of "hot" and "cool" systems as proposed by Metcalfe and Mischel (1999). Effortful control often involves the infusion of emotion into the self-regulatory process. This description is akin to the hot system, which is emotional and is characterized by a "go" idea. In contrast, the cool system is cognitive, emotionally neutral, and strategic. This system is relevant to the executive functioning perspective. It is important to note that there is overlap in hot and cool regulation. This overlap is important to consider when trying to understand the different aspects that make up selfregulation. This hot-cool integration is at the core of self-regulation and inhibition because the 
two opposing systems allow children to regulate emotions and act from a logical, cognitive perspective versus behaving purely on emotions (Metcalfe \& Mischel, 1999). Some research has indicated that hot and cool systems may be distinct yet related processes (Hongwanishkul, Happaney, Less, \& Zelazo, 2005).

Measuring inhibition. Similar to effortful control, inhibition also can be measured directly and indirectly. Because of a shared theoretical background, some measures of inhibition are embedded in larger measures of executive functioning. The theoretical backgrounds of these measures is important to consider, especially when making comparisons to inhibitory control and effortful control.

Direct measures. One way that inhibition is measured is through a battery of executive functioning tests. One example is the Delis-Kaplan Executive Function System (D-KEFS, Ellis, Kaplan, \& Kramer, 2001). The system was originally created for adults and has been adapted for children but not yet for early childhood. Specifically, it can be used to assess people from age 8 to 89 years, but normative data for the ninth test does not begin until age 16. Additionally, each of the 9 tests can be used as stand-alone tests. The Delis-Kaplan Executive Function System is a conglomeration of many tests already in existence that have been combined and normed (Baron, 2004). Another larger test that can be used is the Developmental Neuropsychological Assessment Second Edition (NEPSY-II, Korkman, Kirk, \& Kemp, 2007). One of the major domains measured in the NEPSY is executive functioning, so an overall picture of a child's executive functioning can be drawn from this test. Specifically, subscales target aspects of auditory attention as well as inhibition measured by errors, the total number correct, and timing (Korkman et al., 2007). 
One direct measure called The Shape School tests inhibition through the use of a story. In different conditions, children are required to name some or all of the shapes in the story. The ability for the child to inhibit naming the shapes that are not supposed to be named measures their inhibition (Epsy, 1997). Another direct measure of inhibition is the Antisaccade Task (Hallet, 1978; Munoz, Broughton, Goldring, \& Armstrong, 1998). This task involves a measurement of eye movements when attempting to follow instructions to focus on and inhibit looking at objects in the field of vision. Specifically, a visual cue is presented to the left or right of midline on a screen followed by an arrow. Participants are asked to ignore the visual cue and only respond to the arrow by pressing a button (Garon, Bryson, \& Smith, 2006). In addition, researchers have used Stroop Tasks (Stroop, 1935) to measure inhibition. The Color Word Stroop Task involves inhibiting a prepotent response such as reading a color word and instead naming the ink color of the word (Stroop, 1935). An updated Stroop-like task, Day and Night, requires a child (ages 3.5 to 7 years) to respond "day" to a card that is dark with a moon and stars and "night" to a card that is light with a sun (Gerstadt, Gerstadt, Hong, \& Diamond, 1994). The Day Night Stroop task was one of the direct tasks used in this study to measure self-regulation. In the Bear Dragon task, children are introduced to two hand puppets worn by the researcher. The bear and dragon issue directives to the children by commanding specific movements (e.g., touch your tummy, touch your head), and children are asked to perform the movements requested by the bear but to inhibit the ones requested by the dragon (Reed, 1984). The Bear-Dragon task was another direct-self-regulation measure used in this study.

Executive functioning can also be measured with hot tasks such as those described in the effortful control section (Gift Delay Tasks, and Go/No Go tasks, such as Simon Says and The Hand Game, which involves the child making a different hand gesture than the clinician instead 
of imitating their hand position, Hughes, 1998; Strommen, 1973). These tasks are considered Hot Tasks because of their motivationally salient nature. These tasks are affected by motivation or affect. This is different from cool tasks such as the Stroop Task, where motivation and affect do not affect performance (Zelazo \& Carlson, 2012).

Another form of direct measure that has been used to measure inhibition is the physiological measure of pupil dilation in response to tasks that require inhibition. Specifically, the presence of larger pupils during tasks reveals increased mental effort. This technique has been used in children as young as $3 \frac{1}{2}$ years (Chatham, Frank, \& Munakata, 2009). The BearDragon and Day Night Stroop tasks were selected to serve as direct measures of inhibition as a part of this study.

\section{Integrating Personality and Cognitive Perspectives}

Recently, researchers have called for a model of self-regulation that integrates both the cognitive/executive functioning perspective and the personality/temperament/effortful control perspective (Liew, 2012; Ursache, et al., 2012; Zhou et al., 2012). Zhou et al. (2012) reviewed the literatures and found two major similarities in the definitions. The first major component that both perspectives share is an element of inhibition. Researchers studying executive functioning and effortful control often used the same or similar measures such as the Go/No Go and Stroop tasks (Strommen, 1973; Stroop, 1935). Still, effortful control researchers tend to focus on inhibition of motivation or emotion-driven behavioral responses, whereas executive functioning researchers tend to focus on inhibition in the context of cognitive responses (Zhou et al., 2012). The second major similarity is that both effortful control and executive functioning share a common process of attention. Executive attention and its network are considered a key system underlying a child's development (Zhou et al., 2012). 
Although definitions of effortful control and inhibition as an executive function are similar, often they are examined in different contexts. For example, effortful control is studied in the context of personality and individual differences, whereas executive function is studied in the context of cognitive development. With these different contexts, the behaviors and abilities that result appear to be highly similar. It is important to understand these similarities and contexts in an attempt to bring the literature together. Liew (2012) emphasized that bringing these bodies of research together is essential for appropriately deciding on future directions in educational policy and interventions. It is clear from all of these sources that an integration of these two areas is necessary in looking at future research but also in trying to understand what has already been done and what this tells us about children's development.

For the purpose of this study, it was important to integrate theories and research relevant to both effortful control and inhibition to provide an integrated definition of self-regulation. The integrated approach required multiple measurement techniques that draw upon these various theories. It was for this reason that self-regulation was measured using four different measures. Of these four, some were hot self-regulation measures, some cool. Additionally some were drawn from the effortful control, temperament literature while others were drawn from the executive functioning, inhibition literature. In addition to direct measures of self-regulation, a teacher-report measures $(C B Q)$ also was utilized. The multiple sources of measurement capture the multidimensional nature of self-regulation, and an inclusion of an adult-reporter provided more dimension to the measurement strategies used as a part of this study. 


\section{Self-regulation and Children At Risk}

Children who come from a background of poverty are at-risk for poor development of self-regulation (Blair 2010; Blair \& Raver, 2012; Raver et al., 2011; Ursache et al., 2012).

Studies that have examined this relation often do so in the context of overall cognitive functioning but also in terms of executive functioning development. For example, in a computerized test of attention orientation and competing demands (executive attention), children aged 5 to 7 years from high socioeconomic status (SES) backgrounds performed better than did children from lower SES backgrounds (Mezzacappa, 2004). Gaps in cognitive development in the past have been attributed to parents providing environments that vary in cognitive enrichment, yet this does not account for all differences between high and low SES groups. Specifically, in a study of delay of gratification, which is a measure of self-regulation, family income was positively related to delay. This finding and the pathway of income to self-regulation to achievement operates independently of parental investment, indicating that it is more than parental interactions and provision of resources that impacts children's self-regulation (Evans \& Rosenbaum, 2008). Specifically, opportunities tend to vary as a function of family income, creating an opportunity gap for these children.

\section{Linking Self-Regulation and School Readiness}

Self-regulation is important for children in the context of school, especially during times of transition. When children enter school, they face more demands on their self-regulation skills and their academic skills (McClelland \& Cameron, 2012). Blair and Razza (2007) concluded that self-regulation skills was the most powerful predictor of positive classroom behavior and overall academic achievement, compared to other variables. In this study of 3- to 5-year-old children, measures of self-regulation accounted for unique variance in academic outcomes. Specifically, 
effortful control (i.e., peg tapping and attention shifting) uniquely predicted both early mathematics and reading ability (Blair \& Razza, 2007). Other studies have found moderate correlations between preschooler's effortful control and pre-literacy skills such as phonemic awareness, print knowledge, and vocabulary (Allan, \& Lonigan, 2011). There also are established links between children's early executive functioning skills and their mathematics, literacy, and vocabulary skills (McClelland et al, 2007). Additionally, in a recent study, links were established between both hot and cool aspects of executive functioning and academic and social-emotional aspects of school readiness (Mann, Hund, Hesson-McInnis, \& Roman, 2016). Another method for examining the relation between self-regulation and school readiness is to chart academic growth during the prekindergarten year as a function of self-regulation level. Specifically, Welsh and colleagues (2010) found through path analyses that working memory and attention control predicted growth in emergent literacy and numeracy skills during the prekindergarten year. This growth made unique contributions to prediction of kindergarten mathematics and reading achievement (Welsh et al., 2010).

In addition to the early direct links between a child's self-regulation and their readiness for kindergarten, it is important to consider how children's self-regulation can interact with the school environment. Specifically, self-regulation and factors in the classroom can function reciprocally. On one hand, children's self-regulation at kindergarten entry has been linked to teacher's reports of behavioral self-control, cognitive self-control, and work habits in the spring (Brock, Rimm-Kaufman, Curby, Grimm, Nathanson, \& Brock, 2009). On the other hand, classroom quality, specifically the teacher's classroom management, has been linked to better behavior and self-control, more engagement, and more on-task behavior by children (RimmKauffman et al., 2009). This range of results, can make it difficult to discern which individual 
variable predicts school readiness, but provides information that the classroom is a dynamic environment with many activities that are relevant to children's self-regulatory abilities. These reciprocal findings also point toward the importance of teachers for children's school success.

\section{Self-Regulation as a Mediator}

There are clear connections in the research literature between self-regulation and socioeconomic risk as well as self-regulation and school readiness (Blair, 2010;Blair \& Razza, 2007; Mann, Hund, Hesson-McInnis, \& Roman, 2016; McClelland \& Cameron 2012; Ursache, Blair \& Raver, 2012) Specifically, self-regulation can serve as both an outcome and a predictor. That is, socioeconomic risk can predict self-regulation (Blair \& Raver, 2012; Ursache et al., 2012), thus making it an outcome, while self-regulation can also predict school readiness, making it a predictor (McClellend \& Cameron, 2012). Additionally, there is a strong connection between socioeconomic risk and school readiness, with the understanding that the contributions of school readiness are complex and beyond environment (as indicated by socioeconomic risk), and can be impacted by individuals' development (e.g. Hair et al., 2006; Welsh et al., 2010). Self-regulation has also been proposed and validated in the literature as a mediator between poverty and overall development, with a recognition of the specific implications for schooling and education (Raver, 2012; Ursache, Blair \& Raver, 2012). It is for this reason that selfregulation can serve as an important mediator between socioeconomic risk and school readiness, and was thus conceptualized as such in this study.

\section{Teacher-Child Relationships}

The teacher-child relationship plays an important role in a child's development within the context of the school environment. The teacher-child relationship is characterized by a child's bond with a teacher and the associated interactions. Specifically, children can form relationships 
with teachers from whom they can seek support at school daily (Birch \& Ladd, 1997). This relationship can be reflected in a child's behavior, beliefs, and feelings, as well as influence patterns of expectations within the school environment. Children's beliefs and feelings can include trust, motivation, self-worth, and overall adjustment in the classroom (Pianta \& Steinberg, 1992). Also important is the idea that these relationships can be stable over time and that different teacher-child relationship trajectories can have differential impacts on children's readiness and development throughout schooling (Miller-Lewis, Sawyer, Searle, Militinty, Sawyer, \& Lynch, 2014). Our understanding of the teacher-child relationship is far less studied than the parent-child relationship, but it is important when considering how much time children spend interacting with a teacher on a daily basis. Additionally, teachers have the power to create an environment in which children can contextualize their experiences. Specifically, the quality of a classroom as a whole can be defined by the interactions between teachers and students (Pianta, Downer, \& Hamre, 2016). The teacher-child relationship has the power to predict development in many different domains including cognitive, social, language and literacy (Hamre, Hatfield, Pianta, \& Jamil, 2014). The teacher-child relationship has theoretical roots similar to that of the parent-child relationship, but also some unique outcomes, including the power to predict a child's behavior in future schooling.

\section{Teacher-Child Relationships and the Bio-ecological Model}

It is important to think about the teacher-child relationship as a part of the larger system of relationships and contexts that the child experiences. The system of relationships and contexts can be explained by examining the teacher-child relationship as one of the many systems at play in Bronfenbrenner's $(1977,1998)$ Bioecological Model. Specifically, this model examines children as developing within the context of multiple interactions and environments that have 
direct and indirect influences on their development. This model may be particularly helpful for understanding the influence of the teacher-child relationship over time and how this influence may fluctuate. Specifically, the teacher-child relationship and the school is one of the many contexts that influences a child's development. These findings point to the importance of not only examining the parent-child relationship and parental influences on the child but also the teacher. Additionally, the teacher relationship is linked to the system of the school, which also influences the child's development and viewpoint. Therefore, understanding the constructs of teacher-child relationships and school readiness from an ecological perspective can allow for better understanding of how the two constructs may relate and overlap in the context of a child's school experience and development (O’Connor \& McCartney, 2007). Specifically, considering how a school environment may influence the development or impact of the teacher-child relationship could be important. In one study, researchers found that the teacher-child relationship could be predicted by different types of early childhood education settings and that closeness tended to be lower, but conflict and dependency higher in Head Start settings as compared to other preschools (Garner, Mahatmya, Moses, \& Bolt, 2014).

\section{The Link Between Attachment Theory and Teacher-Child Relationships}

Attachment theory can provide important theoretical details about the mechanisms behind the teacher-child relationship. There are disagreements about whether the teacher-child relationship is a true attachment relationship, although it shares many qualities that could allow it to be considered one (Pianta \& Steinberg, 1992).

Attachment theory and its components are traditionally studied in the context of parentchild relationships; however, there can be important implications for the potential influence of the relationship that is developed between a teacher and child. John Bowlby $(1969 / 1980)$ 
proposed the theory of attachment as an explanation for the bonds that infants form with their primary caregivers, typically their mothers. Bowlby argued that attachment has its base in evolutionary necessities that promote survival. Historically, attachment has been studied in the context of the mother-child relationship. Traditionally, mother-child attachment is measured through the use of the Strange Situation Procedure as well as Q-sort strategies (Ainsworth, Blehar, Waters, \& Wall, 1978; Waters \& Deane, 1985). Recent research has expanded to include the father-child relationship and other caregivers with whom children can form attachment relationships (Howes \& Spieker, 2008). In this context, the teacher emerges as an important figure. Researchers interested in the relationships between teachers and students have drawn from the attachment literature to conceptualize a relationship that shares characteristics of the classic construct. Specifically, the parent-child relationship provides a model for the development of relationships with other adults such as teachers in early years of schooling (Pianta \& Steinberg, 1992).

Internal working models. To understand how an attachment relationship can manifest in behaviors, it is important to consider internal working models. Internal working models of self and other in attachment relationships help members of the attachment dyad to anticipate, interpret, and guide interactions with partners (Bretherton \& Munholland, 2008). Children create models in which they execute specific behaviors and cognitions within the context of the attachment relationship. Just as children may develop an internal working model to guide their interactions with parents, they also may develop them with regard to their teachers. These internal working models help to determine the child's behavior toward the teacher and in school. It has been theorized that having a "secure base" will allow the child to explore and take risks. An internal working model in which children feel comfortable and safe to take risks in the 
classroom will allow them to learn effectively. This theory could explain why a positive teacherchild relationship characterized by closeness and warmth could lead to better academic and social-emotional outcomes. For example, in one study, first grade teachers' strong emotional support related to greater growth in students' early literacy skills (Curby, Rimm-Kauffman, \& Cameron Ponitz, 2009). In another example, teachers' sensitivity to children's different social behaviors predicted future behaviors and time on task in the classroom (Rimm-Kaufman et al., 2002). One potential explanation for this positive outcome is that the close, secure relationship with the teacher allows children to explore, learn, and take risks while benefiting from the safety of the secure relationship (Howes \& Hamilton, 1992).

Multiple attachments and attachment hierarchies. An additional component of attachment theory that may be helpful to consider in the context of teacher-child relationships is the potential for a child to have multiple attachments or a hierarchy of attachments. Bowlby and other researchers proposed that it is possible for infants to develop multiple attachments and also for these relationships to fall within an attachment hierarchy, with a structure that varies by child (Cassidy, 2008). A hierarchy explanation in the context of teacher-child attachment relationships can help to clarify how a child who forms a relationship with a teacher could be influenced in the long term. With this web of variables influencing the development of later attachment relationships, it is important to study empirically and parse apart how these various relationships may differ and influence the child. For example, researchers have examined the unique and joint effects of mother-child relationships and teacher-child relationships on child outcomes. In a study of self-concept, mother-child relationships influenced general self-concept, whereas teacher-child relationships were related to academic self-concept (Verschueren, Doumen, \& Buysse, 2012). Additionally, an indirect effect of mother-child attachment quality influenced 
academics through the dimension of current adult-child relationships in the school. This pattern suggests that the mother-child relationship and teacher-child relationship both influence developmental outcomes for students and that they may also interact with each other (Verschueren et al., 2012).

In cases in which the teacher-child relationship is the child's only secure attachment, it is possible that the teacher-child attachment relationship takes on a higher priority in the child's hierarchy. In these cases, the influence of the teacher-child relationship is especially important because it demonstrates that the teacher-child relationship can help to negate the influence of a child's insecure attachment with a parent or caregiver. In the creation of this strong bond between the child and the teacher, the teacher can help to build positive and consistent expectations into the child's behavioral and emotional repertoire. The classroom and the school can therefore serve as a safe place for the child to learn and take risks both academically and socially. This bond is most influential in the early childhood years because the child's relationship with the teacher is more connected with caregiving activities than schooling in later years (Howes \& Hamilton, 1992). This connection is contrasted with the role the teacher plays later in schooling when tasks are more academically focused, and the child may seek a close relationship with teachers in the context of an orientation toward the fulfillment of academic tasks (Baker, 2006).

One additional possibility is that children are flexible in their development of patterns of relationship and that children can be engaged simultaneously in two important attachment relationships that are completely different. A longitudinal study in which both parent-child and teacher-child relationships were examined found no evidence of a relation between teacher-child and parent-child relationships (Howes \& Hamilton, 1992), suggesting that relationship patterns 
are flexible. In this case, it may be difficult to determine which is the dominant attachment relationship. We know that parent-child and teacher-child relationships have different influences on future externalizing and internalizing behaviors. For example, insecure and other maternal attachment relationships at age 3 years have been associated with externalizing and internalizing behaviors at grade 5 . Teacher-child relationships were found to change if the teacher changed before 30 months but remained stable after 30 months regardless of teachers changing or not. These results led, however, to discordance from the parent-child relationship, because these stability characteristics were present independent of the child's attachment with the parent (Howes \& Hamilton, 1992). An additional finding is that the influence of insecure and other attachment styles on externalizing and internalizing behaviors in late childhood was mediated through teacher-child relationships during childhood (O'Connor et al., 2011). One more related but slightly different concept is considering levels of closeness and conflict within a relationship, concepts that are based on the different attachment styles. In one study, elevated levels of teacher-child conflict during childhood were associated with externalizing behaviors in childhood, whereas low levels of teacher-child closeness were associated with internalizing behaviors (O’Connor, Collins, \& Supplee, 2011). These complex factors all provide a compelling argument for aspects of attachment relationship to be relevant to the teacher-child relationship.

\section{Measuring Teacher-Child Relationship Qualities}

The influence of theories such as the bio-ecological model and attachment theory are evident in the conceptualization and measurement of teacher-child relationship qualities. One way that teacher-child relationships have been examined is as a component of classroom climate (Anhert, Harwardt-Heinecke, Kappler, Eckstein-Madry, \& Milatz, 2012). Another method of 
measurement includes details from attachment theory that have been applied directly to the study of teacher-child relationships. For example, Howes and Hamilton (1992) examined teacher-child attachment side by side with maternal attachment in infancy using the Attachment Q-set. Based on Q-set measurements, researchers determined that children's teacher-child relationship quality was stable if the teacher remained the same for children younger than 30 months. For children older than 30 months, relationship quality remained stable despite changes in the teacher.

Other measures of teacher-child relationships use questionnaires completed by the teacher. Robert Pianta created a survey to measure the teacher-child relationship from an attachment perspective--the Student-Teacher-Relationship Scale (Pianta \& Steinberg, 1992). The original scale included measures of closeness, conflict, and dependency (Birch \& Ladd, 1997; Pianta \& Steinberg, 1992). Specifically, scores are obtained for the teacher's perceived closeness, conflict, and dependency in their relationship with the child. This questionnaire mirrors the attachment literature in which children are determined to have a close, secure attachment or an insecure attachment that is characterized by either avoidance or resistance (conflict and dependency).

Just as a secure attachment with a parent predicts specific child behaviors and outcomes, the relationship with the teacher also predicts child outcomes, such as school adjustment, academic outcomes, and social skills. In one study, researchers examined the relations among aspects of the teacher-child relationships and kindergarteners' academic and social-emotional outcomes. The areas of dependency, conflict, and closeness were examined in the context of the teacher-child relationship via the Student-Teacher-Relationship Scale (Pianta \& Steinberg,1992). In this study, dependency in the teacher-child relationship was strongly correlated with school adjustment difficulties. These difficulties included poor academic performance, negative school 
attitudes, and less positive engagement with the school environment. Teacher-reported conflict was associated with school avoidance and lower self-directedness, school liking, and participation in the classroom. Additionally, closeness was positively linked with academic performance as well as students' school liking and self-directedness (Birch \& Ladd, 1997). In an additional study, children were tested longitudinally from ages 4 to 8 years. The closeness of the teacher-child relationship predicted both cognitive (vocabulary, mathematics, reading) and social skills (cognitive/attention, behavior problems, sociability, Peisner-Feinberg et al., 2001).

\section{Linking Teacher-Child Relationships and School Readiness}

When considering how the teacher-child relationship may be associated with school readiness, it is helpful to examine the influence of teacher-child relationships on present and future academic and social-emotional outcomes. In general, high quality teacher-child relationships have been linked to outcomes of school readiness (Hatfield, Burchinal, Pianta, \& Sideris, 2016). In one large-scale study of outcomes beginning at age three years and continuing for five years, social and cognitive implications of teacher-child closeness were examined in the context of overall childcare quality from multiple perspectives (Peisner-Feinberg et al., 2001). As expected, closeness of the teacher-child relationship predicted the development of both cognitive and social skills. There was a stronger effect, however, for social skills. It is important to note that all of the measures were teacher-reported (Peisner-Feinberg et al., 2001). In another study, Pianta and Stuhlman (2004) found that teacher-child relationship quality at preschool predicted children's skills in first grade. These skills included academic and cognitive skills, vocabulary skills, and an absence of internalizing and externalizing behavior problems as rated by both mothers and teachers (Pianta \& Stuhlman, 2004). 
Other studies have examined specific aspects of child functioning as they relate to the teacher-child relationship. In one early study, teacher-perceived closeness was correlated with academic performance. In contrast, teacher-perceived dependence was correlated with poorer academic performance (Birch \& Ladd, 1997). When controlling for other factors that have historically influenced achievement, significant associations were found with teacher-child relationship quality and achievement (O’Connor \& McCartney, 2007). Teacher effects on academic achievement were dominant factors in the classroom (Wright, Horn, \& Sanders, 1997).

\section{Linking Teacher-Child Relationships and Self-Regulation}

It is important to consider the relations between teacher-child relationships and child selfregulation. Self-regulation has been studied in the context of the teacher-child relationship in preschoolers. In one study involving children from low SES backgrounds, research findings indicated that self-regulation did not serve as a central hindrance to children's learning and development but rather as a quality that had the potential to increase children's rate of learning (Schmitt, Pentimonti, \& Justice, 2012). Self-regulation was therefore conceptualized as a variable that could help break the trajectory of children at-risk for academic difficulties. In addition, teacher-child relationship quality was directly related to grammar gains during the school year. Moreover, researchers found a significant interaction between conflicted teacherchild relationships and children's behavior regulation. This relation is important to consider when parsing the multidimensional characteristics of self-regulation in its interaction with other important variables in the school environment (Schmitt et al., 2012).

An additional strategy for understanding teacher-child relationships and self-regulation is to examine how these variables are related to behavioral outcomes. For instance, Murray and Murray (2004) examined the relation between behavioral orientations, academic orientations, 
and teacher relationships for children with different demographic characteristics. Using hierarchical regression, the researchers found that more variance was predicted by negative relationship characteristics (conflict and dependency) than by positive characteristics. Specifically, teacher-child relationships characterized by more negative components predicted more variance in child behavior. They also found that children's internalizing and externalizing behaviors were predictive of conflict and dependency in teacher-child relationships. In terms of dependency, internalizing symptomatology was the better predictor. This pattern indicates that children with social-emotional and behavior problems are at risk for poor teacher-child relationships. This significant relation is important to consider because these children are at risk for other difficulties academically and socially, so compounding these effects with a poor teacher-child relationship could lead to even poorer outcomes.

\section{Integrating School Readiness, Self-Regulation and Teacher-Child Relationships}

It is clear that that there is a great deal of theoretical background and empirical data that demonstrate the importance of self-regulation and teacher-child relationships as a whole. Additionally, school readiness is conceptualized as an important part of children's early development and as a predictor of future success. Nonetheless, little research has examined the relations among all three of these variables. One exception is a recent study by Eisenberg, Valiente, and Eggum (2010) that proposed a theoretical model in which teacher-child relationships serve as one of several mediators of self-regulation and academic outcomes. The authors offered a conceptual model that proposed the relation between self-regulation and academic performance was mediated by low maladjustment and high-quality relationships with peers and teachers, in addition to school engagement. They noted, however, that little evidence of mediated relations is available in the current literature (Eisenberg et al., 2010). Whereas the 
researchers examined the same variables as are detailed in the theoretical model, they only offered a theoretical model, not a direct empirical study of these variables. Additionally, the researchers did not isolate teacher-child relationships as a potential mediator or moderator. Moreover, they examined academic outcomes rather than the broader context of school readiness. As such, the goal of this project was to understand the process by which teacher-child relationships, child self-regulation, and socioeconomic risk predict school readiness and at what point the teacher-child relationship has an influence.

\section{The Present Study}

This study sought to understand the relations among socioeconomic risk, self-regulation, school readiness, and the teacher-child relationship. The extensive literature on school readiness and its connections with self-regulation and socioeconomic risk have established clear linkages. Specifically, it is clear that there are both direct and indirect connections. Socioeconomic risk is an important predictor for many aspects of development, making it an appropriate overall predictor for school readiness. Self-regulation remains an individual factor that could possibly change the school readiness outcomes for children from a wide range of socioeconomic backgrounds. Self-regulation in this context is serving as both a predictor and outcome in relation to socioeconomic risk. With an understanding that socioeconomic risk can predict school readiness directly, but also indirectly, self-regulation presents itself as a possible mediator between the two. Therefore, the model that was tested included self-regulation mediating the relation between socioeconomic risk and school readiness. The largest unknown was the teacherchild relationship. Specifically, there are studies linking the teacher-child relationship to readiness and self-regulation, but it was unclear what mechanisms drive this pattern of findings. The teacher-child relationship could hypothetically serve as a moderator within this mediated 
relation, although prior to this study it was unclear where in the mediation this moderation occurred.

This study therefore tested the moderating role of teacher-child relationships on the mediation of the relation of socioeconomic risk and kindergarten readiness with self-regulation. This study included complete data from 116 children ages 4 to 5 years (and parents/guardians and teachers) in community early childhood settings. Child self-regulation was assessed via direct measures, including measures of hot (Dinky Toys and Head-Toes-Knee-Shoulders) and cool aspects of self-regulation (Bear Dragon and Day Night Stroop). Children also completed measures of academic and social emotional school readiness (Bracken School Readiness Scale, Bracken 2012, Bracken Early Concepts Scale, Bracken, 2006, respectively). Additionally, children completed one measure of nonverbal reasoning (Matrix Reasoning from the WPPSI-IV, Wechsler, 2012) to provide information about the overall sample. Questionnaire information completed by students' teachers was collected to measure the teacher-child relationship (StudentTeacher Relationship Scale-Short form, [STRS-SF], NICHD Study of Early Child Care, 2000) and self-regulation (the Effortful Control subscale of the Child Behavior Questionnaire [CBQ], Putnam \& Rothbart, 2006). Additionally, demographic information was collected from parents to assess socioeconomic risk (family income, number of people in the home).

This study tested three competing moderated mediator models through the use of path analysis to examine how teacher-child relationships accounted for the relation between socioeconomic risk, self-regulation, and school readiness (see Figure 1). Specifically, the model that served as the best fit could help to explain the relations between these variables and the unique contribution of the teacher-child relationship to these relations. All three models 
examined the teacher-child relationship as a moderator in the context self-regulation serving as a mediator between risk and school readiness.

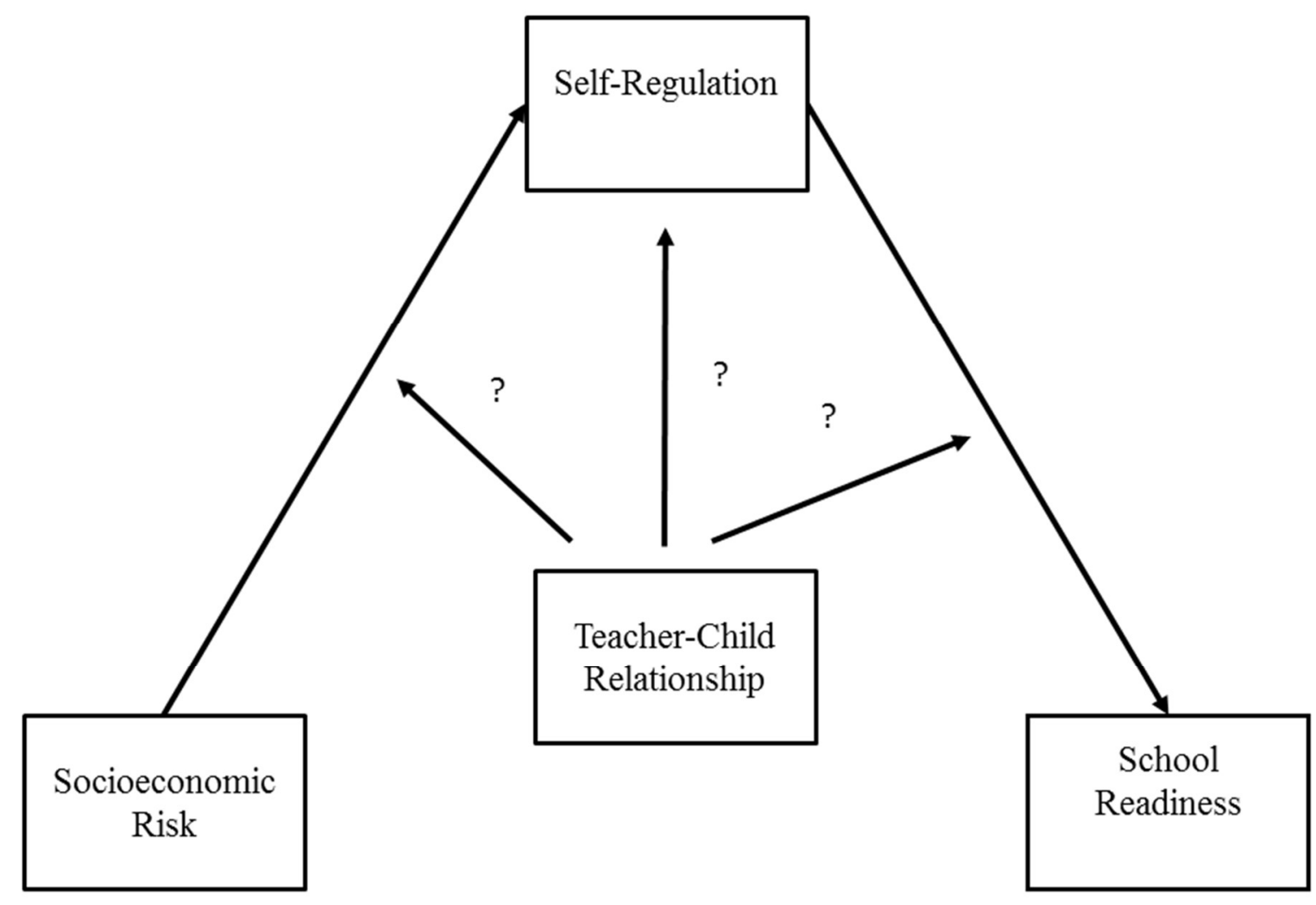

Figure 1. Overview of Hypothesized Models.

The first model included the teacher-child relationship and the interaction between risk and the teacher-student relationship as a moderator of the pathway from risk to self-regulation. The second model examined whether the teacher-child relationship moderated the self-regulation to school readiness pathway. The third model included the teacher-child relationship and the interaction between self-regulation and teacher-child relationship as moderating the relation between self-regulation and school readiness. It was hypothesized that one or several of these models would fit the data well, revealing information about the mediating relation of 
socioeconomic risk and kindergarten readiness on regulation and the moderating role of the teacher-child relationship. 


\section{CHAPTER III: METHOD}

\section{Participants}

One hundred forty-one children aged four to five years were recruited from thirteen local early childhood centers and preschools that serve children/families from a broad range of income levels (e.g., public Pre-K programs, private Pre-K programs, Head Start programs, local preschools, and local daycare centers). To ensure recruitment of participants from families with a range of socioeconomic risk levels, centers that provided both subsidized and unsubsidized child care were included. One hundred sixteen children with complete data were included in the final sample. This included 50 boys (43.10\%) and 66 girls (56.90\%) ranging in age from 48 months to 67 months at session $1(M=57.37$ months, $S D=4.84)$. Parent reports indicated that 69 children identified as White (59.50\%), 20 as African American/Black (17.20\%), 14 as Other (12.10\%), 9 as Hispanic (7.80\%), 3 as Asian American (2.60\%), and 1 (0.90\%) not reported. In general, Matrix Reasoning performance indicated that participants were within the average range of intellectual functioning (standard scores ranged from 1 to $16, M=9.87, S D=3.02$ ). Children received a small toy at the conclusion of each session.

Family demographic information was obtained from 116 parents, which included 97 mothers $(83.63 \%), 12$ fathers $(10.34 \%)$, and 7 who identified as other $(6.03 \%)$. Of the respondents, 102 were female $(88.70 \%)$, and 13 were male $(11.30 \%)$. In terms of race/ethnicity, 84 identified as White (72.41\%); 8 identified as Hispanic (6.90\%); 19 identified as African American/Black (16.38\%); 2 identified as Asian American (1.72\%); and 3 identified as Other $(2.59 \%)$. The highest level of education of the parent and gross household income per year and can be viewed in Tables 1 and 2, respectively. Additionally, information about the number of family members in the household was collected $(M=4.07, S D=1.18)$. The gross family income 
divided by the number of family members in the household was used to calculate the socioeconomic risk variable. This calculation produced an amount of income per individual in the home. This is similar to the calculation of the federal poverty guideline where both family income and number of individuals in the home is considered ("census quick facts," 2017; "Poverty guidelines by the U.S. Department of Health and Human Services., 2017)

Table 1

Parent Education Level

\begin{tabular}{lll}
\hline Education Level & Frequency & Percentage \\
\hline High School & 38 & 32.76 \\
Associate's Degree & 10 & 8.62 \\
Bachelor's Degree & 37 & 31.90 \\
Master's Degree & 25 & 21.55 \\
Doctoral Degree & 5 & 4.31 \\
Total & 115 & 99.14 \\
\hline
\end{tabular}


Table 2

Reported Gross Annual Income for Families

\begin{tabular}{lcc}
\hline Amount & Frequency & Percent \\
\hline$<\$ 20,000$ & 21 & 18.10 \\
$\$ 20,000-\$ 34,999$ & 19 & 16.40 \\
$\$ 35,000-\$ 49,999$ & 6 & 5.20 \\
$\$ 50,000-\$ 74,999$ & 4 & 3.40 \\
$\$ 75,000-\$ 99,999$ & 12 & 10.30 \\
$\$ 100,000-\$ 149,999$ & 26 & 22.40 \\
$\$ 150,000-\$ 199,999$ & 12 & 10.30 \\
$\$ 200,000$ or greater & 16 & 13.80 \\
Total & 116 & 100.00 \\
\hline
\end{tabular}


Table 3

Income Per Person Living in the Home

\begin{tabular}{|c|c|c|}
\hline Income Per Person & Frequency & Percentage \\
\hline$\$ 2,500-5,000$ & 13 & $11.21 \%$ \\
\hline$\$ 5,001-\$ 10,000$ & 22 & $18.97 \%$ \\
\hline$\$ 10,001-\$ 15,000$ & 6 & $5.17 \%$ \\
\hline$\$ 15,001-\$ 20,000$ & 6 & $5.17 \%$ \\
\hline$\$ 20,001-\$ 25,000$ & 10 & $8.62 \%$ \\
\hline$\$ 25,001-\$ 30,000$ & 9 & $7.76 \%$ \\
\hline$\$ 30,001-\$ 35,000$ & 8 & $6.90 \%$ \\
\hline$\$ 35,001-\$ 40,000$ & 16 & $13.79 \%$ \\
\hline$\$ 40,001-\$ 45,000$ & 0 & $0 \%$ \\
\hline$\$ 45,001-\$ 50,000$ & 12 & $10.34 \%$ \\
\hline$\$ 50,0001-\$ 55,000$ & 0 & $0 \%$ \\
\hline$\$ 55,001-\$ 60,000$ & 0 & $0 \%$ \\
\hline$\$ 60,001-\$ 65,000$ & 10 & $8.62 \%$ \\
\hline$\$ 65,001-\$ 70,000$ & 3 & $2.59 \%$ \\
\hline$\$ 70,001-\$ 75,000$ & 0 & $0 \%$ \\
\hline$\$ 75,000-\$ 80,000$ & 0 & $0 \%$ \\
\hline$\$ 80,000-\$ 85,001$ & 1 & $0.86 \%$ \\
\hline Total & 116 & 100 \\
\hline
\end{tabular}


Thirty-three teachers participated in this study. All identified as female. Teachers completed between 1 and 9 sets of child forms $(M=3.52, S D=2.15)$, depending on the number of participating children in their classroom. Teacher demographic information included teacher's gender (33 female,100\%), race/ethnicity (Table 4), highest degree (Table 5), and current position/title. None of the teachers identified being an assistant or aide, while 10 identified as being the Lead Teacher. Seventeen noted that they were teachers, and the six remaining identified as child development specialists. Additional information provided by the teachers included the number of years in their current position $(M=6.50$ years, $S D=7.33)$ In addition, teachers reported how long they knew each child participant $(M=13.33$ months, $S D=11.68)$, and how many hours per week they interacted with each child $(M=26.98$ hours per week, $S D=$ 11.07). Teachers received a $\$ 5$ gift card for each set of surveys returned.

Table 4

Teacher Race/Ethnicity Information

\begin{tabular}{lll}
\hline Race/Ethnicity & Frequency & Percentage \\
\hline White & 28 & 85.85 \\
African American/Black & 3 & 9.10 \\
Total & 31 & 100.00 \\
\hline
\end{tabular}


Table 5

Teacher Education

\begin{tabular}{lll}
\hline Education & Frequency & Percentage \\
\hline Some College & 1 & 3.00 \\
Associate's Degree & 2 & 6.06 \\
Bachelor's Degree & 24 & 72.72 \\
Master's Degree & 3 & 9.10 \\
Doctoral Degree & 1 & 3.03 \\
Total & 31 & 100.00 \\
\hline
\end{tabular}

Participants attended 13 different early childhood centers. $40.5 \%$ of participants came from a range of private early childhood centers $(n=47) .28 .4 \%$ of participants $(n=33)$ came from subsidized preschool programs. $25 \%(n=29)$ came from parochial preschools, and $6 \%(n=$ 7) came from university- or college-based programs.

\section{Child Measures}

\section{Materials}

Self-regulation. Self-regulation was measured through four tasks drawn from the extant literature focusing on effortful control and executive functioning, as well as hot and cool selfregulation. These tasks were coded live by the researchers or via video recordings. Video recordings also were used to assess inter-rater reliability.

Dinky Toys. Dinky Toys was a hot, delay of gratification task that involved a clear box of small toys (i.e., a pencil, stickers, small toy car, Kochanska, Murray, \& Harlan, 2000). 
Head-Toes-Knees-Shoulders (HTKS). HTKS is a hot task that does not involve any materials beyond the list of verbal instructions. Evidence for construct validity of this task was established in the study in which the task debuted, and significant positive correlations were established between the measure and parent ratings in attentional focusing and inhibitory control (Child Behavior Questionnaire Short, Putnam \& Rothbart, 2006), and teacher ratings of classroom behavioral regulation and interpersonal skills (Ponitz et al., 2009).

Bear Dragon. The Bear Dragon Task was a cool task and included a bear puppet (approximately 15 inches long with a head, body and arms) and a dragon puppet (approximately 11 inches long with a head and body (Reed, 1984).

Day Night Stroop. The Day Night Task was a cool, inhibitory control task that included a set of 16 cards $(13.5 \times 10 \mathrm{~cm}), 8$ with a moon and stars pictured and 8 with a bright yellow sun pictured (Gerstadt, et al., 1994).

\section{School readiness.}

Academic readiness. Academic readiness was assessed using the Bracken School Readiness Assessment-Third Edition (BSRA-3, Bracken, 2007), which included 5 subtests. In the color subtest, the child was shown a picture of watercolor paints. In the letters subtest, the child was shown 4 or 8 letters at a time. In the numbers subtest, the child saw 10 numbers or pictures on each trial. In the sizes subtest, the child saw four pictures for each trial. In the shapes subtest, children were shown 9 shapes or pictures on each trial. This measure has established reliability and validity including test-retest reliability at 0.86 . and split half internal reliability at .95 . Validity is evident in the development of the test with consultation with state education standards and expert panel of speech language pathologists and psychologists, as well as intercorrelations 
among the various subtests are a part of the school readiness and social/self-awareness measures (Bracken, 2007).

Social-Emotional Readiness. Social-emotional readiness was measured via the Self/Social-Awareness subtest on the Bracken Basic Concept Scale-Third Edition: Receptive (BBCS-3:R). This subtest involved a stimulus book with pictures, one picture per item. This measure has established reliability and validity including test-retest reliability at 0.78 and split half internal reliability at .91 . Validity is evident in the development of the test with consultation with state education standards and expert panel of speech language pathologists and psychologists as well as intercorrelations among the various subtests in the $B B C S-3: R$ (Bracken, 2006).

Nonverbal reasoning. Children's nonverbal reasoning was estimated using the Matrix Reasoning subtest from the Wechsler Preschool and Primary Scale of Intelligence ${ }^{\text {th }}$ Edition (WPPSI-IV, Wechsler, 2012) and was used to describe the sample. Matrix Reasoning involved a stimulus book in which each page included pictures that could be grouped together or followed a certain pattern. Each group included an empty box. A line of possible pictures that could fit in the empty box was displayed for each group. Matrix Reasoning was chosen because it has a strong correlation $(r=.74)$ with the full scale IQ on the WPPSI-IV. Additionally, the WPPSI-IV has extensive research indicating adequate internal consistency. For example, internal consistency is .90 for the matrix reasoning subtest among children aged 4:0-7:7 years. Additional indicators of reliability for the matrix reasoning subtest include .97 standard error of measurement and adequate test-retest reliability. The WPPSI-IV has also been validated by a panel of experts and based in an extensive literature review. Additionally, it has been validated through its comparison to other intelligence tests for young children (Wechsler, 2012). 


\section{Teacher Questionnaires}

Self-regulation questionnaire. The effortful control portion of the Child Behavior Questionnaire-Very Short Form Teacher (CBQ, ages 3-7 years, Rothbart, Ahadi, Hershey, \& Fisher, 2001; Putnam \& Rothbart, 2006) was used to measure child self-regulation via teacher report. Although the Child Behavior Questionnaire includes three areas of temperament-extraversion/surgency, negative affectivity, and effortful control--only the effortful control dimension was measured in this study. The effortful control dimension included 12 questions that targeted areas such as attention focusing, inhibitory control, low-intensity pleasure, and perceptual sensitivity which included questions such as, “approaches places s/he had been told are dangerous slowly and cautiously." Teachers circled 1-7 on a Likert scale $(1=$ extremely true of this child, 2 = quite untrue of this child, $3=$ slightly untrue of this child, $4=$ neither true nor false of this child, $5=$ slightly true of this child, $6=$ quite true of this child, $7=$ extremely true of this child) for each item. NA (Not Applicable) also was permitted if the teacher believed that she had not seen the child in that situation. Responses were averaged to obtain one effortful control score where higher scores indicate higher effortful control. Cronbach's $\alpha$ for the present sample was .88, demonstrating strong internal consistency of the measure.

Teacher-child relationship questionnaire. Teachers completed the Student Teacher Relationship Scale- Short Form (STRS-SF, NICHD Study of Early Child Care, 2000) for each child participant that was a member of their class. This questionnaire contained 15 items that were rated on a 1-5 scale, 1 being "definitely does not apply" and 5 being "definitely applies." Items on the scale asked teachers to rate how they felt toward a child (e.g., "It is easy to be in tune with what this child is feeling.") and about how the child acted toward them (e.g., "This child easily becomes angry with me"). The questionnaire included two subscales: conflict (e.g., 
"This child remains angry or is resistant after being disciplined") and closeness (e.g., "I share an affectionate, warm relationship with this child).” The conflict subscale was made up of 8 items (Cronbach's $\alpha=.92$ ), whereas the closeness subscale was made up of 7 items (Cronbach's $\alpha=$ .80), both demonstrating strong internal consistency in this sample. These two scales were combined to include all 15 items for a composite teacher-child relationship score (Cronbach's $\alpha$ $=.73)$.

\section{Procedure}

After receiving IRB approval and early childhood center administrator approval, cover letters, consent/permission forms, and parent/guardian demographic forms were sent home with all 4- and 5-year-old children to their parents or guardians. Once signed parent/guardian permission forms (and demographic forms) were returned, the teachers of children who had signed parent/guardian forms were then invited to participate in the study. Teachers granted written consent for their participation. If there were multiple teachers assigned to a particular classroom containing participating children, the teacher who identified as knowing the child best participated in the study. Teachers completed multiple sets of measures if multiple children were participants within their classroom. Children provided verbal assent prior to participation.

All child testing sessions were conducted by two school psychology graduate students, both of whom had formal training in standardized assessment and psychometrics. The lead researcher (author of this dissertation) first learned the administration procedures as outlined in the research protocol. The second administrator learned by first observing these sessions, then practicing the administration while the lead researcher provided feedback until correctly following the research protocol. The second administrator then conducted child sessions while the lead researcher observed and provided feedback. Finally, the second administrator conducted 
child sessions independently. Administrators followed a research protocol that provided detailed directions regarding the order of questions administered, language used in providing directions, and what repeats of questions and prompts could be provided. When standardized, manualized assessments were used (i.e. Bracken Receptive and WPPSI), directions and prompts were followed directly from the manual. Undergraduate research assistants also assisted with scheduling, set up and video recording, as well as coding.

Each undergraduate and graduate student member of the research team was assigned one or two self-regulation tasks to code. The lead researcher provided training using coding protocols. The sequence of training was similar to that described for the second administrator. Coders first viewed videos and live participants and coded them appropriately. The lead researcher then compared these practice codes (which were not retained for research purposes) to codes conducted by the lead researcher. Feedback was provided to the coders. Once coders achieved reliability with the lead researcher on the coding, they began coding participants independently for research purposes. Pairs of coders were assigned to each task, and both coded a subset of participants independently (approximately 20\%) to ensure adequate interrater reliability.

Children completed the self-regulation, school readiness, and matrix reasoning measures individually in a quiet area of their preschool building. Children participated in two sessions, each lasting approximately 15 minutes. One session included the 4 self-regulation tasks, and the other session included the school readiness tasks and nonverbal reasoning task. The order of sessions was counterbalanced across participants. Additionally, the order of tasks within sessions was counterbalanced using two pre-specified orders. The number of participants per order can be viewed in Table 6. During the self-regulation session, children participated in the tasks in one of 
two orders: Head-Toes-Knees-Shoulders, Day Night Stroop, Bear Dragon, Dinky Toys or Bear Dragon, Day Night Stroop, Head-Toes-Knees-Shoulders, and Dinky Toys. The Dinky Toys task always occurred last because the child received a small toy that could have become a distraction. During the readiness session, children completed the academic readiness or the social readiness task first, then the other readiness task second. The nonverbal reasoning task always occurred last because it provided information about the sample but was not essential for hypothesis testing. These orders were chosen to ensure that children remained engaged based on the time that each task took, allowing for breaks during administration. 
Table 6

Number of Participants Completing Each Order

\begin{tabular}{|c|c|c|c|c|c|}
\hline Order \# & Session \#1 & School Readiness & Self-Regulation & Number of & Percentage \\
\hline & & Order & Order & Participants & \\
\hline 1 & $\begin{array}{l}\text { School } \\
\text { Readiness }\end{array}$ & $\begin{array}{l}\text { Academic, } \\
\text { Social/Self } \\
\text { Awareness }\end{array}$ & $\begin{array}{l}\text { Bear Dragon, } \\
\text { Stroop, HTKS, } \\
\text { Dinky Toys }\end{array}$ & 14 & 12.07 \\
\hline 2 & $\begin{array}{l}\text { School } \\
\text { Readiness }\end{array}$ & $\begin{array}{l}\text { Academic, } \\
\text { Social/Self - } \\
\text { Awareness }\end{array}$ & $\begin{array}{l}\text { HTKS, Stroop, } \\
\text { Bear Dragon, } \\
\text { Dinky Toys }\end{array}$ & 12 & 10.34 \\
\hline 3 & $\begin{array}{l}\text { School } \\
\text { Readiness }\end{array}$ & $\begin{array}{l}\text { Social/Self- } \\
\text { Awareness, } \\
\text { Academic }\end{array}$ & $\begin{array}{l}\text { Bear Dragon, } \\
\text { Stroop, HTKS, } \\
\text { Dinky Toys }\end{array}$ & 13 & 11.21 \\
\hline 4 & $\begin{array}{l}\text { School } \\
\text { Readiness }\end{array}$ & $\begin{array}{l}\text { Social/Self- } \\
\text { Awareness, } \\
\text { Academic }\end{array}$ & $\begin{array}{l}\text { HTKS, Stroop, } \\
\text { Bear Dragon, } \\
\text { Dinky Toys }\end{array}$ & 16 & 13.79 \\
\hline 5 & Self-Regulation & $\begin{array}{l}\text { Academic, } \\
\text { Social/Self } \\
\text { Awareness }\end{array}$ & $\begin{array}{l}\text { Bear Dragon, } \\
\text { Stroop, HTKS, } \\
\text { Dinky Toys }\end{array}$ & 15 & 12.93 \\
\hline 6 & Self-Regulation & $\begin{array}{l}\text { Academic, } \\
\text { Social/Self } \\
\text { Awareness }\end{array}$ & $\begin{array}{l}\text { HTKS, Stroop, } \\
\text { Bear Dragon, } \\
\text { Dinky Toys }\end{array}$ & 14 & 12.07 \\
\hline 7 & Self-Regulation & $\begin{array}{l}\text { Social/Self- } \\
\text { Awareness, } \\
\text { Academic }\end{array}$ & $\begin{array}{l}\text { Bear Dragon, } \\
\text { Stroop, HTKS, } \\
\text { Dinky Toys }\end{array}$ & 17 & 14.66 \\
\hline 8 & Self-Regulation & $\begin{array}{l}\text { Social/Self- } \\
\text { Awareness, } \\
\text { Academic }\end{array}$ & $\begin{array}{l}\text { HTKS, Stroop, } \\
\text { Bear Dragon, } \\
\text { Dinky Toys }\end{array}$ & 15 & 12.93 \\
\hline
\end{tabular}




\section{Child Tasks}

\section{Self-regulation tasks.}

Head-Toes-Knees-Shoulders Task. In the Head-Toes-Knees-Shoulders Task (Ponitz, McClelland, Mathews, \& Morrison, 2009), the child was first familiarized with two oral commands from the examiner (touch your head, touch your toes). Then, 20 trials were conducted in which the child was asked to respond in an unnatural way (for example touching their toes when the examiner said, "touch your head"). For the first 10 trials, the child was provided with two types of commands ("touch your head" "touch your toes"). For the second 10 trials, four different types of commands were provided ("touch your head" "touch your toes" "touch your knees" "touch your shoulders"). The child's response on each trial was coded $0-2(0=$ incorrect response, 1 = self-corrected response after motion to incorrect response, $2=$ correct response without any self-corrections). Children's scores were summed across test trials, with higher scores indicating stronger self-regulation. Coding was completed by one of two independent coders. To ensure accuracy of coding, inter-rater reliability was conducted for 24 randomly selected participants by having the two trained coders independently rate each trial. Cohen's Kappa was .86, representing good inter-rater reliability.

Dinky Toys Task. In this task, a clear box full of small toys (e.g., party favors, pencils, stickers) was placed in front of the child (Kochanska et al., 1996; Kochanska, Murray, \& Harlan, 2000). The child was instructed to place his or her hands on his or her knees and to tell the researcher which toy he/she wanted while the researcher showed the child the contents of the box. The child was instructed not to touch or point to the toy. Coding ranged from 0 to $5(0=$ grabs the toy, $1=$ touches the toy but does not take it out, 2 = points to the toys without touching, $3=$ removes hands from knees but does not point, $4=$ hands twitching but remaining on knees, 5 
$=$ hands immobile on the knees, Kochanska et al., 1996, 2000). Coding was completed by one of two independent coders. To ensure accuracy of coding, inter-rater reliability was conducted for 24 randomly selected participants by having the two trained coders independently rate each trial. Cohen’s Kappa was .76, representing acceptable inter-rater reliability.

Bear Dragon Task. In this task, the child was introduced to two hand puppets worn by the researcher (Kochanska, et. Al., 1996; Kochanska et al., 1996). The bear and dragon issued directives to the child commanding specific movements (touch your tummy, touch your head). The child was asked to perform the movement requested by the bear but to inhibit the one that was requested by the dragon. Six trials were conducted for each puppet. Coding for the bear trials included ratings from 0-3 $(0=$ failure to move, $1=$ wrong movement, $2=$ partial movement, 3 = full correct movement). Coding for the dragon trials also ranged from 0-3 $(0=$ full movement, 1 = a wrong movement, 2 = partial movement, 3 = a full inhibition of movement). The dragon trials were scored only if the child passed the bear trials meaning that they performed the correct movement for 4 out of 6 trials. All participants except for one passed the bear trials; therefore, this participant's score for bear-dragon was not included as a part of their self-regulation composite score. The 6 dragon trials were utilized to calculate a final score for the task by averaging across trials. A child's score could range from 0 to 3 with 0 being the least inhibited and 3 being the most inhibited (Kochanska, et al., 1996; Kochanska et al., 1996). Coding was completed by one of two independent coders. To ensure accuracy of coding, interrater reliability was conducted for 24 randomly selected participants by having the two trained coders independently rate each trial. Cohen's Kappa was .94, representing good inter-rater reliability. 
Day Night Stroop Task. Children were shown a black moon card and asked to say "day" when they saw the card (Gerstadt et al., 1994). Children were asked to repeat the word "day." The other white card with a sun on it was introduced and the children was instructed to say "night" for this card and asked to repeat "night." Children were then shown the sun card and subsequently the moon card for a practice trial without any directions. If children responded correctly after each card, the examiner praised them. If they were incorrect, another trial was administered, and the children was reminded of the rules. Children needed to answer each rule correctly at least once during the course of practice trials. If children were unable to do this and then got either of the first two experimental trials incorrect, testing was discontinued. This occurred for one participant. This task was therefore not included in the self-regulation composite for that child. For the experimental trials, 16 trials were administered in which 8 sun and 8 moon cards were presented in a predetermined random order (Gerstadt et al., 1994). Coding was completed by one of two independent coders. Each response was coded as a 1 or 0 and summed, with 1 representing a correct response and 0 incorrect and therefore higher sums representing better overall self-regulation. To ensure accuracy of coding, inter-rater reliability was conducted for 24 randomly selected participants by having the two trained coders independently rate each trial. The intra class correlation was 0.91 , representing good inter-rater reliability.

\section{School readiness tasks.}

Academic readiness. The Bracken School Readiness Assessment Third Edition (BSRA-3) is a composite of 5 subtests from Bracken Basic Concept Scale - Third Edition: Receptive (BBCS-3: R). In the Color subtest, the child was presented with a picture of a set of watercolors, and the researcher asked the child to point to 10 different colors. In the letter subtest, the child 
was presented with several letters at a time on a page and asked to identify specific letters (both upper case and lower case). On the numbers/counting subtest, the child was asked to identify specific numbers and count items on a page. On the size comparisons subtest, the child was asked to look at pictures and point to which picture represented different sizes. For example, "which animal is big." On the shape subtest the child was asked to identify shapes from a choice of several. Some items had pictures of two dimensional shapes whereas others asked children to find shapes within a larger picture (e.g., children in a line, ducks in a row).

Procedures outlined in the Bracken Basic Concept Scale Third Edition: Receptive (BBCS3: R), manual were followed. For all 5 subtests, the child was awarded a score of 1 for a correct answer and a score of 0 for an incorrect answer. Each test was discontinued if the child got 3 consecutive items wrong, and the examiner then moved on to the next subtest. The subtest scores were summed to create a School Readiness Composite Raw score. This composite raw score was standardized for use in analyses. Two independent coders both coded 24 participants to ensure inter-rater reliability. The intraclass correlation was .99, demonstrating excellent interrater reliability.

Social-emotional readiness. In the Self/Social-Awareness subtest on the Bracken Basic Concept Scale Third Edition: Receptive (BBCS-3: R), the child was presented with a picture in the stimulus book and asked to make a reference about the picture that involved emotions or social cues. For example, a picture including four choices of faces was presented and the child was asked, "Who is sad?" Later questions were about inferences, for example, "Which person is doing something difficult?" A child's response was awarded a score of 1 for a correct answer and a score of 0 for an incorrect answer. The subtest was discontinued if the child got 3 consecutive items wrong. This raw score was standardized for use in analyses. To ensure accuracy of coding, 
interrater reliability was conducted for 24 randomly selected participants. The intraclass correlation was .99 , demonstrating excellent inter-rater reliability.

Nonverbal reasoning. The researcher administered the Matrix Reasoning subtest of the WIPPSI-IV. The child was asked to select a missing picture in a group of 6 pictures from among 4 or more choices displayed in a horizontal row below the group (Wechsler, 2012). Once a child answered 4 questions in a row incorrectly, questions were discontinued. The number of questions correct was summed, and the score converted to a standard score based on national norms established in the test manual.

\section{Teacher Questionnaires}

Teacher questionnaires included the $C B Q$ Effortful Control subtest to measure child selfregulation and the Student Teacher Relationship Scale-Short Form to measure student-teacher relationship qualities.

\section{Parent/Guardian Questionnaires}

Parent/Guardians were asked to complete a demographic survey. 


\section{CHAPTER IV: RESULTS}

Data was analyzed using LISREL computer program version 8.80 (Joreskog \& Sorbom, 2006).

\section{Data Reduction}

Socioeconomic risk was conceptualized as income per person within the home. First, the family income and the number of adults and children living in the home were obtained from the demographic survey completed by parents. Then, the family income was divided by the number of family members in the home. Specifically, the highest number of the indicated income range was utilized. This calculation produced a number representing the amount of income per person within the home. This is similar to the calculation used by the U. S. Census Bureau per capita income (Census quick facts, 2017; "Poverty guidelines the U.S. Department of Health and Human Services", 2017). Specifically, the number of family members living in the home and the total income are considered. This calculation produced a mean income per person in our sample of $\$ 28,556.37$ per person in the household $(S D=\$ 19,893.47)$. Additionally there was a minimum income of $\$ 2,500$ and maximum of $\$ 83,333.33$ per person in the household.

Composite scores for the remaining measured variables were created by combining all pieces of data related to that variable and averaging them. For self-regulation, data drawn from the four direct measures of self-regulation (Dinky Toys, Head-Toes-Knees-Shoulders, Day Night Stroop, and Bear Dragon) and from the Child Behavior Questionnaire (CBQ-S) gathered from the teacher were converted to a standard ( $\mathrm{z}$ ) scores via linear transformations and combinations and averaged. Higher scores indicated stronger self-regulation. Cronbach's alpha was calculated to examine the internal consistency of the self-regulation composite. Traditional standards for Cronbach's alpha are used with measures that include about 30 items in a typical survey, so what 
appears to be a low Chronbach's alpha of 0.58 for the 5 self-regulation items (Dinky Toys, HeadToes-Knees-Shoulders, Day Night Stroop, Bear Dragon, and Teacher-Reported CBQ) may not be representative of its internal consistency. Thus, I used the Spearman-Brown prophecy to predict the internal consistency one would expect if the 5-item self-regulation composite had six times as many parallel items. Specifically, the Spearman-Brown prophecy formula predicted a Cronbach's alpha of 0.89 if one had six times as many items, representing adequate internal consistency for utilizing this composite in further analyses.

The school readiness composite score was created by averaging the standardized scores from the Bracken School Readiness Scale and the Self/Social-Awareness subtest on the Bracken Basic Concept Scale-Third Edition: Receptive (BBCS-3:R, Bracken, 2006) to create one measure of school readiness. Higher scores indicated stronger school readiness. The Cronbach's alphas with Spearman-Brown prediction was applied for the two-item school readiness composite because what appears to be a low Cronbach's alpha at 0.57 may not be representative of its internal consistency. The prophecy formula predicted a Cronbach's alpha of .95 if one had 15 times as many items, representing adequate internal consistency for using this composite in further analyses.

For teacher-child relationships, scores were drawn from the Student-Teacher Relationship Survey-Short Form (STRS-SF, NICHD, 2000). Responses to subscale items were averaged to obtain a mean closeness score $(M=30.74, S D=3.81)$ and mean conflict score $(M=15.14, S D=$ 7.84) for each participant. These subscale scores were combined with a negative value assigned to conflict and positive to closeness. With all 15 items combined, the mean was 15.57 and standard deviation 9.94, providing one measure of teacher-child relationship quality. Therefore, a value that was negative indicated higher conflict than closeness, a value that was close to zero 
indicated equal conflict and closeness, and a value that was positive indicated higher closeness than conflict.

\section{Excluded Data}

Data from one participant who did not have at least two measures of self-regulation was excluded from analyses. This participant was excluded because the child did not attempt any activities in the self-regulation session. The number participants for whom data was missing or excluded for each self-regulation task can be viewed in Table 7. The primary reasons for excluding data were administration errors or failure to meet requisite criteria for tasks (i.e., did not get enough trial items correct to demonstrate that the participant understood the task).

Table 7

Number of Participants Completing the Self-Regulation Tasks

\begin{tabular}{ll}
\hline Task & Number of Participants \\
\hline Head Toes Knees Shoulders & 116 \\
Stroop & 115 \\
Bear-Dragon & 114 \\
Dinky Toys & 113 \\
Child Behavior Questionnaire- Short form & 115 \\
Total Number of Participants & 116 \\
\hline
\end{tabular}




\section{Test of Order Effects}

\section{Preliminary Analyses}

Univariate analyses were used to test for effects of task order on self-regulation and school readiness outcomes. No order effects were found for self-regulation, $F(7,108)=1.89, p$ $=.08, \eta_{\mathrm{p}}^{2}=.04$, or for school readiness, $F(7,108)=.69, p=0.68, \eta^{2} \mathrm{p}=.11$, so task order was not considered in the analyses or discussion that follow.

\section{Nesting Screening}

Screening using intraclass correlations was conducted to test the extent to which nesting of students within classrooms would need to be accounted for in modeling. Specifically, the degree to which the non-independence of students being nested within particular classrooms (or with particular teachers would necessitate multilevel path analysis rather than the more mundane and typical application of path analysis was examined. The screening was completed by comparing the variance within a particular classroom (teacher, $n=32$ ) to the overall variance across all classrooms from which data were collected. Conducting the screening was important since individual teachers completed questionnaires for multiple children in their class. These correlations were conducted for all 141 participants using the composite variables that would be used in the modeling necessary for hypothesis testing (socioeconomic risk, self-regulation, school readiness, teacher-child relationship). An examination of the intraclass correlations in Table 8 reveals fairly substantial intraclass correlations for the school readiness and selfregulation composites. Because the path model would ultimately use socioeconomic risk as an exogenous control variable, I recomputed the intraclass correlations using socioeconomic risk as a covariate. Examination of the intraclass correlations in Table 9 revealed that the intraclass correlations dropped substantially after controlling for socioeconomic risk. This drop in intraclass correlations suggested, therefore, that controlling for socioeconomic risk precludes the 
need to employ multi-level modeling as long as socioeconomic risk was retained in the model (Hox, 1995). Thus, hypothesis testing involved standard path analysis.

Table 8

Variance Estimates and Intraclass Correlations (ICC) With No Covariate

\begin{tabular}{lccc}
\hline \multicolumn{1}{c}{ Variable } & Teacher Variance & Error Variance & ICC \\
\hline School & 0.22 & 0.62 & 0.26 \\
Self-Regulation & 0.09 & 0.30 & 0.22 \\
Socioeconomic Risk & $196,738,506.20$ & $205,599,428.10$ & 0.49 \\
$\begin{array}{l}\text { Teacher-Child } \\
\text { Relationship }\end{array}$ & 13.76 & 85.61 & 0.14 \\
\hline
\end{tabular}

Table 9

Variance Estimates and Intraclass Correlations(ICC) with Socioeconomic Risk as a Covariate

\begin{tabular}{lccc}
\hline \multicolumn{1}{c}{ Variable } & Teacher Variance & Error Variance & ICC \\
\hline School Readiness & 0.10 & 0.63 & 0.13 \\
Self-Regulation & 0.06 & 0.31 & 0.15 \\
$\begin{array}{l}\text { Teacher-Child } \\
\text { Relationship }\end{array}$ & 12.90 & 86.51 & 0.13 \\
\hline
\end{tabular}

A summary table including a correlation matrix and descriptive statistics for all composite variables can be viewed in Table 10 below. These details reveal a strong and significant positive correlation between self-regulation and school readiness. Additionally, significant correlations were evident in the relation between socioeconomic risk and school 
readiness as well as socioeconomic risk and self-regulation. Relations between teacher-child relationship and the other variables were weaker, but positive.

Table 10

Correlation Matrix and Descriptive Statistics for Composite Variables

\begin{tabular}{lcccc}
\hline & $\begin{array}{l}\text { Socioeconomic } \\
\text { Risk* }\end{array}$ & Self-Regulation & $\begin{array}{l}\text { School } \\
\text { Readiness }\end{array}$ & $\begin{array}{c}\text { Teacher-Child } \\
\text { Relationship }\end{array}$ \\
\hline $\begin{array}{l}\text { Socioeconomic } \\
\text { Risk* }\end{array}$ & -- & $.28^{* *}$ & $.38^{* *}$ & .10 \\
Self-Regulation & & -- & $.64^{* *}$ & .18 \\
School Readiness & & & -- & .22 \\
Teacher-Child & & & & -- \\
Relationship & & & & \\
$M$ & 28556.37 & -0.02 & -0.04 & 15.57 \\
$S D$ & 19894.47 & 0.62 & 0.92 & 9.94 \\
\hline
\end{tabular}

Note. *family income per person (in US Dollars)

$* *$ correlation is significant at the 0.01 level

\section{Hypothesis Testing}

The goal of this study was to examine whether the teacher-child relationship moderated the mediation between socioeconomic risk, self-regulation, and the teacher-child relationship, and if so, where within the mediated model it does so. This study tested three competing moderated mediator models through the use of path analysis to help explain how teacher-child relationships accounted for the relations between socioeconomic risk, self-regulation, and school readiness (see Figure 1). The models required at least 96 completed cases (at least 8 participants per parameter). Data from 116 participants were included in the modeling, representing an 
acceptable ratio of between 9 and 10 participants per parameter (Bentler \& Chou, 1988). The analyses were conducted via a structural equation modeling approach through the use of path analysis. In particular, whether one or more of the proposed models fit the data well was examined.

All three models examined the teacher-child relationship as a moderator in the context of self-regulation serving as a mediator between socioeconomic risk and school readiness (see Figure 1). In testing these three models, it was possible to understand how teacher-child relationship qualities influenced the relation between socioeconomic risk, self-regulation, and school readiness. Specifically, this project uncovered the point at which teacher-child relationship characteristics are involved with these broader processes by examining the moderating role of teacher-child relationships in the mediating relation of socioeconomic risk, self-regulation, and kindergarten readiness. It is possible that there was one answer or several answers to this question, but this study was the first to examine, socioeconomic risk, selfregulation, school readiness and teacher-child relationships in combination and to illuminate the mechanisms by which teacher-child relationship qualities, socioeconomic risk, and selfregulation impact school readiness in early childhood. Model 1 examined the teacher-child relationship as well as the interaction between socioeconomic risk and the teacher-student relationship as a moderator of the pathway from socioeconomic risk to self-regulation. Specifically, the interaction variable was used to represent the moderation of a mediating relation. In this model it was hypothesized that socioeconomic risk was interacting with the teacher-child relationship to change a child's level of self-regulation which in turn impacts school readiness. Model 2 examined whether the teacher-child relationship moderates the selfregulation to school readiness pathway. Specifically, did the teacher-child relationship on its own 
influence the level of self-regulation as a part of the relation of socioeconomic risk to selfregulation which in turn influences school readiness? Model 3 examined the teacher-child relationship as well as the interaction between self-regulation and the teacher-child relationship as moderating the relation between self-regulation and school readiness. The interaction between self-regulation and the teacher-child relationship represented the moderation of the overall mediating relation. In this model, it was hypothesized that self-regulation is interacting with the teacher-child relationship to influence school readiness as it is predicted by socioeconomic risk. Overall, these models reflected three possible ways in which the teacher-child relationship moderated the mediation between socioeconomic risk and kindergarten readiness with selfregulation.

A multifaceted approach is recommended for testing model fit (Tanaka, 1993), and this approach was used here. The statistics used to test fit included the $\square^{2}$ and degrees of freedom; however, the $p$ value was not used in this analysis because the $p$-value computed is based on the test statistic having an asymptotic $\square^{2}$ distribution. The presence of this distribution could mean that small samples from populations without multivariate normal distributions may have produced inaccurate $p$ values (Bollen, 1989, p. 415). In addition, the root mean square error of approximation (RMSEA) was used to determine approximate fit. An RMSEA with a value of 05 or less indicated support for approximate fit. Use of the multifaceted approach was helpful because as suggested by Browne and Cudeck (1993), the ratio of $\chi^{2}$ methods that test the hypothesis of perfect fit may be too stringent. Other indices that were used included the Norm Fit Index (NFI), Nonnormed fit Index (NNFI), and Comparative Fit Index (CFI), all of which needed to be 0.95 or more to represent good fit. Additionally, the Standardized Root Mean Square, Residual (S-RMR) needed to be 0.05 or less to represent good fit. Finally, the 
standardized-RMR for each of the pathways was examined indicating the explained variance for that portion of the model. Additional exploratory analyses were completed by examining an additional direct pathway between socioeconomic risk and school readiness as adjustments to Models 1 and 3. These are presented as Models $1 \mathrm{~b}$ and 3b. Fit statistics for all models can be viewed in Table 11, with specific descriptions and modeling displayed below for each model.

Table 11

Fit Statistics for All Models

\begin{tabular}{lllllllll}
\hline Model & $\begin{array}{l}\text { Minimum } \\
\text { Function } \chi^{2}\end{array}$ & $d f$ & $P$ & RMSEA & S-RMR & NFI & NNFI & CFI \\
\hline Model 1A & 9.84 & 3 & 0.02 & 0.19 & 0.08 & 0.78 & 0.33 & 0.80 \\
Model 1B & 2.28 & 2 & 0.32 & 0.05 & 0.03 & 0.95 & 0.96 & 0.99 \\
Model 2 & 2.27 & 1 & 0.15 & 0.11 & 0.04 & 0.95 & 0.79 & 0.97 \\
Model 3A & 11.73 & 3 & 0.01 & 0.21 & 0.08 & 0.74 & 0.18 & 0.75 \\
Model 3B & 3.43 & 2 & 0.18 & 0.09 & 0.06 & 0.92 & 0.80 & 0.96
\end{tabular}

\section{Model 1A Teacher-Child Relationship and the Interaction Between Teacher-Child Relationship Moderating Socioeconomic Risk to Self-Regulation Pathway}

Model 1A tested teacher-child relationship and the interaction between socioeconomic risk and teacher-student relationship as a moderator of the pathway from socioeconomic risk to self-regulation on school readiness. The overall fit of this model was poor based on multiple criteria. First, the Minimum Fit Function $\chi^{2}$ test $=9.84(p=0.02, n=116, d f=3$, Bollen, 1989, p. 415). An additional criterion test was the S-RMR which was 0.08. Additionally, the RMSEA 
was 0.19 , the NFI was 0.89 , the NNFI was 0.33 , and CFI was 0.80 (Bentler \& Chou, 1988). All of these statistics indicate that Model 1a, which examined the interaction between the teacherchild relationship and socioeconomic risk on the relation between socioeconomic risk to selfregulation, was a poor fit for the present data.

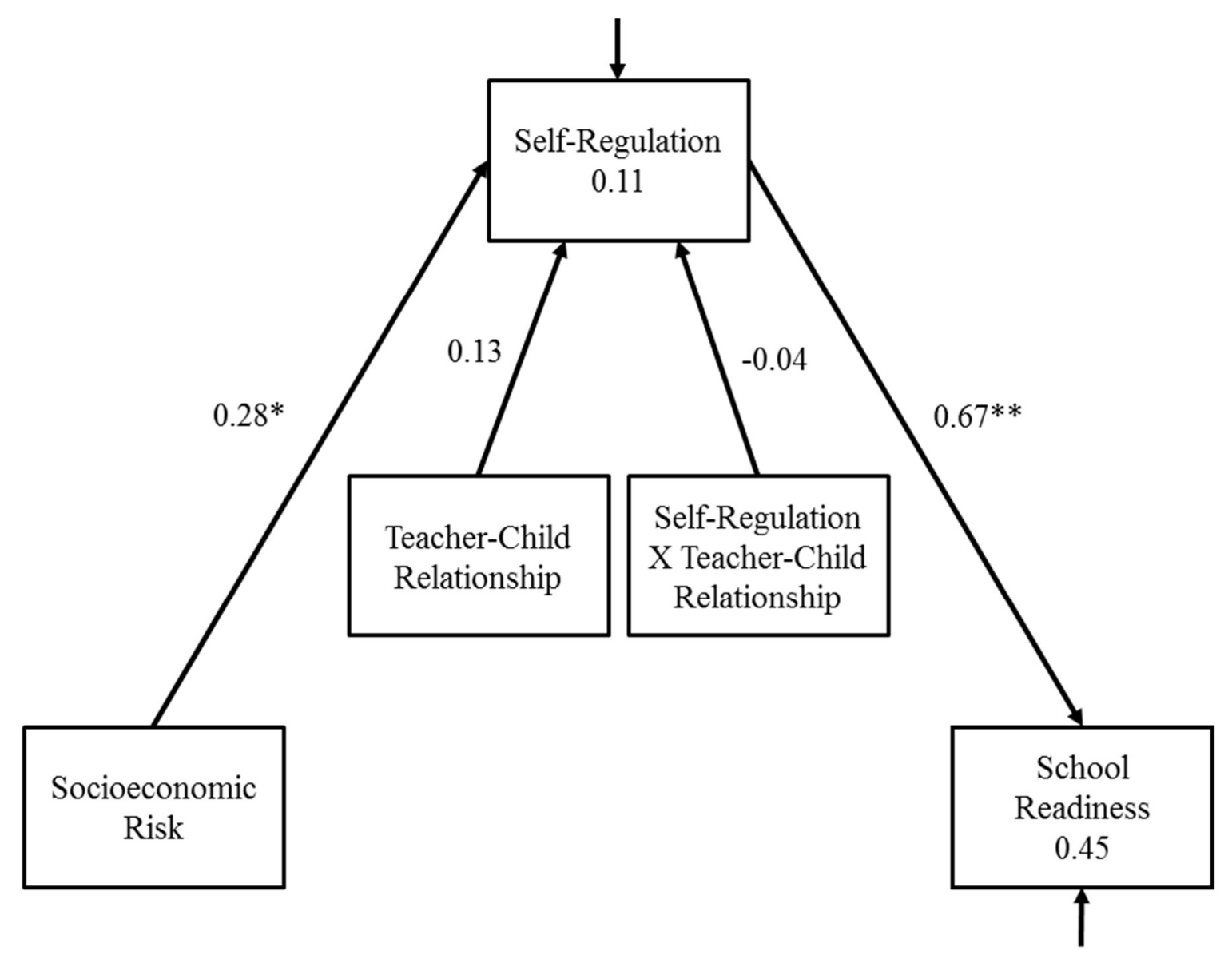

Figure 2. Model 1A. Teacher-Child Relationship and the Interaction Between TeacherChild Relationship Moderating Socioeconomic Risk to Self-Regulation Pathway. Minimum function $\chi^{2}=9.84, d f=3, p=0.02, \mathrm{RMSEA}=0.19, \mathrm{~S}-\mathrm{RMR}=0.08, \mathrm{NFI}=$ $0.89, \mathrm{NNFI}=0.33, \mathrm{CFI}=0.80 .{ }^{*} T \geq|2| * * T \geq|3|$ 
Model 1B Teacher-Child Relationship and the Interaction Between the Teacher-Child Relationship Moderating Socioeconomic Risk to Self-Regulation Pathway With Direct Socioeconomic Risk to Readiness Path

Model 1B tested the teacher-child relationship and the interaction between socioeconomic risk and teacher-student relationship as a moderator of the pathway from socioeconomic risk to self-regulation on school readiness and also included a direct path from socioeconomic risk to school readiness. The overall fit for this model was good based on multiple criteria. First, the Minimum Fit Function $\chi^{2}$ test was $2.28(p=0.32, n=116, d f=2)$. The S-RMR was 0.03, indicating good fit. Additionally, the RMSEA was 0.05, and therefore met the criterion of being 0.05 or less. Additionally, the S-RMR was 0.03 , also indicating good fit. Additionally, the NFI and NNFI were 0.95 and 0.96 , respectively, both of which met the necessary criteria of at least 0.95 to indicate good fit. Finally, the CFI was 0.99 , which provided an additional indicator of good fit. This good fit indicates that the teacher-child relationship may moderate the relation between self-regulation and school readiness when the direct path from socioeconomic risk to school readiness is included. 


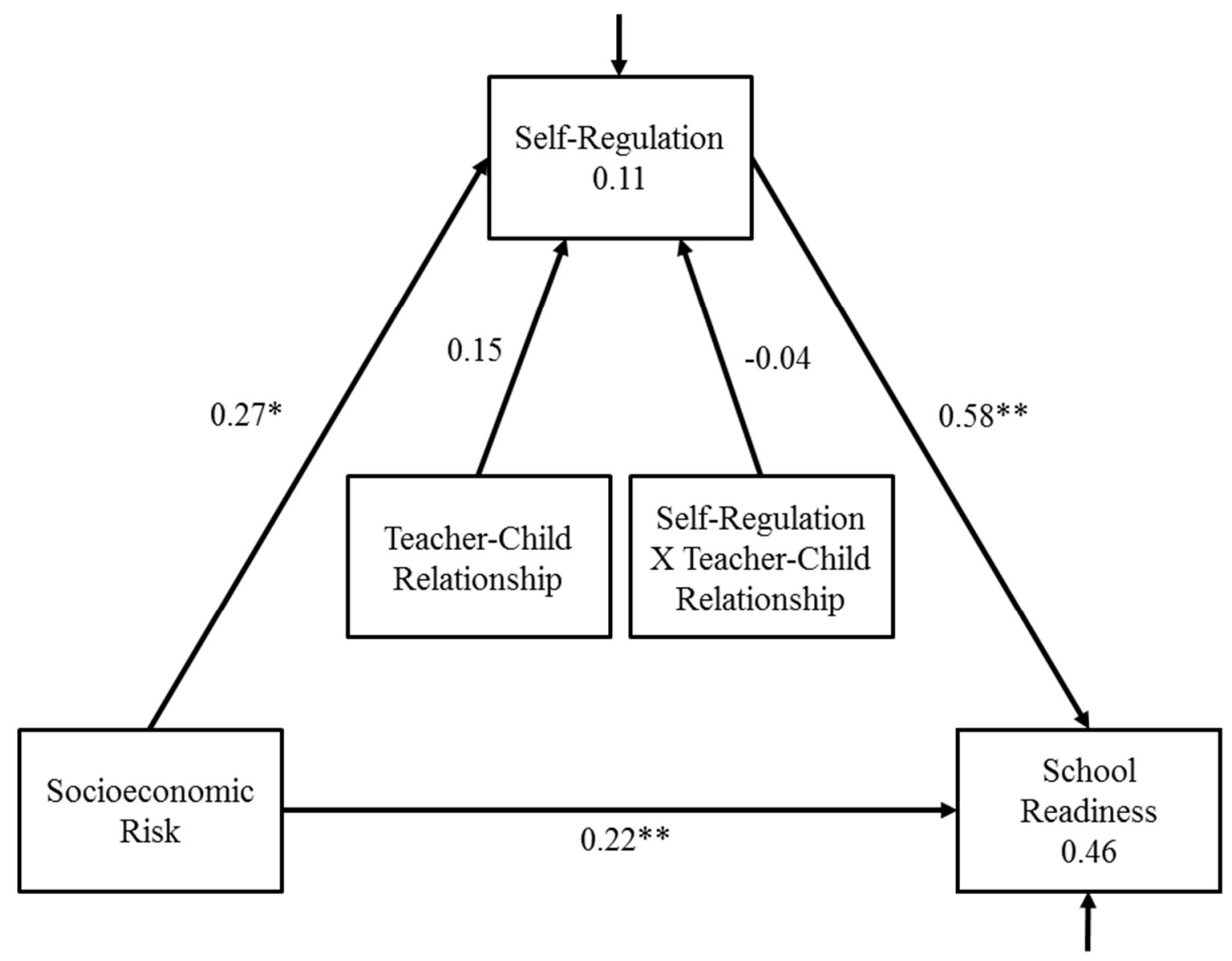

Figure 3. Model 1B. Teacher-Child Relationship and the Interaction Between TeacherChild Relationship Moderating Socioeconomic Risk to Self-Regulation Pathways With Direct Socioeconomic Risk to Readiness Path. Minimum function $\chi^{2}=2.28, d f=2$, $p=0.32, \mathrm{RMSEA}=0.05, \mathrm{~S}-\mathrm{RMR}=0.03, \mathrm{NFI}=0.95, \mathrm{NNFI}=0.96, \mathrm{CFI}=0.99 .{ }^{*} T \geq \mid 2$ $|* * T \geq| 3 \mid$

\section{Model 2 Teacher-Child Relationship Moderating Self-Regulation}

Model 2 tested whether the teacher-child relationship moderates the self-regulation to school readiness pathway including a direct path from socioeconomic risk to school readiness. Several indicators suggested that that this model was a good fit for the present data. The overall fit for this model was good based on multiple criteria. First, the Minimum Fit Function $\chi^{2}$ test was $2.27(p=0.13, n=116, d f=1)$. Additionally, the S-RMR was 0.04 , also indicating good fit. 
The NFI was 0.95 , which meets the necessary criteria of at least 0.95 to indicate good fit. Finally, the CFI was 0.97, which provided an additional indicator of good fit. The NNFI and RMSEA, 0.79 and 0.10 , respectively, do not meet the criteria for good fit; however, the other measures provide enough evidence for overall good fit of the model. This good fit indicates that teacherchild relationships may moderate the relation between self-regulation and school readiness.

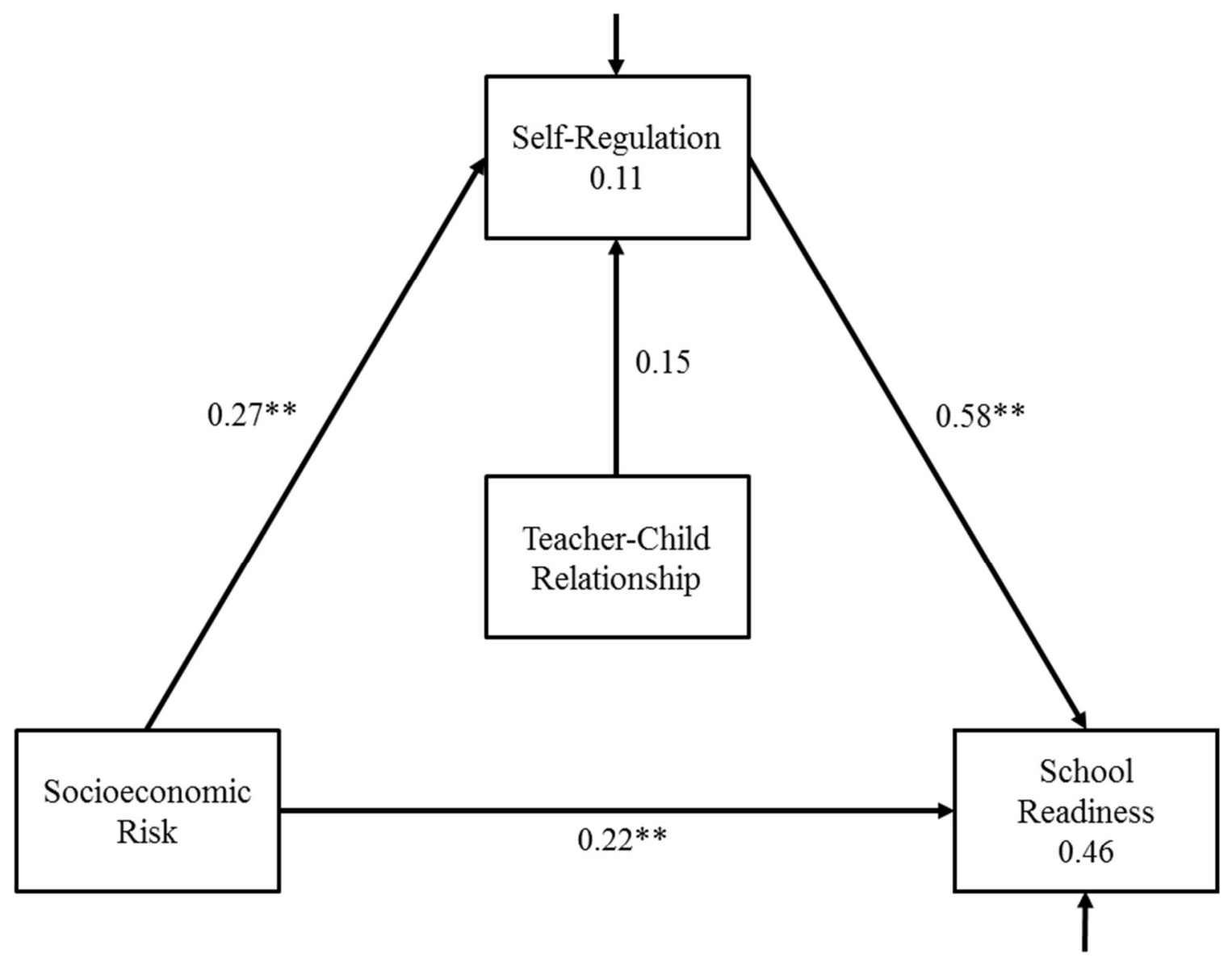

Figure 4. Model 2. Teacher-Child Relationship Moderating Self-Regulation. Minimum function $\chi^{2}=2.26, d f=1, p=0.15$, RMSEA $=0.11, \mathrm{~S}-\mathrm{RMR}=0.04, \mathrm{NFI}=$ $0.95, \mathrm{NNFI}=0.79, \mathrm{CFI}=0.97 .{ }^{*} T \geq|2|{ }^{* *} T \geq|3|$ 


\section{Model 3A Teacher-Child Relationship and Teacher-Child Relationship Self-Regulation Interactions Moderating Path from Self-Regulation to School Readiness}

Model 3A tested the teacher-child relationship as well as the interaction between selfregulation and the teacher-child relationship as moderating the relation between self-regulation and school readiness. The overall fit of this model was poor based on multiple criteria. First, the Minimum Fit Function $\chi^{2}$ test $=11.73(p=0.01, n=116, d f=3)$. An additional criterion tested was the S-RMR, which was 0.08 . Additionally, the RMSEA was 0.21 , the NFI was 0.74 , the NNFI was 0.18 and the CFI was 0.75 . All of these statistics indicate that Model 3a, which examined the interaction between the teacher-child relationship and socioeconomic risk on the relation between socioeconomic risk to self-regulation, was a poor fit for the present data. 


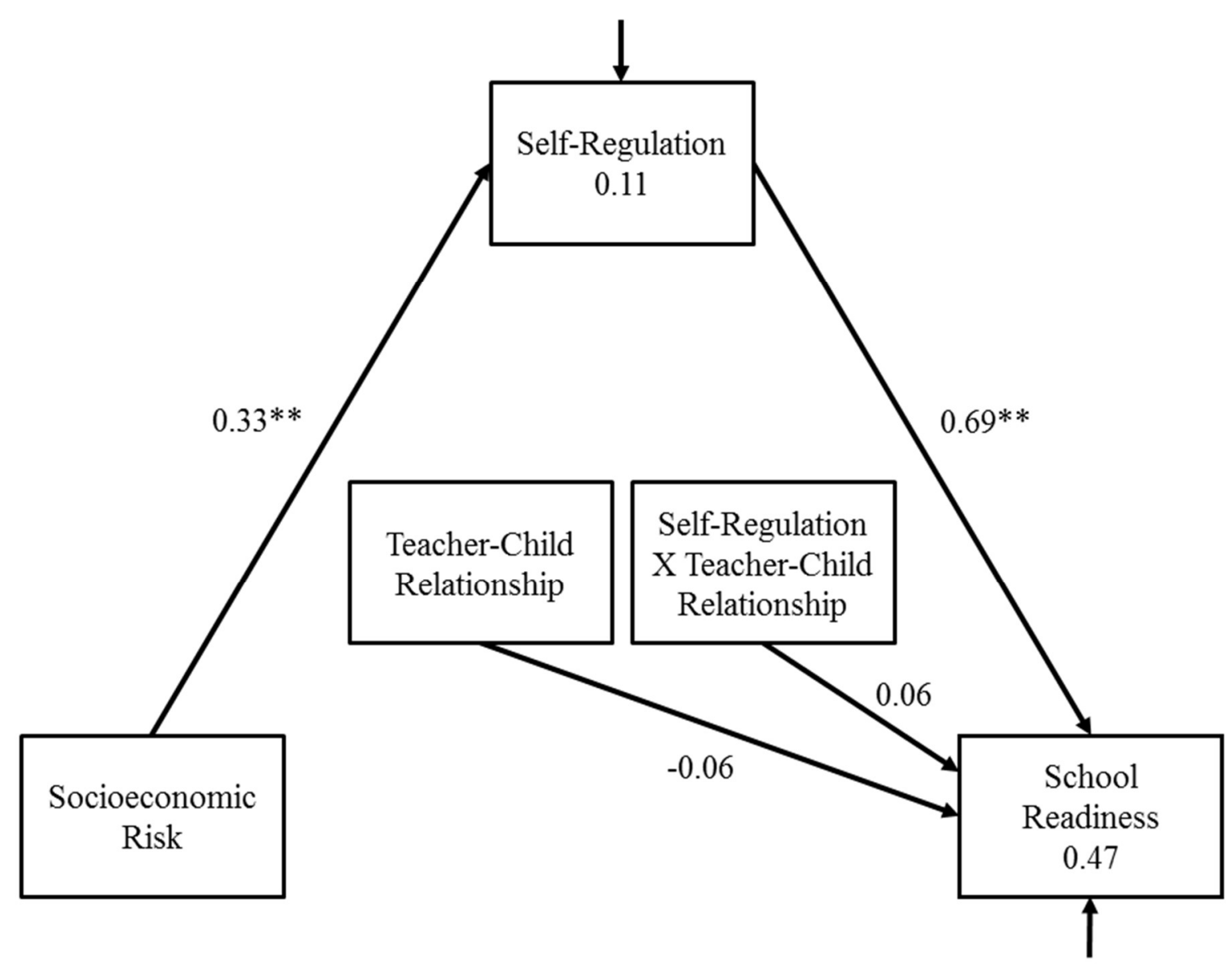

Figure 4. Model 3A. Teacher-Child Relationship and Teacher-Child Relationship SelfRegulation Interactions Moderating Path from Self-Regulation to School Readiness. Minimum function $\chi^{2}=11.73, d f=3, p=0.01, \mathrm{RMSEA}=0.21, \mathrm{~S}-\mathrm{RMR}=0.08, \mathrm{NFI}=$ $0.74, \mathrm{NNFI}=0.18, \mathrm{CFI}=0.75 .{ }^{*} T \geq|2| * * T \geq|3|$

Model 3B Teacher-Child Relationship and the Interaction between Self-Regulation and Teacher-Child Relation Moderating Path from Self-Regulation to School Readiness with Direct Path from Socioeconomic Risk to School Readiness

Model 3B tested the teacher-child relationship as well as the interaction between selfregulation and the teacher-child relationship as moderating the relation between self-regulation and school readiness including a direct path from socioeconomic risk to school readiness. The 
overall fit of this model was poor based on multiple criteria. First, the Minimum Fit Function $\chi^{2}$ test $=3.43(p=0.00, n=116, d f=2)$. An additional criterion tested was the S-RMR, which was 0.06. Additionally, the RMSEA was 0.09 , the NFI was 0.92 , the NNFI was 0.80 and the CFI was 0.96. All of these statistics indicate that Model 3b, which examined the interaction between the teacher-child relationship and socioeconomic risk on the relation between socioeconomic risk to self-regulation, was a poor fit for the present data.

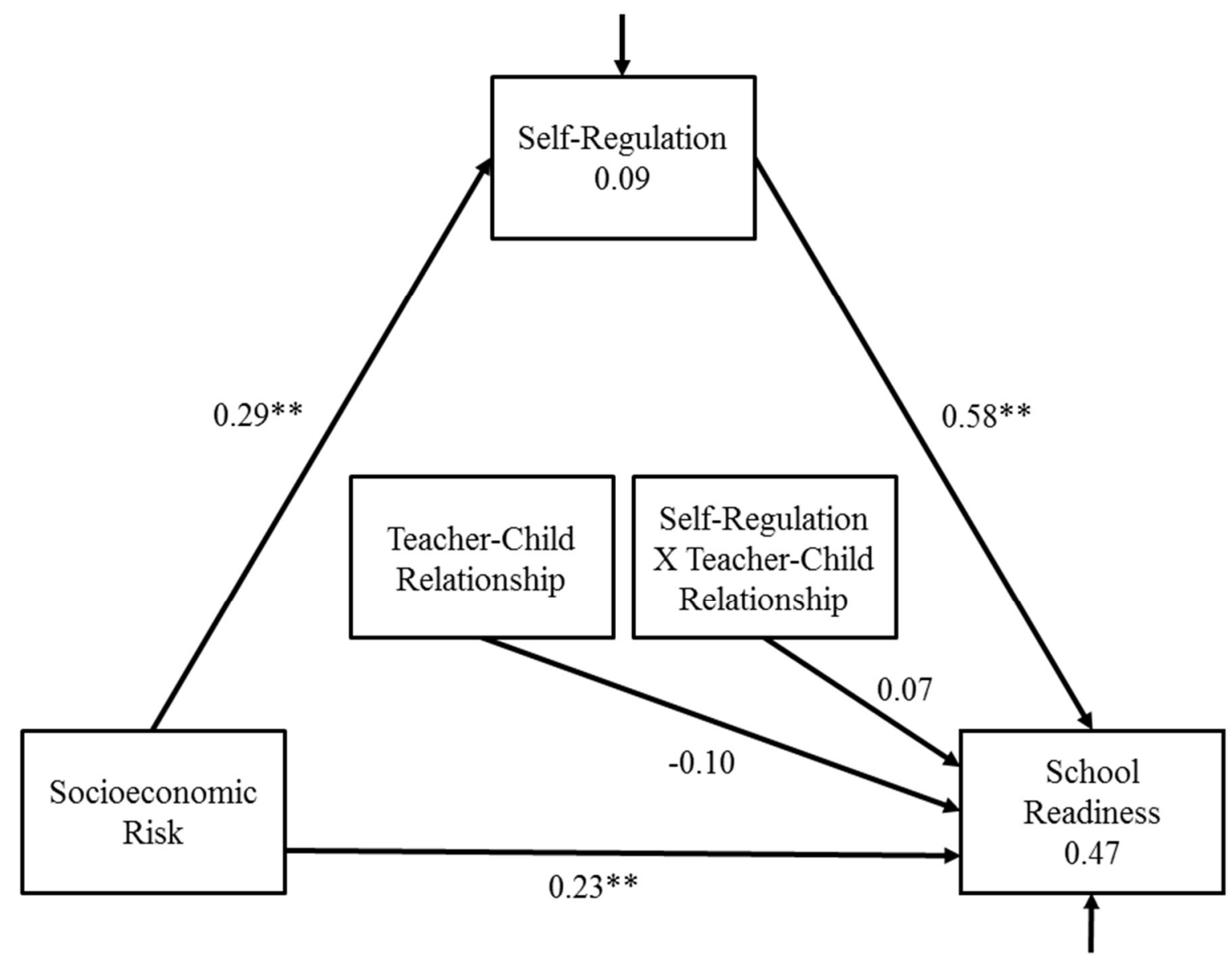

Figure 5. Model 3B. Teacher-Child Relationship and Teacher-Child Relationship SelfRegulation Interactions Moderating Path from Self-Regulation to School Readiness With Direct Path from Socioeconomic Risk to School Readiness.

Minimum function $\chi^{2}=3.43, d f=2, p=<0.01$, RMSEA $=0.09, \mathrm{~S}-\mathrm{RMR}=0.06, \mathrm{NFI}=$ $0.92, \mathrm{NNFI}=0.80 \mathrm{CFI}=0.96 \cdot{ }^{*} T \geq|2|{ }^{* *} T \geq|3|$ 


\section{Synthesis of Results}

Two models represented good fit for the current data (Models $1 \mathrm{~b}$ and 2), both of which indicated moderation at the level of self-regulation. In one of the mediated moderator models, the teacher-child relationship moderated self-regulation. In the other model, it was the interaction between socioeconomic risk and the teacher-child relationship moderating self-regulation. This moderation was all in the context of self-regulation mediating the relation between socioeconomic risk and school readiness. Further examination revealed that, in fact, these two models were quite similar. By examining the path coefficient values within the models, we can see that there was limited contribution of the interaction between socioeconomic risk and the teacher-child relationship as moderating the relation between socioeconomic risk and selfregulation (0.11). The SMR values for self-regulation and readiness for both of these models, however, were identical ( 0.11 and 0.46 , respectively, for both models). The similarity in fit statistics followed a similar pattern. These details brought me to the conclusion that the fit represented in the two models were nearly identical. This strengthens the argument for the finding in Model 2, which had the teacher-child relationship moderating at the self-regulation level without an interaction. The data from Model $1 \mathrm{~b}$ is essentially communicating the same information. These findings indicated that the strongest fit for our data was that within the existing relation between socioeconomic risk and self-regulation on school readiness outcomes. The teacher-child relationship can make changes to the effects of self-regulation. This moderation of the teacher-child relationships means that a child with poor self-regulation who was on track to have specific school readiness outcomes can have these outcomes moderated by the teacher-child relationship. Specifically it is at the level of self-regulation that this moderation occurs. 


\section{CHAPTER V: DISCUSSION}

\section{Summary of Results}

This study examined whether and, if so, how, the teacher-child relationship moderated the mediated relation between socioeconomic risk and self-regulation on school readiness outcomes. Specifically, this study demonstrated that the teacher-child relationship can change how socioeconomic risk and self-regulation contribute to school readiness in preschool children. The most unique aspect of this study was the integration of teacher-child relationship characteristics into the mediating model described above. To accomplish this, three possible mediated moderator models were proposed and tested. Each model included the same mediated relation (self-regulation mediating the relation between socioeconomic risk and school readiness) but moved the teacher-child relationship moderator at different points on the model including interactions between the teacher-child relationship and one of the other variables in question. The teacher-child relationship moderated this mediated relationship specifically at the selfregulation level. Additional exploratory models were tested to account for a direct relation between socioeconomic risk and school readiness in addition to the mediated relation. Two models that fit the data were discovered. One model included the teacher-child relationship moderating at the level of self-regulation, whereas the other included the teacher-child relationship interacting with socioeconomic risk moderating at the self-regulation level. The only difference between the two models was an interaction between the teacher-child relationship and self-regulation as a moderator. This interaction, however, represented a very small contribution to the overall model. When removing that interaction, the two models that represented good fit were identical, providing further evidence for the finding of the teacher-child relationship changing the level of self-regulation as it relates to school readiness. Importantly, this finding 
suggests that the teacher-child relationship can affect the relation between self-regulation and school readiness. That is, the teacher-child relationship has the potential to change the level of self-regulation's direct impact on school readiness. Specifically, for a child with poor selfregulation skills, the teacher-child relationship can help the child to move toward better school readiness than would be predicted without the positive relationship.

\section{School Readiness}

School readiness is an important indicator of future success; therefore, it is a focus for school-based professionals, families, children, and policy makers. Knowing the possible variables that influence readiness is important in establishing how to promote success, especially children who may be struggling for all children. This study validated a direct relation between both self-regulation and socioeconomic risk as important contributors to school readiness. Each of these relations represented a strong path between the individual variables in addition to the overall fit of the model (i.e., 0.22 from socioeconomic risk to school readiness, 0.27 from socioeconomic risk to self-regulation, and 0.58 from self-regulation to school readiness, all significant). This mediated model is consistent with previous literature that there are many different factors that can lead to differences in school readiness, including a strong validation for self-regulation and socioeconomic risk as contributors to readiness for kindergarten (e.g., Allan \& Lonigan, 2011; Blair \& Razza, 2007; Mann et al., 2016; McClelland \& Cameron, 2012; Ramey \& Ramey, 1999). There is also some literature on how the teacher-child relationship may be involved with school readiness (Pianta \& Stuhlman, 2004). Literature has indicated all of these different factors, often with individual correlations or direct contributions to school readiness; however, their combined influence was not tested prior to the current study. 
This project was unique in examining the indirect contribution of teacher-child relationship characteristics on school readiness, in the context of variables that are established to be connected. The use of these variables as both indirect and direct contributors to school readiness reflects a more ecological view of school readiness, similar to the idea of Bronfenbrenner's (1977) Ecological Model. Specifically, there are many direct and indirect processes that can be contributing to a child's readiness for kindergarten, including the child's environment, personal characteristics of the child, and the child's relationships. The modeling presented in this study incorporated multiple variables as they contribute to the complex construct that is school readiness, including socioeconomic risk, self-regulation, and teacherchild relationships.

Another contribution of this study was its use of an integrated measurement approach for school readiness. There are many components of a school readiness, including cognitive, academic, social-emotional, and behavioral readiness (Bierman, Torres, Domitrovich, Welsh, \& Gest, 2008). Many contemporary definitions of readiness include multiple components, noting that it is difficult to separate the cognitive and social-emotional aspects of readiness, given they are interdependent (Duncan, et al., 2007; Hair, Halle, Terry-Humen; Lavelle, \& Calkins; 2006). The school readiness composite measure included in this study included both academic and social-emotional components, consistent with contemporary definitions. Additionally, the composite relied on child measures of readiness rather than teacher or parent perspectives of readiness, which could be biased by a variety of factors. Despite these strengths, this method did not allow for an examination of the possible differences in predictors of social-emotional and academic readiness that could be present. Children with varying profiles of social-emotional and academic readiness may have distinct patterns of influence and outcomes. Nonetheless, creating 
an integrated measure of school readiness for this study was an important aspect of testing succinct models that could encompass not only school readiness but also important predictor variables.

\section{Socioeconomic Risk}

There also were important findings in this study relevant to socioeconomic risk. First, it is important to note that the fit of the model was strengthened when accounting for a direct relation between socioeconomic risk and school readiness, in addition to the mediated relation including self-regulation. This relation was also reflected in the significant positive correlation between socioeconomic risk and self-regulation. Overall, the mediated model was strengthened when considering both the direct relations between socioeconomic risk and school readiness, and the indirect relation via self-regulation. That is, it is important to consider these three variables (socioeconomic risk, self-regulation and school readiness) on their own in how they may be correlated and contribute to each other rather than being strictly independent within a mediated relationship. It can be helpful to think about these multiple possible pathways when considering the complex processes that can lead to school readiness.

Children who come from low socioeconomic backgrounds may have difficulty with school readiness for a variety of reasons. Previous studies have indicated that children from low socioeconomic backgrounds have a history of poorer school readiness because of a variety of factors such as family stress, access to resources to support physical health, and adequate shelter (Conger, Conger, \& Martin, 2010; Ryan, et al., 2013). However, there is diversity within children living in poverty, and understanding how to capitalize on children's resilience and what can occur in schools to ensure increased success is important in working with all students (Masten, 2014). This study contributed to the idea prevalent in the resilience literature that 
education systems can serve as adaptive systems for students who experience other risk factors and that relationships with adults in the environment can serve as important protective factors that can promote resilience. In fact, the school environment and those additional relationships have been described as a part of the "short list" of major variables that can promote resilience as evidenced by a conglomeration of resiliency research (Masten, 2014).

\section{Direct and Indirect Links Between Socioeconomic Risk and School Readiness}

This study supported the notion that socioeconomic risk has both direct and indirect linkages with school readiness. The original modeling accounted for the indirect relation by way of self-regulation. Specifically, a direct relation between socioeconomic risk and self-regulation was examined as well as a direct relation between self-regulation and school readiness. The direct relation between socioeconomic risk and school readiness was not necessarily included in the modeling, and therefore only an indirect relation between socioeconomic risk and school readiness was examined. In the analysis process, however, it was discovered that the direct connection between socioeconomic risk and school readiness could not be ignored. The consideration of both direct and indirect processes occurred at two different points of the analytical process. First, before the main analyses of examination of model fit could be assessed, testing for nesting was conducted. This test was used to ensure that all measures were independent of each other. Upon first glance, nesting was occurring: it appeared that socioeconomic risk was accounting for a large proportion of variance in school readiness outcome. Therefore, when socioeconomic risk was covaried, the nested relationship diminished, and the intraclass correlations dropped substantially. This drop in intraclass correlations suggested, therefore, that controlling for socioeconomic risk precludes the need to employ multilevel modeling as long as socioeconomic risk was retained in the model (Hox, 1995). 
Although not intended to be one of the major analyses of this study, this finding has important implications. When studying young children who attend a structured setting such as preschool, it is impossible to remove effects of socioeconomic risk because where a child attends preschool is likely highly dependent on socioeconomic factors. Specifically, programs that offer low cost or subsidized care versus those in which costs are high and without subsidies vary and likely do not attract that wide socioeconomic sample that was examined as a part of this study. The existence of these different types of settings is an important consideration in future studies of early child care settings. In the case of this study, a range of types of settings were represented, although not analyzed. As evidenced in the literature, socioeconomic factors can impact a broad range of outcomes (Bierman et al 2008; Campbell \& Ramey, 1994); however, considering socioeconomic risk at the level of the early childcare setting can be important, especially when considering factors that may be related to organization and structure of the centers and classrooms, as well as the teachers, their education, and behaviors. The presence of these various settings is especially important when considering an early childhood setting because as compared to public school settings for children at both the elementary and secondary level, there is less consistency from early child center to center or preschool to preschool on structure and curriculum, given the piecemeal approach to early childhood care in the United States. Specifically, early childhood public school settings are not universal and different children have access to these services in different places. Additionally, though a heavily researched field, the reality of educational policy and implementation is not necessarily aligned in all settings with these best practices (Pianta, Barnett, Burchinal, \& Thornburg, 2009). Closely related can be teachers' experience levels and education, because varying levels of education of teachers may be required and rewarded in different settings. As a result, family income and what 
type of early childhood education setting can be afforded by a family can have a major impact on the resources to which children have access, which can have implications on their learning. A high quality early childhood setting is especially important for children who may experience other risk factors that could be associated with low socioeconomic status (Burchinal, PeisnerFeinberg, Bryant \& Clifford, 2000).

A second important finding related to measuring socioeconomic risk in relation to the other variables occurred at the analysis level. The models that provided the best fit needed to account for a direct link between socioeconomic risk and school readiness in addition to the indirect link inherent in the mediated model. In one of the models, with the addition of a direct link between socioeconomic risk and school readiness through exploratory analyses, the fit was strengthened. The addition of the direct link led to adequate fit of an additional model (model 1b). The necessity to include both the direct and direct links between socioeconomic risk and self-regulation is important because it points to the idea that there are both direct and indirect contributions of socioeconomic risk to school readiness. Given a constellation of risk and resilience factors that are specifically relevant to socioeconomic status in relation to school readiness exist, it was necessary to account for both in our modeling to ultimately best predict school readiness.

\section{Self-Regulation}

Self-regulation includes processes of voluntary control over approach or withdrawal behavior tendencies, the ability to inhibit a dominant response, and the ability to resist interference or distraction (Liew, 2012; Rothbart \& Bates, 2006; Ursache, 2012). Self-regulation has important implications for children's overall development, including school readiness. In this study, self-regulation represented a mediator in the relation between socioeconomic risk and 
school readiness. It therefore served as both a predictor and an outcome with the mediated moderator model. In terms of the predictor, self-regulation is considered an important resiliency factor for general outcomes related to development, including school readiness and academic achievement. The inclusion of self-regulation as both a predictor and outcome was validated through the fit of the model, which included self-regulation mediating the relation between socioeconomic and school readiness. Specifically, there was a 0.27 relation between socioeconomic risk and self-regulation and a 0.58 relation between self-regulation and school readiness. Also validated was the direct linkage between self-regulation and school readiness (0.58, Blair \& Razza, 2007; McClelland \& Cameron, 2012). Whereas these previous studies focused for the most part on academic outcomes, the present study uniquely incorporated an element of social-emotional readiness with the academic outcomes. With equal weighting of the social-emotional readiness, this study drew a strong linkage to a more integrated view of school readiness as it relates to self-regulation. Similarly, this study included an integrated measure of self-regulation including teacher-report and direct child measures, as well as an incorporation of hot and cool measures (Metcalfe \& Mischel, 1999). Finally, measures from both the cognitive and temperament literature were integrated. Inclusion of this range of measures provided validation for this multifaceted definition of self-regulation as it is linked to school readiness. Overall, the nature of self-regulation owes itself to the ability to perform learning activities, which contributes to its possible impact on school readiness including academic, behavioral, and social-emotional skills (McClelland \& Cameron, 2012). Additionally, the fact that the years leading up to kindergarten are a particularly important time in the development of self-regulation lends itself to studying the variety of measures that reflect the multidimensionality of the selfregulation construct (Rothbart \& Bates, 2006). Theoretically, these findings make sense, that 
children's readiness for kindergarten can be directly linked to their ability to perform specific behaviors within the classroom, many of which require self-regulation. Additionally, with the knowledge that one particularly significant time in the development of self-regulation is in the years leading up to kindergarten (Rothbart \& Bates, 2006), it makes sense that school readiness would be impacted by the gradual development of self-regulation. This promotes an understanding of the linkage between these specific behaviors and cognitive processes as they are translated to children's success in the educational environment.

\section{The Teacher-Child Relationship}

The most distinctive aspect of this study was the integration of the variable of the teacher-child relationship into the mediating model described above. This study reveals that teacher-child relationship can affect the relation between self-regulation and school readiness. Specifically, this study demonstrated that the teacher-child relationship can change how socioeconomic risk and self-regulation contribute to school readiness in preschool children. The teacher-child relationship as a moderator is important to consider in the context of these strong connections amongst the other variables. This study found that the teacher-child relationship specifically contributes at the level of self-regulation. That is, teacher-child relationships change the level at which self-regulation is changing a trajectory of school readiness. Specifically, a child with poor self-regulation who has a positive teacher-child relationship could have positive school readiness outcomes. Understanding the role of the teacher-child relationship in this context is important because although interventions can be implemented to strengthen selfregulation skills, the strengthening of self-regulation in young children may require a targeted program (i.e. Head Start, REDI, Ursache, Blair, \& Raver, 2012) and therefore may be more 
difficult to achieve (and more expensive to achieve) than targeting the teacher-child relationship directly.

\section{The Teacher-Child Relationship and Resilience}

Finding that the teacher-child relationship can affect the relation between self-regulation and school readiness is consistent with the literature on resilience (Masten, 2014). Specifically, the present findings could point to the connection between secure attachment relationships and resiliency as validated in the resiliency literature (Masten, 2014). Although an attachment relationship was not directly examined in this study, the measure of the teacher-child relationship has important connections with attachment. Teachers can serve as an attachment figure to ameliorate other negative attachment relationships and other risk factors to promote positive development and readiness (Baker, 2006; Howes \& Spieker, 1992). The teacher-child relationship as an attachment figure may also be reflected in examining the specific levels of closeness and conflict between a teacher and student, which was not examined in this study. Because positive relationships with adults and a positive school community are considered a part of the "resiliency short list that promote children's development, teacher-child closeness could be a reflection of resiliency. There is literature that demonstrates that the promotion of positive attachment relationships and relationships with trusted adults are important for overall development (Masten, 2014). Another important resilience factor noted was emotion regulation. There have been specific findings that self-regulatory abilities can promote or hinder resilience (Masten, 2014). It would make sense then, that resilience factors specific to school would contribute to school readiness. The contribution of this study of the integration of the teacherchild relationship as changing the level of the effect of self-regulation on school readiness is connected. Thus, a possible risk factor (self-regulation difficulties) can be countered by a 
protective factor (the teacher-child relationship). Specifically, a child with poor self-regulation who has a positive teacher-child relationship could have positive school readiness outcomes.

Although a child may not be able to control their level of self-regulation, the teacherchild relationship can help move that child's development along, which in turn, could influence their future regulatory skills. This lack of control is present for children with poor self-regulation based on their point in overall development, as well as those who have not had exposure to strategies for coping and regulating emotions. The importance of the teacher-child relationship is also useful because it allows teachers to have an additional strategy for reaching their students. Teachers may be able to indirectly promote children's self-regulation skills by forming a positive relationship with students. Overall the findings of this study support that the resilience factor of a positive teacher-child relationship has the potential to outweigh the risk factor of poor selfregulation to promote better school readiness.

Another important point that connects this study with the literature on resilience is that an overall positive community and school environment can be important for promoting a child's development. The present findings demonstrated that teacher-child relationship characteristics can contribute to readiness in children with a variety of self-regulatory abilities. It could be argued that this teacher-child relationship or attachment aspect could contribute to something larger than itself. Specifically, this measured relationship could represent an overall positive school community for that child as a place that they feel comfortable and therefore learn most effectively. The positive school community is especially important for children for whom there are risk factors in their environment such as violence, inconsistent housing and food access, and poor health resources. Perhaps the school can serve as an adaptive environment—a safe place for learning and growth. This directly links to the research that the effects of the teacher-child 
relationship are not isolated to that particular relationship but provide a schema, or an internal working model, for children, predicting how they view future school experiences (Howes \& Hamilton, 1992).

When considering the results of this study, there are many possible variables that can contribute to a child's readiness that may feel difficult to change for teachers or schools as a whole (i.e., socioeconomic risk, self-regulation based on temperament or developmental level). These variables may include factors in their environment but also factors related to the child themselves. For example, although the development of self-regulation and other developmental tasks can be supported and promoted, it may simply take time for children to develop these skills because it is something still in process in the years leading up to kindergarten. Or, for others who may have environments that make it more difficult for school readiness to develop (i.e., lack of resources, healthcare, and food), the teacher-child relationship can be especially important. The teacher-child relationship is something that can be promoted. If teachers have the tools to be able to build these relationships actively, especially with children who may be struggling otherwise, this can be important. The difficulty arises because children with poor self-regulation can often be among the most difficult for teachers to work with and therefore have the potential to have that negative relationship occur. Specifically, children with poor self-regulation often have difficulty performing the expected behaviors within the classroom. The presence of children with poor self-regulation makes it difficult for teachers to execute planned programming, which may lead to higher conflict and lower closeness, the inverse of strong teacher-child relationships.

With an understanding of the importance of the teacher-child relationship as an opportunity to intervene and contribute to a child's positive development, important interventions can take place, and efforts to support teachers in working with all students can be 
emphasized. Specifically, with a greater emphasis and understanding of the significance of the teacher-child relationship, administrators and other professionals within the early childhood setting can help to give teachers strategies to work with students and to also focus on relationship outcomes between the teacher and student instead of simply examining academic achievement outcomes for the students.

\section{The Teacher-Child Relationship as a Moderator}

The teacher-child relationship is important to consider when attempting to investigate other factors such as self-regulation and socioeconomic background as contributing to school readiness. In this study, the teacher-child relationship affected the relation between selfregulation and school readiness. Whereas these other factors represent characteristics of the child and their environment outside of school, the teacher-child relationship can provide additional information about the direct school processes. Because school readiness is an outcome directly related to the school environment, it would only make sense to include a variable that is occurring as a part of the school environment. The direct relation between school readiness as an outcome and the school environment was the theoretical reasoning for including the teacherchild relationship as a possible moderator. This conceptualization was important given the limited research that tests the connection between self-regulation, socioeconomic risk, and the teacher-child relationship in one cohesive model to examine contributions to school readiness. Only one existing article included all of these concepts, but it proposed a theoretical model that connects theses variables rather than offering an empirical test (Eisenberg et al., 2010). With the strong connection in the literature between socioeconomic risk and self-regulation as it relates to school readiness, but with less information about the teacher-child relationship, it made sense to consider the teacher-child relationship as a moderator within this larger mediated model. It 
theoretically made sense that the teacher child relationship could have the power to come into this strong existing mediated relation and moderate levels in some way to influence overall school readiness outcomes. One major outcome of this study was the validation of a mediating role of self-regulation on socioeconomic risk in its outcomes of school readiness. The outcome is consistent with previous literature that pointed to these strong linkages between these pairs of variables (i.e., Blair \& Razza, 2007; McClelland, \& Cameron, 2012; Peisner-Feinberg et al., 2001; Schmitt et al., 2012) and with findings showing that self-regulation can serve as a mediator between socioeconomic risk and school readiness (Raver, 2012). However, it is the overall model with the inclusion of the teacher-child relationship as a moderating variable that is this study's major contribution to the literature.

\section{Implications for Schools}

This study's aim was to examine the complex relationships that occur involving student's backgrounds, personal characteristics, and their relationships within the school setting in predicting readiness for kindergarten. Given this study demonstrated that the teacher-child relationship can change how socioeconomic risk and self-regulation contribute to school readiness in preschool children, there are many implications of this study for the school setting. There are also important considerations for the role of the school psychologist in light of these findings.

The first major implication of the present findings for schools is that this study provides support for early intervention and quality early childhood education. The present findings are consistent with previous research showing that the teacher-child relationship is related to readiness for kindergarten (O’Connor \& McCartney, 2007; Peisner-Feinberg et al., 2001; Pianta $\&$ Stuhlman, 2004). This relation between the teacher-child relationship and school readiness is 
occurring despite factors that are less changeable in the moment such as socioeconomic status. With a focus on involving students early in a structured school setting, there is the ability to promote children's readiness in a variety of ways.

Inherent in this implication is the need for quality early childhood programs, especially for children from low socioeconomic backgrounds. In fact, poor quality programming could lead to negative effects on a child's cognitive development (Barnett, 2008; Cote, Geoffroy \& Baptise Pingault, 2014). As the analysis of nesting revealed, there was a clear relation between children's socioeconomic risk and the classroom where they were located. It is known that children from different socioeconomic backgrounds are being educated in different places from each other, which leads us to question whether a possible factor in differences in readiness could be the structure and resources contained within the educational programs themselves. Different aspects of quality to be considered could be teacher-student ratios and the overall classroom environment. With this newfound understanding that the teacher-child relationship can help or impede a child who has poor self-regulation and comes from a low socioeconomic background, this leads us to question if quality teaching is occurring and if students in these variety of settings have opportunities to form positive relationships with their teachers.

A possible solution to the various differences in quality teaching and early childhood educational settings is increased public Pre-K programs that are contained within school districts. Research suggests that public preschool is beneficial for children from low-income backgrounds (Coley, Cotruba-Drzal, Collins, Cook, \& Cook, 2016; Frede \& Barnett, 1992). Some states already have a mandated universal Pre-K, while other states leave it up to the district to determine; however, the number of children enrolled in public Pre-K programming has been steadily increasing (Rous, Hallam, McCormick, \& Cox, 2010). It may also be important to 
consider whether accreditation of programs such as the one provided by the National Association of Education of Young Children (NAEYC) can help when considering important aspects of quality. Specifically, according to the website of the NAEYC (National Association of Education of Young Children, 2016), NAEYC accreditation focuses on the curriculum, teaching and assessment of child progress, teacher certification, family and community programming, the physical environment, and leadership within a program. This type of accreditation can help to ensure increased quality for a wide variety of programs in multiple areas, including an examination of children's interactions with their teachers, but largely focusing on aspects of curriculum and the physical environment within a program. Considering the significance of the teacher-child relationship and documentation of the long-term impact of the teacher-child relationship over time, perhaps the teacher-child relationship could be strengthened when students are oriented earlier to the school setting.

While understanding the importance of the strengthening of the teacher-child relationship, it is also important to consider the many possible barriers to building this relationship. Barriers include teacher experience and education, teacher pay and stress, teacher turn over, access to educational materials within the school setting, the physical setting of the school, and many other factors. One specific factor to consider is teacher training. Teachers may not have extensive training in working with children with behavioral difficulties or who have difficulty acquiring the behavioral skills necessary for success in an educational environment. It is also important to consider what is emphasized for teachers in an era of high stakes testing and emphasis on meeting specific academic milestones, where a focus on the relationships formed with students may be deprioritized. Specifically, teachers may be evaluated based on teaching specific concepts and students achieving a certain level of mastery. These evaluations would 
typically not include an evaluation of teachers' interactions with students, making it difficult for teachers to emphasize this important facet.

It is important to focus on the factors at home and school that may impede a child's development of readiness skills. There is also consideration of how congruent goals of preschool settings are with kindergartens that children will attend in the future. For example, in one study, kindergarten teachers were surveyed on their existing students' readiness for kindergarten (Rimm-Kauffman et al., 2000). This concept could be used to explore the variables examined in this study to gain additional perspective on what kindergarten teachers may be seeing as gaps in children's behaviors and knowledge that are essential for their success in kindergarten, as well as barriers to those teachers forming positive relationships with their students.

\section{Supporting Self-Regulation}

It may also be important to consider how to provide appropriate teacher training and support, especially for working with children with poor self-regulation. Because the teacherchild relationship has the potential to change the course of a child's readiness trajectory, it is important for teachers to learn about ways to build relationships with students. Relationship building strategies can include increasing self-reflection, recognizing times when they may be upset about students' behaviors and monitoring their responses, as well as seeking out support

from appropriate personnel when working with children with difficult behaviors. Specifically, teachers who are stressed and who display negative affect are more likely to have poor relationships with students (Yoon, 2002). It is therefore important to consider strategies for teachers to reduce this stress and negative affect as they interact with their students.

Building positive relationships can be particularly difficult with children with poor selfregulation because these children likely pose a challenge within the classroom for teachers in 
terms of behavior management and the need for supplemental direct instruction on both academic and behavioral necessities for functioning within the classroom. Therefore, these students can become increasingly frustrating for teachers to work with. Support for teachers can come from multiple sources. Starting with teacher training, teachers should be trained to effectively implement behavior management techniques and to understand concepts such as selfregulation and its variability. By becoming better at distinguishing whether student cannot do tasks versus choosing to not do the task, teachers can better support their students by having a better grasp of the root of their behaviors within the classroom.

\section{The Roles of Administrators and School Psychologists}

Professionals with the school can contribute to supporting early childhood educators to foster positive relationships with their students. Providing this support is especially important for students with self-regulation difficulties. Strategies could involve administrators ensuring that teachers of children with poor self-regulation have support. This support could involve training and access to curricula that support the development of self-regulation. More broadly, support can be access and requirements to implement universal programs that promote social-emotional development within the classroom. Programs could include curricula such as 2 nd Step, I Can Problem Solve, The Incredible Years (CASEL, 2013). Other points of support could include important assessment tools such as the battery suggested by Denham (2006) or others (i.e., $A S Q$, $D E C A-2, D E S S A)$ to help determine social-emotional competence, with its link to school readiness (Denham, 2006; Nickerson \& Fishman, 2009; Squires \& Bricker, 2009).

Support can also come from other professionals within the school, including school psychologists. School psychologists have unique training in being able to adequately assess for cognitive skills such as self-regulation as well as help to implement screening systems and 
manage data within the school. Effective screening can allow for schools to be able to identify children who may need additional support within the classroom and teachers who therefore could benefit from additional support. School psychologists also have extensive training in behavior management techniques and mental health interventions and could serve as consultant to teachers on these issues (NASP, 2010). Effective consultation with teachers can be extremely helpful given the complex nature of teachers' jobs and their varying responsibilities (Erchul \& Martens, 2010). Effective consultation can be key to impacting issues related to preschool expulsion due to behavioral difficulties. Preschool children are expelled at a rate of 3 times more than K-12 students, and helping teacher to work more effectively with children with behavioral difficulties is key, since the presence of behavior specialists reduces the likelihood of expelling children from preschool (Gilliam, 2010).

School psychologists can provide suggestions for teachers in working on developing selfregulation skills but also on building empathy and positive relationship with students. School psychologists can also provide additional interventions around self-regulation and other executive functions and essential classroom behaviors to provide additional support to teachers. Finally, school psychologists' experiences with counseling and mental health, and their role as a consultant in the school setting, can also be utilized to provide strategies for the teacher to effectively work with students (Merrell, Ervin, \& Gimpel Peacock, 2012). Specifically, school psychologists can apply a behavioral consultation model that involves assessment, problem identification, implementation and analysis of data, all completed collaboratively with the teacher (Watson \& Sterline-Turner, 2008). School psychologists can provide support that comes from an extensive knowledge base but that is not inherently evaluative since the school psychologists are not serving as the teachers' supervisor. It is important to mention that the role 
of the school psychologist is most likely occupied within public school settings and some private parochial schools. It is unlikely that a daycare center or smaller early childhood programs could afford to hire a school psychologist, providing further evidence for the need of early childhood education services integrated into school districts or to seek out other collaborative and consultative relationships to help with these types of public initiatives. There are also state-based initiatives that provide resources and referrals for families, such those present in the state of Illinois, for example (Early Childhood Mental Health Consultation Project-TIER, 2017). Additional programs such as Head Start are required to consult with mental health professionals as a part of their programming (Office of Head Start, 2017)

It is also important that teachers who do have access to mental health personnel understand how to utilize them and what they know. Appropriate utilization may be a matter of school psychologists or social workers forging relationships with teachers, but it also may be necessary to consider advocacy of the field as a whole so that there is a broader knowledge among the educational community of the training of these personnel so that they can utilize them. An additional consideration is also the administrative structure within a school.

\section{One Possible Structure: Response to Intervention}

One possible organizational structure that can promote all of these activities within a school system is a Response-to-Intervention model. Already widely implemented in elementary school settings, and mandated by several states, Response-to-Intervention is a preventative-based model in which all students are provided universal services while mechanisms are in place to identify students who need increasingly intensive interventions (Buysse \& Peisner-Feinberg, 2013). Those who do not respond to these interventions are then considered for special education services. The Response-to-Intervention model can be used to promote academic and social- 
emotional /behavioral skills including self-regulation. With the end of the year goal of kindergarten readiness in mind, children who are struggling can be identified and provided assistance throughout the year leading up to kindergarten (Buysse \& Peisner-Feinberg, 2013). Response-to-Intervention fits well within the model of early childhood education, specifically its focus on a preventative approach (Fox, Carta, Strain, Dunlap, \& Hemmeter, 2009). This can also include an integration of a pyramid model that includes responsive caregiving relationships, high quality supportive environments as primary supported and targeted social-emotional supports, and intensive interventions at the secondary and tertiary levels, respectively (Fox et al., 2009). Response-to-Intervention in early childhood settings is less common for several reasons. One issue is that Response-to-Intervention is not widely recognized as needing to be implemented by school districts or state governing bodies. Another issue is trying to implement Response-toIntervention within the structure of early childhood education, at the preschool level, which can be widely varied as compared to K-12 education (Buysse \& Peisner-Feinberg, 2013).

Additionally, Response-to-Intervention is included in the federal IDEA (2004) law for K-12 as a recommendation; however, this legislation does not include early childhood education as a part of these recommendations. Additionally, the implementation of Response-to-Intervention requires data collection systems, screening measures, and interventions. Particularly on the data collection side, there is less availability of screening and monitoring measures for preschool, although there are some measures available (Landry, Assel, Anthony \& Swank, 2013). Two examples are the Individual Growth and Developmental Indicators (IGDIs, Carta et al., 2002) and Circle Phonological Awareness Language and Literacy System (C-Palls, Landry Anthony, Swank, \& Monsegue-Bailey, 2009). Social emotional measures are even more difficult to find, although there has been a recent proliferation of social emotional interventions and curricula 
(CASEL, 2013). All of these structures require professionals such as school psychologists who can select appropriate interventions and the willingness of teachers to implement programs with fidelity and integrity while managing existing curricular demands. Having structured socialemotional curricula, structured systems for teachers to make decisions about increased interventions, and access to other professionals to deliver these interventions can help to reduce

teacher stress. One example of programs currently available include the Teaching Pyramid Observation Tool (TPOT) which includes an observational measure to examine teacher implementation of pyramid systems such as those implemented with Response-To-Intervention (TPOT, Fox, et al., 2009). With these systems in place, teachers can better access supports from professionals with unique and valuable skills, allowing teachers to have the tools to be effective with all students and build positive relationships with all children in their classroom.

\section{Other Strategies for Supporting Teachers}

One practical direction that this research can be taken is in the creation of curricula and concrete steps that educators can engage in to promote regulatory skills and positive teacherchild relationships in the classroom. Curricula can implemented through the training of administrators or support personnel such as psychologists and social workers or training of the teachers themselves. Because this study provides the potential for these variables to impact school readiness for children experiencing socioeconomic risk, having specific strategies to intervene can be helpful. One possible strategy is to provide opportunities in the classroom to link emotional and motivational arousal with activities that exercise executive functions such as games and problem solving activities (Blair \& Diamond, 2008). Existing curricula that support overall social-emotional development by increasing children's emotional and behavioral awareness can also provide important strategies for enhancing self-regulation. Existing curricula 
include Tools of the Mind, Head Start REDI, and The Chicago School Readiness Project (LiGrining, Lennon, Marcus, Flores, \& Haas, 2014). There could be many possible directions of the curriculum. Possible directions could include providing education and continuing professional development opportunities to teachers about concepts such as self-regulation and overall child development and how to address concerns. Other strategies could include instructions about behavior management, as well as important resources about teacher self-care. Increased awareness regarding preventing burn out, including recognizing when certain behaviors are impacting teaching and ways to manage stress. Closely related, teachers can learn about how to access resources to deal with difficult students including personnel within the building as well as places to learn more about the strategies that could be introduced. Additionally, teachers can use the context of an ecological systems theory (Bronfenbrenner, 1977) to consider their relationship with their students, and factors that may be impacting the student directly and indirectly. Just as the teacher-child relationship can be an important part of a child's greater ecological system, it may be helpful for teachers to consider the other systems at work in a child's life. Additionally, the teacher may want to consider systems within the classroom that may impact the teacher's interaction with various students and their interactions with each other (Pianta, 1999).

\section{Policy Implications}

All of these recommendations cannot be considered without reference to policy. As mentioned in the literature review in the overarching definition of school readiness, school readiness has increasingly become an area of focus for policy makers. This increasing focus has been evident in the passing of laws such as the school readiness act (Liew, 2012) and federal and state-level funding efforts (e.g., Race to the Top). The results of this study confirm that if school readiness is going to be valued, efforts must start early. Efforts could include funding, utilization 
of standards, high educational standards for early childhood educators, and funding for early childhood positions. These can allow more children to access quality early childhood education within their communities that is not dependent on having a high-income level. It is also important that future research is responsive to shifts in policy toward early child education.

\section{Specific Strategies for Promoting the Teacher-Child Relationship}

A major finding of this study was that the teacher-child relationship can change the level at which self-regulation can predict school readiness. It would therefore make sense to target the building of positive teacher-child relationships specifically, especially for children who may struggle with self-regulation or have other behavioral difficulties. One important way that the relationship can be built is considering ways to build empathy between the teacher and student, as well as finding points at which teachers and students can make connections and develop a close relationship. One way to do so is to increase school-family collaboration as well as schoolcommunity collaboration. Collaboration is especially important for teachers who may be working with students and families who have different cultural, racial, ethnic, or socioeconomic backgrounds than them (McCallister \& Irvine, 2000). By creating connections inside and outside of the classroom, teachers can be more flexible in their interpretation of different behaviors and can better identify strategies to address those behaviors. These increased connections could help to make difficult behaviors, sometimes associated with poor self-regulation, more tolerable. One strategy for building empathy could be through the utilization of a growth versus fixed mindset approach (Dweck, 2006). This theory asserts that if teachers can take the mindset of positive resiliency factors that students have and also that students have the capacity to change and will not always have certain behaviors or difficulties define them, then students are more likely to achieve growth or success. Additionally, if students believe that their efforts will lead to success 
academically (versus inherent abilities), then they are more likely to have success in school (Dweck, 2006; Yeager \& Dweck, 2012). This pervasive attitude within the classroom can also contribute to teachers feeling like their teaching behaviors can have a positive impact on students.

Another important consideration is that teachers may have more difficulty building empathy or that positive relationship with students who have a different cultural, racial, ethnic or socioeconomic background than themselves. Working with students who are different from them require teachers to be continuously building their cultural competency and awareness of their own biases that may impact their teaching. This is especially important considering that students from specific racial and ethnic backgrounds are disproportionally expelled from preschools (U.S. Department of Education). Teachers must take steps to understand better their students' cultures, being aware of their own attitudes and biases and be able to adjust their own behaviors through this understanding (Delpit, 2006). Specifically, self-awareness and adjustment of behavior will involve using a culturally responsive framework to organize the environment of their classroom that can best match the races and cultures of their students (Stone Hanley \& Noblit, 2009). Taking a culturally responsive framework can be challenging for teachers who are not familiar with cultural aspects of their students' lives or who have students from multiple cultural backgrounds in their classroom. Teachers and other professionals must also consider how measurement techniques may be impacted by culture. Even when considering such variables as self-regulation, there can be documented differences in norms of self-regulation among different groups. These norms are not always considered in the context of assessments, even when they are translated to different languages (McClellend \& Cameron, 2012). These aspects of teachers' behaviors and attitudes may be something to consider in future research in this area. 


\section{Limitations and Future Directions}

This study had many important contributions to the field in demonstrating that the teacher-child relationship can change how socioeconomic risk and self-regulation contribute to school readiness in preschool children, but there are many future directions and ways to expand upon this research in the future. One limitation of this study was the sample. Although the number of participants was adequate for sufficient power for the analyses conducted, all participants were drawn from a small Midwestern city. In terms of income, there were some participants with very high incomes (greater than $\$ 200,000 /$ year for the family), more so than is representative of the overall country's median income of \$56,516 (U.S. Census Bureau, Proctor, Semega, \& Kollar, 2016). Specifically, the median income in this study was between $\$ 75,000$ and $\$ 99,000$ per family. There was also not a large sample in the middle income range measured (\$35,000-\$99,000 per year). Specifically, this only represented $18.9 \%$ of the sample.

Additionally, racial representation in this sample was different than national samples. Specifically, although White participants were the majority of the sample in this study percentage wise, it was slightly less than the national average of $77 \%$ at $59 \%$ ("United States Census Bureau Quick Facts, United States Census" (2015). Additionally, Hispanic children were underrepresented with a $7.8 \%$ representation in this sample compared to a $17.6 \%$ national representation. Asian Americans were also under represented at 2.6\% compared to the national percentage of 5.6\%. Additionally, children identifying as African American/Black were slightly over represented ( $17 \%$ compared to $13 \%$ nationally). Finally, this study did not include any students who identified as Alaska Native, American Indian, Native Hawaiian or Pacific Islander. It may also be helpful to consider how parental factors such as parental education may impact results. 
Future research can draw upon other populations to see if findings can be replicated in rural or larger urban populations. Future studies could include a more detailed examination of family structure, more information about how race or ethnicity and culture play into these variables and processes, and possible gender differences that could be occurring. It may be helpful to examine in more detail children who are at different points in the year, getting closer to kindergarten. It would also be interesting to examine outcomes in students who are already in kindergarten to test the predictive power of these variables in reality for students.

This study also comprehensively examined variables that are quite complex, many that have extensive literatures that can be broken down into sub-variables or different components. Future variables to be examined includes things such as hot versus cool self-regulation, social emotional versus academic readiness, and teacher-child conflict and closeness. Future studies and analyses can examine these multiple aspects more closely and examine whether some more subtle clues regarding the linkages between certain variables and school readiness can be found. Considering different ways to conceptualize variables can also lend itself to the examination of additional modeling approaches beyond what was utilized in this study. Future models using structural equation modeling can be developed based on the findings of this study. Additionally, it may be important to intentionally examine the nesting that occurs when examining processes happening within a particular classroom.

Beyond the overall models, it is important to consider the range of possible ways to measure the variables that were investigated. Additionally, it may be helpful to have a more narrow age range included so that measurements could be selected that would be most sensitive to that range with few children obtaining scores at the ceiling or basal level. One future direction relevant to measurement is continuing to examine and develop appropriate measures of social- 
emotional readiness. Whereas the Early Concepts Scale Social and Self-Awareness Subtest (Bracken, 2006) used in this study provided a good overview of children's social-awareness, it did not examine children's social-emotional readiness in action. Future research should focus on developing measures that examine social-emotional readiness via direct observation of children within the classroom setting. Measurement strategies could include observing children's adherence to classroom expectations during structured times, social interactions, and play activities with other students. Observation measures could provide an ecologically valid measure that can more closely connect with what teachers and children are experiencing within the classroom. This can build upon existing measures such as the Classroom Assessment System (CLASS, Pianta, Hamre, Downer, 2015), the TPOT (Fox et al., 2009), and the Early Childhood Environment Rating Scale, Revised Edition (ECERS-R, Harms, Clifford \& Cryer, 2005). All of these measures examine classroom climate, and aspects of the teacher-child relationship, but it would be useful to develop tools that use similar strategies to examine the teacher-child relationships existing within the classroom in greater depth. It may be interesting to consider whether specific factors of teachers or centers may influence the variables examined. Specifically, did teachers with specific education or experience level have different relationships with their students? Additionally, how could higher pay for teachers or teaching in more expensive or high-quality programs impact the development of relationships with students?

Another important way to reconceptualize readiness in terms of measurement in future research is to examine it from a systems perspective rather than an individual child's perspective. That is, instead of the question being "is the child ready for school?" the question can be, "is the school ready for the child?" Asking difficult questions about whether or not schools are ready for children from diverse backgrounds and how to capitalize on strengths and skills that these 
students possess would be beneficial. These questions and alternate perspectives are related to an idea of capitalizing on resilience of children from diverse backgrounds to better understand their learning process, what they know, and how that can be used to expand upon their knowledge. Thinking about how young children may view themselves in the context of "smartness," school success and ability can be important in considering how to inform teaching practices and behaviors (Dweck, 2006; Hatt, 2012).

These questions about school readiness measurement are also linked with questions about how to measure and conceptualize socioeconomic risk or risk factors more generally in relation to readiness. This study narrowly defined socioeconomic risk by considering income per person in the household, but socioeconomic status is much more complex than that; there are many different ways to examine what socioeconomic risk can mean (i.e., education level, employment prestige, number of children under a certain age, standard of living, access to health care, family structure). How these intricacies can be related to school readiness should be considered. Future research can examine multiple models with these different risk and resilience factors examined, such as understanding additional problem solving skills and other executive functions, examining collective efficacy in neighborhoods and communities, and making connection between effective caregiving among parents and close relationships between teachers and students (Masten, 2014).

In terms of self-regulation, there are a plethora of measurement techniques available. This study integrated multiple perspectives and theories into one composite variable. There is evidence that self-regulation is complex and that there could be individual differences in skills and abilities relevant to different aspects of self-regulation (Carlson, 2005; Eisenberg et al., 2011; McClellend \& Cameron, 2012). Future research can delve deeper into these intricacies including examining the differential effects of hot and cool self-regulation on readiness, as well 
as a comparison of teacher, parent, and child-based measures. Further research could also examine the relation of other executive functions to school readiness, socioeconomic risk, and the teacher-child relationship. For example, are varying levels of cognitive flexibility related to teacher-child relationships differently than children with different levels of self-regulation? This question could tap into the role executive functions play in teachers' perceptions of problematic student behaviors within the classroom, or behaviors and difficulties that teachers may find frustrating.

One important variable that deserves further attention and development of additional measures is the teacher-child relationship. The Student Teacher Relationship Scale Short Form produces two different scores: conflict and closeness. Further research could examine these subcomponents of the teacher-child relationship in relation to the variables and models examined here. It is possible that there are distinct characteristics and linkages with both of these aspects of the relationship, and that they are not necessarily considered "opposites" as they were in this study's creation of the composite variable. Specifically, perhaps there are aspects of conflict or closeness that provide reasoning for specific connections among variables. Just as there may be various outcomes for differing attachment styles identified between infants and their parents, there can be different outcomes for the set of distinct behaviors related to conflict and closeness with teachers. When considering that children may develop classroom-based patterns of behaviors similar to the concept of internal working models in the attachment literature (Bretherton \& Munholland, 2008), this distinction could be important. It may also be interesting to consider possible profiles of students, for example those high in conflict and closeness, high in one or the other, or low in both. Perhaps there are different implications for children's experiences and learning in the classroom with these varying profiles. 
At present, there are a limited number of validated measures of the teacher-child relationship. There are some observational attachment measures adapted from parent-child attachment measures such as the Attachment Q-set (Howes \& Hamilton, 1992), but most prominent in the literature is the Student Teacher Relationship Scale (STRS, Pianta and Steinberg, 1992), and the short-form version of this form (NIHCD, 2000). Beyond these two measures, there is nothing validated in the field that specifically focuses on the teacher-child relationship. Using the $S T R S-S F$, this study examined the teacher-child relationship solely from the teacher's perspective. It is possible by gaining the child's perspective or by observing interactions between the child and teacher, different findings can be discovered. There simply are not many validated measures to accomplish this at the moment. It is important that additional new and innovative ways to examine the teacher-child relationship are examined. Building upon the attachment literature, it may be helpful to develop an observational measure similar to the attachment Q-sort or Strange Situation (Ainsworth, Blehar, Waters, \& Wall, 1978; Waters \& Deane, 1985). Perhaps the STRS could be adapted to an observational measure, taking those items to create criteria that could be used observationally. Observational strategies could include examining children's behaviors, but also the teachers' behaviors, as well as exchanges between the two. It may also be important to consider using measurement that can take into consideration children's attachment hierarchies (Cassidy, 2008), therefore identifying how significant of an attachment relationship that with the teacher is for that particular child. Considering attachment hierarchies within this measurement strategy could provide information about the differential effects of the teacher-child relationship on different children depending on their other attachment relationships and experiences. It may be helpful to develop measures in which children report about their feelings about their relationships with teachers. Measuring attachment in this context 
can be tricky given developmental constraints or children's possible biases and fears about discussing negative aspects of their teachers but could be important in considering a more comprehensive measurement of the teacher-child relationship.

It may be helpful to consider other aspects of the relationships between students and teachers. It may be interesting to better understand how issues of race, ethnicity, and gender may impact these relationships. Specifically, does a match or lack of match among these characteristics bias teachers or students in a specific way? One strategy to assist with this issue is to have culturally responsive teaching practices taught as a part of pre-service teachers' curricula (Gay, 2002). Is it enough to ensure that cultural suppression is not happening in the classroom (Valencia, 2015), or must students be able to have teachers who share their culture? Also relevant is personality matches between teachers and students. Does a certain combination of factors among students and teachers promote a close or conflictual relationship? Related to this may be teachers' education, experiences and perspectives. Although information about teachers' years in their current position was gathered as a part of this study $(M=6.6$ years $)$, it was not included in the analyses. Perhaps years of experience can provide important information that may inform teacher behaviors and strategies used to build relationships with students. Finally, it may be interesting to understand teachers' perspectives on the significance of their relationship and how their behaviors may impact children's learning. Is it just the academics that are important for learning? Should discipline be stern or compassionate? Teachers' philosophies on their relationships with students could help to explain the development of specific relationships with students.

It is impossible to consider the teacher-child relationships without considering the broader systems in which these relationships lie. As mentioned in the implications for schools, 
understanding what the early childhood setting looks like and who is present in the variety of settings is essential to understanding children's development within these settings as they prepare to move on to kindergarten. Understanding the early childhood environment is closely related to the theoretical concept of the bioecological model and considering the various direct and indirect systems that could be impacting a child's functioning and development (Bronfenbrenner, 1977) As mentioned above, it may be helpful to think about classroom quality and climate. In studies examining classroom climate, positive interactions with teachers and a child-centered instructional climate were less common for children from low income backgrounds enrolled in early childhood programs (Pianta et al., 2002). It is essential to not examine teacher-child relationships in isolation but think about them as operating within a system and that it is possible that systematic changes may need to occur within the school environment to support more positive relationships between teachers and students.

\section{Conclusions}

The goal of this study was to examine the moderating role of the teacher-child relationship on the mediation of self-regulation on socioeconomic risk for school readiness outcomes. Overall, the findings of this study support a moderated mediator model with an integration of these variables. Specifically, the teacher-child relationship can affect the relation between self-regulation and school readiness. To come to this conclusion, this study first validated a strong mediated model where self-regulation mediates the relation between socioeconomic risk and school readiness. Additionally, this study validated the moderation of the teacher-child relationship on this mediated relation. Specifically, it is at the level of selfregulation that the teacher-child relation is moderating this model and therefore impacts school readiness. A child with poor self-regulation who has a positive teacher-child relationship could 
have positive school readiness outcomes. Overall, the results suggest that the teacher-child relationship can play an important role in considering the many possible variables that can contribute to school readiness, and can serve as an important place for intervention within the school setting. Specifically, by working with teachers to improve relationships with students, school readiness can be enhanced, thereby allowing children to begin their formal schooling experience on a trajectory for high achievement and success. 


\section{REFERENCES}

Ainsworth, M. D., Blehar, M., Waters, E., \& Wall, S. (1978). Patterns of attachment: A psychological study of the Strange Situation. Hillsdale, NJ: Erlbaum.

Aksan, N., \& Kochanska, G., (2004). Links between systems of inhibition from infancy to preschool years. Child Development, 75, 1477-1490.

Allan, N. P., \& Lonigan, C. J. (2011). Examining the dimensionality of effortful control in preschool children and its relation to academic and socioemotional indicators. Developmental Psychology, 47, 905-915.

Anhert, L., Harwardt-Heinecke, E., Kappler, G., Eckstein-Madry, T., \& Milatz, A. (2012). Student-teacher relationships and classroom climate in first grade: How do they relate to students' stress regulation? Attachment \& Human Development, 14, 249-263.

Baker, J. A. (2006). Contributions of teacher-child relationships to positive school adjustment during elementary school. Journal of School Psychology, 44, 211-229.

Barkley, 2011. Attention-deficit/hyperactivity disorder and self-regulation: Taking an evolutionary perspective on executive functioning (2011). In K.D.Vohs \& R.F. Baumeister (Eds). Handbook of self-regulation: Research, Theory, and Applications $2^{\text {nd }}$ Edition (497-513). New York: Guilford.

Barnett, S. W. (2008). Why governments should invest in early education. CESifo DICE Report, 6, 9-14.

Baron, I. S. (2004). Delis-Kaplan Executive Function System. Child Neuropsychology, 10, $147-$ 152. 
Bentler, P. M., \& Chou, C. (1988). Practical issues in structural modeling. In J. S. Long (Ed.), Common Problems/Proper Solutions: Avoiding Error in Quantitative Research (pp.161192). Newbury Park, CA: Sage.

Bierman, K. L., Torres, M. M., Domitrovich, C. E., Welsh, J. A., \& Gest, S. D. (2008). Behavioral and cognitive readiness for school: Cross-domain associations for children attending Head Start. Social Development, 18, 305-323.

Birch, S. H., \& Ladd, G. W. (1997). The teacher-child relationship and children's early school adjustment. Journal of School Psychology, 25, 61-79.

Blair, C. (2010). Stress and the development of self-regulation in context. Child Development Perspectives, 4, 181-188.

Blair, C., \& Diamond, A. (2008). Biological processes in prevention and intervention: The promotion of self-regulation as a means of preventing school failure. Development and Psychopathology, 20(03), 899-911.

Blair, C., \& Raver, C. (2012). Child development in the context of adversity: Experiential canalization of brain and behavior. American Psychologist, 67, 309-318.

Blair, C., \& Razza, R. P. (2007). Relating effortful control, executive function, and false belief understanding to emerging math and literacy ability in kindergarten. Child Development, $78,647-663$.

Blair, C., \& Ursache, A. (2011). A Bidirectional model of executive functions and selfregulation. In K. D. Vohs \& R. F. Baumeister (Eds). Handbook of self-regulation: Research, Theory, and Applications $2^{\text {nd }}$ Edition (300-320). New York: Guilford.

Boivin, M., \& Bierman, K. (2014). School readiness: Introduction to a multifaceted and developmental construct. In M. Boivin \& K. L. Bierman (Eds). Promoting School 
Readiness and Early Learning: Implications of Developmental Research for Practice (314). New York: Guilford.

Bollen, K. A. (1989). Structural Equations with Latent Variables. New York, NY: Wiley.

Bowlby, J. (1969). Attachment and loss: Attachment (Vol. 1). New York, NY: Basic Books (2 ${ }^{\text {nd }}$ revised ed., 1982).

Bowman, B.T. (1999). Kindergarten practices with children from low-income families. In R. Pianta \& M. Cox (Eds). The Transition to Kindergarten (pp. 39-66). Baltimore, MD: Brookes.

Bracken, B. A. (2006). Bracken Basic Concept Scale - Third Edition: Receptive (BBCS-3:R). New York, Pearson.

Bretherton, I., \& Munholland, K. A. (2008). Internal working models in attachment relationships: Elaborating a central construct in attachment theory. In. J. Cassidy \& P. Shaver (Eds.). Handbook of attachment (pp. 3-23). New York, NY: Guilford.

Brigance, A. H., \& French, B. F. (2013). Brigance Inventory for Early Development III. Curriculum Associates North Billerica, MA.

Brock, L.L., Rimm-Kaufman, S.E., Nathanson., L., \& Grimm, K.J. (2009). The contributions of 'hot' and 'cool' executive function to children's academic achievement, learning-related behaviors, and engagement in Kindergarten. Early Childhood Research Quarterly, 24, 337-349.

Bronfenbrenner, U. (1977). Toward an experimental ecology of human development. American Psychologist, 32, 513-531.

Bronfenbrenner, U., Morris, P.A.. (1998). The ecology of developmental processes. In William Damon \& Richard M. Lerner (Eds).Handbook of child psychology: Theoretical models of 
human development, Volume 1, 5th ed., (pp. 993-1028). Hoboken, NJ, US: John Wiley \& Sons.

Browne, M. W., \& Cudeck, R. (1993). Alternative ways of assessing model fit. In K. A. Bollen \& J. S. Long (Eds.), Testing Structural Equation Models (pp. 136-162). Newbury Park, CA: Sage.

Burchinal, M. R., Peisner-Feinberg, E., Bryant, D. M., \& Clifford, R. (2000). Children's social and cognitive development and child-care quality: Testing for differential associations related to poverty, gender, or ethnicity. Applied Developmental Science, 4, 149-165.

Buysse, V., \& Peisner-Feinberg, E. (2013). Response to intervention: Conceptual foundations for the early childhood field. In V. Buysse \& E. Peisner-Feinberg (EDs). Handbook of response to intervention in early childhood $1^{\text {st }}$ Edition (pp 3-26) Baltimore: Brookes.

Calkins, S. D., \& Keane, S. P. (2004). Cardiac vagal regulation across the preschool period: Stability, continuity, and implications for childhood adjustment. Developmental Psychobiology, 45, 101-112.

Campbell, F. A., \& Ramey, C. T. (1994). Effects of early intervention on intellectual and academic achievement: A follow-up study of children from low-income families. Child Development, 65, 684-698.

Carlson, S. M. (2005). Developmentally sensitive measures of executive function in preschool children. Developmental Neuropsychology, 28, 595-616.

Carlson, S. T., \& Moses, L. J. (2001). Individual differences in inhibitory control in children's theory of mind. Child Development, 72, 1032-1053.

Carlson, S. M., \& Wang, T. S. (2007) Inhibitory control and emotion regulation in preschool children. Cognitive Development, 22, 489-510. 
Carta, J. J., Greenwood, C. R., Walker, D., Kaminski, R., Good, R., McConnell, S., \& McEvoy, M. (2002). Individual growth and development indicators (IGDIs): Assessment that guides intervention for young children. Young Exceptional Children Monograph Series. Division of Early Childhood, of the Council for Exceptional Children.

CASEL Guide: Effective Social and Emotional Learning Programs Preschool and Elementary School Edition. (2013). Collaborative for Academic, Social and Emotional Learning. Chicago, IL.

Cassidy, J. (2008). The nature of child's ties. In. J. Cassidy \& P. Shaver (Eds.). Handbook of attachment (pp. 3-23). New York, NY: Guilford.

Quick Facts United States Census Bureau (2017).. Retrieved on March 19'2017, https://www.census.gov/quickfacts/table/PST045216/00.

Chatham, C. H., Frank, M. J., \& Munakata, Y. (2009). Pupillometric and behavioral markers of developmental shift in the temporal dynamics of cognitive control. Proceedings of the National Academy of Sciences, 106, 5529-5533.

Cole, P. (1986). Children's spontaneous control of facial expression. Child Development, 57, 1309-1321.

Coley, R. L., Votruba-Drzal, E., Collins, M., \& Cook, K. D. (2016). Comparing public, private, and informal preschool programs in a national sample of low-income children. Early Childhood Research Quarterly, 36, 91-105.

Conger, R. D., Conger, K. J., \& Martin, M. J. (2010). Socioeconomic status, family processes, and individual development. Journal of Marriage and Family, 72, 685-704.

Cote, S.M., Geoffroy, MC., Pingault, J.B. (2014) Early child care experiences and school readiness. In M. Boivin \& K. Bierman (Eds.), Promoting School Readiness and Early 
Learning: Implications of Developmental Research for Practice (pp. 105-132). New York, NY: Guilford.

Curby, T. W., Rimm-Kaufman, S. E., \& Pontiz, C. C. (2009). Teacher-child interactions and children's achievement trajectories across kindergarten and first grade. Journal of Educational Psychology, 101, 912-925.

Delpit, L. (2006). Lessons from teachers. Journal of teacher education, 57, 220-231.

Denham, S. A. (2006). Social-emotional competence as support for school readiness: What is it and how do we assess it? Early Education \&Development, 17, 57-89.

Denham, S. A., Bassett, H., Mincic, M., Kalb, S., Way, E., Wyatt, T., \& Segal, Y. (2012). Social-emotional learning profiles of preschoolers' early school success: A personcentered approach. Learning and Individual Differences, 22, 178-189.

Devereux Early Childhood Assessment for Preschoolers-Second Edition (DECA-2, 2013). Center for Resilient Children, Villanova, PA.

Dionne, G., Mimeau, C., \& Mathieu, E. (2014). The role of oral language development in promoting school readiness. In M. Bovin \& K. Bierman (Eds.), Promoting School Readiness and Early Learning: Implications of Developmental Research for Practice (pp. 105-132). New York, NY: Guilford.

Duncan, G. J., Dowsett, C. J., Claessens, A., Magnuson, K., Huston, A. C., Klebanov, Pagani, L. S., Feinstein, L., Engel, M., Brooks-Gunn, J., Sexton, H., Duckworth, K., \& Japel, C. (2007). School readiness and later achievement. Developmental Psychology, 43, 14281446.

Dunn Lloyd, M., Dunn, D. D. (2007). PPVT-4: Peabody Picture Vocabulary Test. Pearson, New York, NY. 
Dweck, C. S. (2006). Mindset: The New Psychology of Success. New York: Random House.

Early Childhood Mental Health Consultation Project (TIER) (2017).. Illinois Children's Mental Health Partnership. Accessed: March 20 th 2017 at: http://icmhp.org/icmhp-inaction/projects/early-childhood-mental-health-consultation-project-tier/.

Eisenberg, N., Cumberland, A. J., Spinrad, T. L., Fabes, R. A., Shepard, S., Reiser, M., Murphy, B. C., Losoya, S. H., \& Guthrie, I .K. (2001). The relations of regulation and emotionality to children's externalizing and internalizing problem behavior. Child Development, 72, $1112-1134$.

Eisenberg, N., Smith, C. L., \& Spinrad, T. L. (2011). Effortful control. In K. D. Vohs \& R. F. Baumeister (Eds). Handbook of self-regulation: research, theory, and applications $2^{\text {nd }}$ Edition (263-283). New York, NY: Guilford.

Eisenberg, N., Valiente, C., \& Eggum, N. D. (2010). Self-regulation and school readiness. Early Education \& Development, 21, 681-698.

Ellis, D. C., Kaplan, E., \& Kramer, J. H. (Eds.). (2001). Delis-Kaplan Executive Function System, D-KEFS. The Psychological Corporation, San Antonio, TX.

Epsy, K. A. (1997) The Shape School: Assessing executive function in preschool children. Developmental Neuropsychology 13, 495-499.

Erchul, W. P., \& Martens, B. K. (2010). School consultation: Conceptual and empirical based of practice, $3^{\text {rd }}$ Edition. New York, NY: Springer.

Evans, G. W. (2004). The environment of childhood poverty. American Psychologist, 59 ,77-92.

Evans, G. W., \& Rosenbaum, J. (2008). Self-regulation and the income-achievement gap. Early Childhood Research Quarterly, 23, 504-514. 
Fox, L., Carta, J., Strain, P., Dunlap, G., \& Hemmeter, M.L. (2009). Response to Intervention and the Pyramid Model. Tampa, Florida: University of South Florida, Technical Assistance Center on Social Emotional Intervention for Young Children.

Frede, E., \& Barnett, W. S. (1992). Developmentally appropriate public school preschool: A study of implementation of the High/Scope curriculum and its effects on disadvantaged children's skills at first grade. Early Childhood Research Quarterly, 7(4), 483-499.

Garner, P. W., Mahatmya, D., Kimberly Moses, L., \& Bolt E. N. (2014). Associations of preschool type and teacher-child relational quality with young children's socialemotional competence. Early Education and Development, 25, 399-420.

Garon, N., Bryson, S. E., \& Smith, I. M. (2008). Executive function in preschoolers: A review using and integrative framework. Psychological Bulletin, 134, 31-60.

Gartstein, M. A., \& Rothbart, M. K. (2003). Studying infant temperament via the Revised Infant Behavior Questionnaire. Infant Behavior \& Development, 26, 64-86.

Gay, G (2002). Preparing for culturally responsive teaching. Journal of Teacher Education, $53,106$.

Gerstadt, C., Hong, Y., \& Diamond, A. (1994). The relationship between cognitive and action: Performance of 3/4 to 7-year-old children on a stroop-like day-night test. Cognition, 53.

Gioia, G. A., Epsy, K. A., \& Isquith, P. K. (2003). Behavior rating inventory of executive function preschool version (BRIEF-P). Lutz, FL: Psychological Assessment Resources.

Gilliam, W.S. (2010). Prekindergartners left behind: Expulsion rates in state prekindergarten systems. New York, NY: Foundation for Child Development.

Gioia, C. G., Isquith, P. K., Guy, S. C., \& Kenworthy, L. (2000). Behavior Rating of Executive Function. Lutz, FL: Psychological Assessment Resources. 
Gioia, G. G., Isquith, P. K., Retzlaff, P. D., \& Espy, K. A., (2002). Confirmatory factor analysis of the Behavior Rating Inventory of Executive Function (BRIEF) in a clinical sample. Child Neuropsychology, 8, 249-257.

Gullone, E., \& Taffe, J. (2012). The Emotion Regulation Questionnaire for Children and Adolescents (ERQ-CA): A psychometric evaluation. Psychological Assessment, 24, 409417.

Hair, E., Halle, T., Terry-Humen, E., Lavelle, B., \& Calkins, J. (2006). Children's school readiness in the ECLS-K: Predictions to academic, health, and social outcomes in first grade. Early Childhood Research Quarterly, 21, 431-454.

Hallett, P. E. (1978). Primary and secondary saccades to goals defined by instructions. Vision Research, 18, 1279-1296.

Hamre, B, Hatfield, B., Pianta, R., \& Jamil, F. (2014). Evidence for general and domain-specific elements of teacher-child interactions: Associations with preschool children's development. Child Development, 86, 1257-1274.

Harms, T., Clifford, R.M., \& Cryer, D. (2005). ECERS Early Childhood Environment Rating Scale, Revised Edition, Updated (ECERS R). New York, NY: Teacher's College Press

Hatfield, B. D., Burchinal, M. R. Pianta, R. C. \& Sideris, J. (2016). Thresholds in the association between quality of teacher-child interactions and preschool children's school readiness skills. Early Childhood Research Quarterly, 26.

Hatt, B. (2012). Smartness as a cultural practice in schools. American Educational Research Journal, 49, 438-460. 
Hongwanishkul, D., Happaney, K. R., Less, W. S. C, \& Zelazo, P. D. (2005). Assessment of hot and cool executive function in young children: Age-related changes and individual differences. Developmental Neuropsychology, 28, 617-644.

Howes, C., \& Hamilton, C. E. (1992). Children's relationships with child care teachers: Stability and concordance with parental attachments. Child Development, 63, 867-878.

Howes, C., \& Spieker, S. (2008). Attachment relationships in the context of multiple caregivers. In. J. Cassidy \& Phillip Shaver (Eds.), Handbook of attachment (pp. 3-23). New York, NY: Guilford.

Hox, J. J. (1995) Applied Multilevel Analysis. TT-Publikaties, Amsterdam, Netherlands.

Hu, L., \& Bentler, P. M. (1999). Cutoff criteria for fit indexes in covariance structure analysis: Conventional criteria versus new alternatives. Structural Equation Modeling, 6, 1-55.

Hughes, C. (1998) Finding your marbles: Does preschoolers' strategic behavior predict later understanding of mind? Developmental Psychology, 34, 1326-1339.

Isquith, P. K., Crawford, J. S., Espy, K. A., Gioia, G. A. (2005). Assessment of executive function in preschool-aged children. Mental Retardation Developmental Disability Research Review, 11, 209-215.

Joreskog, K., \& Sorbom, D. (2006). LISREL Version 8.0 [Computer software]. Lincolnwood, IL: Scientific Software International.

Karoly, P. (1993). Mechanisms of Self-Regulation: A Systems View. Annual Review Psychology, 44, 23-52.

Kieras, J. E., Tobin, R. E., Graziano, W. G., \& Rothbart, M. K. (1993). You can't always get what you want: Effortful control and children's responses to undesirable gifts. Psychological Science, 16, 391-396. 
Kim, S., Nordling, J. K., Yoon, J. E., Boldt, L. J., Kochanska, G. (2013) Effortful control in "hot" and "cool" tasks differentially predicts children's behavior problems and academic performance. Journal of Abnormal Child Psychology, 41, 43-56.

Kochanska, G. (2002). Committed compliance, moral self, and internalization: A mediational model. Developmental Psychology, 38, 339-351.

Kochanska, G., \& Knaack, A. (2003). Effortful control as a personality characteristic of young children: Antecedents, correlates, and consequences. Journal of Personality, 71, 10871112.

Kochanska, G., Murray, K., \& Coy, K. C. (1997). Inhibitory control as a contributor to conscience in childhood: From toddler to early school age. Child Development, 68, 263277.

Kochanska, G., Murray, K. T., Jacques, T. Y., Koenig, A. L., \& Van-degeest, K. A. (1996). Inhibitory control in young children and its role in emerging internalization. Child Development, 67, 490-507.

Kochanska, G., Tjebkes, T., \& Forman, D. (1998). Children's emerging regulation of conduct: Restraint, compliance, and internalization from infancy to the second year. Child Development, 69, 1378-1389.

Kochanska, G., Murray, K. T., \& Harlan, E. T. (2000). Effortful Control in early childhood: continuity and change, antecedents, and implications for social development. Developmental Psychology, 36, 220-232.

Korkman, M., Kirk, U., \& Kemp, S. (2007) Developmental Neuropsychological Assessment Second Edition (NEPSY-II). San Antonio, TX: Psychological Corporation. 
Landry, S. H., Anthony, J. L., Swank, P.R., Monseque-Bailey, P. Effectiveness of comprehensive professional development of teachers of at-risk preschoolers. Journal of Educational Psychology, 101,448-465.

Landry, S. H., Assel, M. A., Anthony, J. L., \& Swank, P. R. (2013) Development of a universal screening and progress monitoring tool and its applicability for use in responses to intervention. In V. Buysse \& E. Peisner-Feinberg (EDs). Handbook of response to intervention in early childhood $1^{\text {st }}$ Edition (pp 155-168.) Baltimore: Brookes.

Liew, J. (2012). Effortful control, executive functions, and education: Bringing self-regulatory and social-emotional competencies to the table. Child Development Perspectives, 6, 105111.

Ling, D. S., Wong, C. D., \& Diamond, A. (2016). Do children need reminders on the day-night task, or simply some way to prevent them from responding too quickly?. Cognitive Development, 37, 67-72.

Lonigan, C. J., \& Phillips, B. M. (2001). Temperamental influences on the development of anxiety disorders. In M. W. Vasey \& M. R. Dadds (Eds.), The developmental psychopathology of anxiety (pp. 60-91). New York, NY: Oxford University Press.

Mann, T. D., Hund, A. M., Hesson-McInnis, M. S., \& Roman, Z. (2016). Pathways to school readiness: Executive functioning predicts academic and social-emotional aspects of school readiness. Mind, Brain, \& Education, 11, 21-31.

Mardell, C., \& Goldenberg, D.S. (2011). Developmental Indicators for the Assessment of Learning, Fourth Edition (DIAL-4). New York, NY: Pearson. 
Marks, L. C. (2014). School Readiness and Teacher-Child Relationships in the Context of High, Moderate, and Low Self-Regulation: A Preliminary Examination of Ratings by Head Start Teachers. Unpublished report.

Markwardt, F. C. (1997) Peabody Individual Achievement Test- (PIAT-R/NU). New York, NY: Pearson.

Masten, A. S. (2007). Resilience in developing systems: Progress and promise as the fourth wave rises. Development and Psychopathology, 19, 921-930.

Masten, A. S. (2014). Ordinary Magic: Resilience in Development. New York, NY: Guilford.

McAllister, G, \& Irvine, J. J.(2002) The role of empathy in teaching culturally diverse students a qualitative study of teachers' beliefs. Journal of Teacher Education 53, 433-443.

McClelland, M. M., \& Cameron, C. E. (2012). Self-regulation in early childhood: Improving conceptual clarity and developing ecologically valid measures. Child Development Perspectives, 6, 136-142.

McClelland, M. M., Cameron, C. E., Connor, C. M., Farris, C. L., Jewkes, A. M., \& Morrison, F. J. (2007). Links between behavioral regulation and preschoolers' literacy, vocabulary, and math skills. Developmental Psychology, 43, 947-959.

Merrell, K.W., Ervin, R.A. \& Gimpel Peacock, G. (2012). School Psychology for the $21^{s t}$ Century: Foundations and Practices $2^{\text {nd }}$ Edition. New York, NY: Guilford.

Metcalfe, J., \& Mischel, W. (1999). A hot/cool-system analysis of delay of gratification: Dynamics of willpower. Psychological Review, 106, 3-19.

Mezzacappa, E. (2004). Alerting, orienting, and executive attention: Developmental properties and sociodemographic correlates in an epidemiological sample of young, urban children. Child Development, 75, 1373-1386. 
Miller-Lewis, L. R., Sawyer, A. C P., Searle, A. K., Militinty, M. N., Sawyer, M. G., \& Lynch, J. W. (2014). Student-teacher relationship trajectories and mental health problems in young children. BMC Psychology, 2.

Miesels, S. J. (1999). Assessing readiness. In R. Pianta \& M. Cox (Eds). The Transition to Kindergarten (pp. 39-66). Baltimore, MD: Brooks.

Miyake, A., Friedman, N. P., Emerson, M. J., Witzki, A. H., Howerter, A. \& Wager, T. D. (2000). The unity and diversity of executive functions and their contribution to complex "frontal lobe" tasks: A latent variable analysis. Cognitive Psychology, 41, 49-100.

Model for Comprehensive and Integrated School Psychological Services (2010). NASP Practice Model Overview. Bethesda, MD: NASP.

Mullen, E. M. (1995). Mullen Scales of Early Learning. New York, NY: Pearson.

Munoz, D. P., Broughton, J. R., Goldring, J. E., \& Armstrong, I. T. (1998). Age-related performance of human subjects on saccadic eye movement tasks. Experimental Brain Research, 121, 391-400.

Murray, C., \& Murray, K. M. (2004). Child level correlates of teacher-student relationships: An examination of demographic characteristics, academic, orientations, and behavioral orientations. Psychology in the Schools, 4, 751-762.

Murray, J., Theakston, A., \& Wells, A. (2016). Can the attention training technique turn one marshmallow into two? Improving children's ability to delay gratification. Behaviour Research and Therapy, 77, 34-39.

National Association for the Education of Young Children. Retrieved on December 16, 2016 www.NAEYC.org 
NICHD Study of Early Child Care. (2000). Teacher's relationship with child; first grade studentteacher relationship scale. Child Care Data Report - 309. Research Triangle Park, NC: Research Triangle Institute.

Nickerson, A. B., \& Fishman, C. (2009). Convergent and divergent validity of the Devereux Student Strengths Assessment. School Psychology Quarterly, 24, 48-59.

O'Connor, E. E., Collins, B. A., \& Supplee, L. (2012). Behavior problems in late childhood: The roles of early maternal attachment and teacher-child relationship trajectories. Attachment \& Human Development, 14, 265-288.

O’Connor, E., \& McCartney, K. (2007). Examining teacher-child relationships and achievement as part of an ecological model of development. American Educational Research Journal, 44, 340-369.

Office of Head Start: (2017). About: Head Start Services. Retrieved from: http://www.acf.hhs.gov/programs/ohs/about/head-start.

Pajunar Li-Grining, C., Lennon, J., Marcus, M., Flores, V., \& Haas, K. (2014). The development of self-regulatory skills and school readiness. In M. Boivin \& K.L. Bierman (Eds). Promoting School Readiness and Early Learning: Implications of Developmental Research for Practice (pp. 212-230). New York, NY: Guilford.

Panter, J. E., \& Bracken, B. A., (2009). Validity of the Bracken School Readiness Assessment for predicting first grade readiness. Psychology in the Schools. 46, 397- 409.

Peisner-Feinberg, E. S., Burchinal, M. R., Clifford, R. M., Culkin, M. L., Howers, C., Kagan, S. L., \& Yazejian, N. (2001). The relation of preschool child-care quality to children's cognitive and social developmental trajectories through second grade. Child Development, 72, 1534-1553. 
Pianta, R. C. (1999). How the parts affect the whole: Systems theory in classroom relationships. In Enhancing relationships between children and teachers, (pp. 23-43). Washington, DC, US: American Psychological Association.

Pianta, R. C., Barnett, W. S., Burchinal, M., \& Thornburg, K. R. (2009). The effects of preschool education what we know, how public policy is or is not aligned with the evidence base, and what we need to know. Psychological Science in the Public Interest, 10, 49-88.

Pianta, R., Downer, J., \& Hamre, B. (2016). Quality in early education classrooms: Definitions, gaps and systems. The Future of Children. 26,119-137.

Pianta, R. Hamre, B., \& Downer, J (2015) Classroom Assessment Scoring System (CLASS-R) University of Virginia, CASTL.

Pianta, R. C., La Paro, K. M., Payne, C., Cox, M. J., \& Bradley, R. (2002). The relation of kindergarten classroom environment to teacher, family, and school characteristics and child outcomes. The Elementary School Journal, 102, 225-238.

Pianta, R.C., \& Steinberg, M. (1992) Teacher-child relationships and the process of adjusting to school. New Directions for Child Development, 57, 61-80.

Pianta, R. C., \& Stuhlman, M. W. (2004). Teacher-child relationships and children's success in the first years of school. School Psychology Review,33, 444-458.

Pianta R. C., \& Walsh, D. J. (1996) High Risk children in schools: Constructing sustaining relationships. New York, NY: Routledge.

Ponitz, C. C., McClelland, M. M., Matthews, J. S., \& Morrison, F. J. (2009). A structured observation of behavarioal self-regulation and its contribution to kindergarten outcomes. Developmental Psychology, 45 ,605-619. 
Poverty guidelines updated periodically in the Federal Register by the U.S. Department of Health and Human Services under the authority of 42 U.S.C. 9902(2). (2017). Retrieved from: https://aspe.hhs.gov/poverty-guidelines, March 25, 2017.

Proctor, Semega, \& Kollar (2016). Income and Poverty in the United States. U.S. Census Bureau. Retrieved on December 27 2016. http://www.census.gov/data/tables/2016/demo/income-poverty/p60-256.html.

Promising practices: Progress toward the goals (2000). National Education Goal Panel.

Putnam, S. P., \& Rothbart, M. K. (2006). Development of short and very short forms of the Children's Behavior Questionnaire. Journal of Personality Assessment, 87, 103-113.

Race to the top early learning challenge. Retrieved on 12/14/16. http://www2.ed.gov/programs/racetothetopearlylearningchallenge/index.html

Ramey, C. T., \& Ramey, S. L. (1999) Beginning school for children at risk. In R. C. Pianta \& M. J. Cox (Eds.), The transition to kindergarten (pp. 217-251). Baltimore, MD: Paul H. Brookes.

Ramey, C. T., \& Ramey, S. L. (2004). Early learning and school readiness: Can early intervention make a difference? Merrill-Palmer Quarterly, 50, 471-491.

Raver, C.C. (2012). Low-income children's self-regulation in the classroom: Scientific inquiry for social change. American Psychologist, 67, 681-689.

Raver, C. C., Jones, S. M., Li-Grining, C., Zhai, F., Bub, K., \& Pressler, E. (2011). CSRP's impact on low-income preschoolers' preacademic skills: Self-regulation as a mediating mechanism. Child Development, 82, 362-378.

Reed, M., Pien, D. L., \& Rothbart, M. K. (1984). Inhibitory self-control in preschool children. Merrill Palmer Quarterly, 30, 131-147. 
Rimm-Kaufman, S. (2004). School transition and school readiness: An outcome of early childhood development. In R.E.Tremblay, R.G. Barr, \& RD. Peters. Encyclopedia on Early Childhood Development, 1-7.

Rimm-Kaufman, S. E., Early, D. M., Cox, M. J., Saluja, G., Pianta, R. C., Bradley, R. H., \& Payne, C. (2002). Early behavioral attributes and teachers' sensitivity as predictors of competent behavior in the kindergarten classroom. Journal of Applied Developmental Psychology, 23, 451-470.

Rimm-Kaufman S. E., Pianta, R. C., \& Cox, M. J. (2000). Teachers' judgments of problems in the transition to kindergarten. Early Childhood Research Quarterly, 15, 147-166.

Rimm-Kaufman, S. E., Curby, T. W., Grimm, K. J., Nathanson, L., Brock, L. L. (2009). The contribution of children's self-regulation and classroom quality to children's adaptive behaviors in the kindergarten classroom. Developmental Psychology, 45, 958-972.

Roid, G. H. (2003). Stanford-Binet Intelligence Scales, Fifth Edition. Itasca, IL: Riverside Publishing.

Rothbart, M. K. (1981). Measurement of temperament in infancy. Child Development, 52, 569578.

Rothbart, M. K., Ahadi, S. A., Hershey, K. L., \& Fisher, P. (2001). Investigations of temperament at three to seven years: The Children's Behavior Questionnaire. Child Development, 72,1394-1408.

Rothbart, M. K., \& Bates, J. E. (2006). Temperament. In W. Damon \& R. Lerner (Series Eds.), \& N. Eisenberg (Vol. Ed.), Handbook of child psychology, Vol. 3. Social, emotional, and personality development (6th ed., pp. 99-166). New York, NY: Wiley. 
Rothbart, M.K., Ellis, L.K. \& Posner, M.I. (2011). Temperament and self-regulation. In K.D. Vohs \& R.F. Baumeister (Eds). Handbook of self-regulation: Research, theory, and applications $2^{\text {nd }}$ Edition (pp. 441-460). New York, NY: Guilford.

Rous, B., Hallam, R., McCormick, K., \& Cox, M. (2010). Practices that support the transition to public preschool programs: Results from a national survey. Early Childhood Research Quarterly, 25(1), 17-32.

Rueda, M. R., Posner, M. I., \& Rothbart, M. K (2011). Attentional control and self-regulation. In K.D. Vohs \& R.F. Baumeister (Eds). Handbook of self-regulation: Research, theory, and applications $2^{\text {nd }}$ Edition (pp. 284-299). New York, NY: Guilford.

Ryan, R. M., Fauth, R. C., \& Brooks-Gunn, J. (2006). Childhood poverty: Implications for school readiness and early childhood education. In B. Spodek \& O.N. Saracho (eds). Handbook of Research on the Education of Young Children, 2nd ed. (pp 323-346). Mahwah, NJ: Lawrence Erlbaum Associates.

Ryan, R. M., Fauth, R. C., \& Brooks-Gunn, J. (2013). Childhood poverty: Implications for school readiness and early childhood education. In B. Spodek \& O. N. Saracho (eds). Handbook of research on the education of young children, 3rd ed. (301-321). Erlbaum, Mahwah.

Saarni, C. (1984). An observational study of children's attempts to monitor their expressive behavior. Child Development, 55, 1504-1513.

Schoemaker, K., Mulder, H., Deković, M., \& Matthys, W. (2013). Executive functions in preschool children with externalizing behavior problems: A meta-analysis. Journal of Abnormal Child Psychology, 41, 457-471. 
Schmitt, M. B., Pentimonti, J. M., Justice, L. M. (2012). Teacher-child relationships, behavior regulation and language gain among at-risk preschoolers. Journal of School Psychology, 50, 681-699.

Smith-Donald, R., Raver, C. C., Hayes, T., \& Richardson, B. (2007). Preliminary construct and concurrent validity of the Preschool Self-Regulation Assessment (PSRA) for field-based research. Early Childhood Research Quarterly, 22, 173-187.

Squires, J., \& Bricker, D. (2009). Ages \& Stages Questionnaires, Third Edition (ASQ-3). Baltimore, MD: Brookes Publishing.

Stone Hanley, M., \& Noblit, G. W. (2009). Cultural responsiveness, racial identity and academic success: A review of literature. A Paper Prepared for the Heinz Endowments.

Strommen, E. A. (1973). Verbal Self-Regulation in a Children's Game: Impulsive Errors on" Simon Says." Child Development, 44, 849-853.

Stroop, J. R. (1935). Studies of interference in serial verbal reactions. Journal of Experimental Psychology, 18, 643-662.

Tanaka, J. S. (1993). Multifaceted conceptions of fit in structural equation models. In K. A. Bollen \& J. S. Long (Eds.), Testing Structural Equation Models. Newbury Park, CA: Sage.

United States Census Bureau Quick Facts. https://www.census.gov/quickfacts/table/PST045216/00. Retrieved on December 27th, 2016.

Ursache, A., Blair, C., \& Raver, C. (2012). The promotion of self-regulation as a means of enhancing school readiness and early achievement in children at risk for school failure. Child Development Perspectives, 6, 122-128. 
Valencia, R. (2015). Students of color and the achievement gap: Systematic challenges, systematic transformations. New York, NY: Routledge.

Vernon-Feagans, L., \& Cox, M. (2013). Poverty, rurality, parenting, and risk: An introduction. Monographs of the Society for Research in Child Development, 78, 1-23.

Verschueren, K., Doumen, S., \& Buysse, E. (2012). Relationships with mother, teacher, and peers: Unique and joint effects on young children's self-concept. Attachment \& Human Develpoment,14, 233-248.

Warren, C. A. (2013). The utility of empathy for white female teachers' culturally responsive interactions with black male students. Interdisciplinary Journal of Teaching and Learning, 3(3), 175-200.

Waters, E., \& Deane, K.E. (1985). Defining and assessing individual differences in attachment relationships: Q-methodology and the organization of behavior in infancy and early childhood. In I. Bretherton \& E. Waters (Eds.), Growing points of attachment theory and research. Monographs of the Society for Research in Child Development, 50, 41-65.

Watson, T. S., \& Sterling-Turner, H. (2008). Best practices in direct behavioral consultation. In A. Thomas \& J. Grimes (Eds.), Best practices in school psychology V (Vol. 5, pp. 16611672). Bethesda, MD: NASP Publishing.

Welsh, J. A., Nix, R. L., Blair, C., Bierman, K. L., \& Nelson, K. E. (2010). The development of cognitive skills and gains in academic school readiness for children from low-income families. Journal of Educational Psychology, 102, 45-53.

Wechsler, D. (2012). Wechsler Preschool and Primary Scale of Intelligence - Fourth Edition $(W P P S I-I V)$. Administration and scoring manual. San Antonio, TX: The Psychological Corporation. 
Willoughby, M., Kupersmidt, J., Voegler-Lee, M., \& Bryant, D. (2011). Contributions of hot and cool self-regulation to preschool disruptive behavior and academic achievement. Developmental Neuropsychology, 36, 162-180.

Woodcock, R., Schrank, F. A., McGrew, K. \& Mather, N. (2014). Woodcock-Johnson IV (WJ $I V$;). Riverside Publishing, Riverside CA.

Wright, P. S., Horn, S. O., \& Sanders, W. L. (1997). Teacher and classroom context effects on student achievement: Implications for teacher evaluation. Journal of Personnel Evaluation in Education, 11, 57-67.

Yeager, D. S. \& Dweck, C. S. Mindsets that promote resilience: When students believe that personal characteristics can be developed. Educational Psychologist, 47, 302-314.

Yoon, J. S. (2002). Teacher characteristics as predictors of teacher-student relationships: Stress, negative affect, and self-efficacy. Social Behavior and Personality, 30, 485-494.

Zhou, Q., Chen, S. H., \& Main, A. (2012). Commonalities and differences in the research on children's effortful control and executive function: A call for an integrated model of selfregulation. Child Development Perspectives, 6, 112-121.

Zelazo, P. D., \& Carlson, S. M. (2012). Hot and cool executive function in childhood and adolescence: Development and plasticity. Child Development Perspectives, 6, 354-360.

Zelazo, P. D., \& Müller, U. (2010). Executive function in typical and atypical development, In U. Goswami (Ed). The Wiley-Blackwell Handbook of Childhood Cognitive Development, Second edition, Wiley-Blackwell, Oxford, UK. 